\title{
A Report on the Implementation of Smart Grids in Mexico
}

\section{Principal Authors}

Ron Binz ${ }^{1}$ and Riccardo Bracho ${ }^{2}$

\section{Contributing Authors}

Art Anderson, ${ }^{2}$ Michael Coddington, ${ }^{2}$

Elaine Hale, ${ }^{2}$ Michael Ingram, ${ }^{2}$ Maurice Martin, ${ }^{2}$ Ismael Mendoza, ${ }^{2}$ Bo Normark, ${ }^{3}$

Magnus Olofsson, ${ }^{4}$ Barbara O'Neill, ${ }^{2}$

Patricia Statwick ${ }^{2}$, and Bethany Speer ${ }^{2,5}$

1 Public Policy Consulting

2 National Renewable Energy Laboratory

3 Royal Swedish Academy of Engineering Sciences

4 Energy Institute of Sweden

5 International Smart Grid Action Network 


\section{A Report on the Implementation of Smart Grids in Mexico}

Principal Authors

Ron Binz ${ }^{1}$ and Riccardo Bracho ${ }^{2}$

Contributing Authors

Art Anderson, ${ }^{2}$ Michael Coddington, ${ }^{2}$

Elaine Hale, ${ }^{2}$ Michael Ingram, ${ }^{2}$ Maurice Martin, ${ }^{2}$ Ismael Mendoza, ${ }^{2}$ Bo Normark, ${ }^{3}$ Magnus Olofsson, ${ }^{4}$ Barbara O'Neill, ${ }^{2}$ Patricia Statwick ${ }^{2}$, and Bethany Speer ${ }^{2,5}$

1 Public Policy Consulting

2 National Renewable Energy Laboratory

3 Royal Swedish Academy of Engineering Sciences

4 Energy Institute of Sweden

5 International Smart Grid Action Network

\section{Suggested Citation}

Binz, Ron, Riccardo Bracho, Art Anderson, Michael Coddington, Elaine Hale, Michael Ingram, Maurice Martin, et al. 2019. A Report on the Implementation of Smart Grids in Mexico. Golden, CO: National Renewable Energy Laboratory. NREL/TP-7A40-72699.

https://www.nrel.gov/docs/fy19osti/72699.pdf

NREL is a national laboratory of the U.S. Department of Energy, Office of Energy Efficiency \& Renewable Energy, operated by the Alliance for Sustainable Energy, LLC.

Technical Report

NREL/TP-7A40-72699

January 2019

Contract No. DE-AC36-08GO28308
National Renewable Energy Laboratory 15013 Denver West Parkway Golden, CO 80401

303-275-3000 • www.nrel.gov 


\section{NOTICE}

This work was authored in part by the National Renewable Energy Laboratory, operated by Alliance for Sustainable Energy, LLC, for the U.S. Department of Energy (DOE) under Contract No. DE-AC36-08G028308. Funding provided by the 21st Century Power Partnership. The views expressed herein do not necessarily represent the views of the DOE or the U.S. Government.

This report is available at no cost from the National Renewable Energy Laboratory (NREL) at www.nrel.gov/publications.

U.S. Department of Energy (DOE) reports produced after 1991 and a growing number of pre-1991 documents are available free via www.OSTI.gov.

NREL prints on paper that contains recycled content. 


\section{List of Acronyms}

\begin{tabular}{|c|c|}
\hline $\mathrm{A} / \mathrm{A}$ & aire acondicionado (air conditioning) \\
\hline ADMS & advanced distribution management system \\
\hline AES & advanced encryption system \\
\hline AMI & advanced metering infrastructure \\
\hline BC Hydro & British Columbia Hydro \\
\hline BPA & Bonneville Power Administration \\
\hline CAIDI & customer average interruption duration index \\
\hline CAIFI & customer average interruption frequency index \\
\hline CEL & certificados de energías limpias (clean energy certificate) \\
\hline CENACE & $\begin{array}{l}\text { Centro Nacional de Control de Energia (National Center for } \\
\text { Energy Control) }\end{array}$ \\
\hline CFE & Comisión Federal de Electricidad (Federal Electricity Commission) \\
\hline CRE & Comisión Reguladora de Energía (Energy Regulatory Commission) \\
\hline CT & current transformers \\
\hline DA & distribution automation \\
\hline DER & distributed energy resource \\
\hline DERMS & distributed energy resources management system \\
\hline DLR & dynamic line rating \\
\hline DNP3 & Distributed Network Protocol 3 \\
\hline DOE & Department of Energy (United States) \\
\hline DoS & denial of service \\
\hline DR & demand response \\
\hline DSM & demand side management \\
\hline DTE & DTE Energy (Michigan electric utility) \\
\hline EFR & enhanced frequency response \\
\hline EPRI & Electric Power Research Institute \\
\hline EPROSEC & $\begin{array}{l}\text { equipamiento de protección y seccionamiento (distribution control } \\
\text { and protection devices) }\end{array}$ \\
\hline ERCOT & Electric Reliability Council of Texas \\
\hline EU & European Union \\
\hline $\mathrm{EV}$ & electric vehicle \\
\hline FACTS & flexible AC transmission system \\
\hline FERC & Federal Energy Regulatory Commission (United States) \\
\hline FIDVR & fault-induced delayed voltage recovery \\
\hline FLISR & fault location, isolation, and service restoration \\
\hline GBps & gigabits per second \\
\hline $\mathrm{GHz}$ & gigahertz \\
\hline GIS & geographic information system \\
\hline GW & gigawatt \\
\hline GWAC & GridWise Architecture Council \\
\hline HVDC & high-voltage direct current \\
\hline ICPP & Inter-Control Center Communications Protocol \\
\hline IEA & International Energy Agency \\
\hline IEC & International Electrotechnical Commission \\
\hline
\end{tabular}




\begin{tabular}{|c|c|}
\hline IEEE & Institute of Electrical and Electronics Engineers \\
\hline IFAI & Federal Institute for Access of the Information \\
\hline ISGAN & $\begin{array}{l}\text { IEA Implementing Agreement for a Co-operative Programme } \\
\text { on Smart Grids }\end{array}$ \\
\hline ISO & independent system operator \\
\hline ISO & International Organization for Standardization \\
\hline ISO-NE & ISO New England (United States) \\
\hline IT & information technology \\
\hline KWh & kilowatt-hour \\
\hline LIE & Ley de la Industria Eléctrica (Electrical Industry Act) \\
\hline LMP & locational marginal price \\
\hline LTC & load tap changer \\
\hline LTE & Ley de Transición (Energy Transition Law) \\
\hline MEM & Mercado Eléctrico Mayorista (Wholesale Electric Market) \\
\hline $\mathrm{MHz}$ & megahertz \\
\hline MVAR & mega volt ampere reactive \\
\hline MW & megawatt \\
\hline MWh & megawatt-hour \\
\hline NEA & National Energy Administration (China) \\
\hline NIST & National Institute of Standards and Technology (United States) \\
\hline NREL & National Renewable Energy Laboratory (United States) \\
\hline NYPA & New York Power Authority \\
\hline OASIS & Open Access Same-time Information Systems \\
\hline OpenPDC & Open Source Phasor Data Concentrator \\
\hline OSI & Open Systems Interconnection \\
\hline PCI-DSS & Payment Card Industry Data Security Standards \\
\hline PDC & phasor data concentrator \\
\hline PGCIL & Power Grid Corporation of India Limited \\
\hline PIE & productores independientes energia (private generators) \\
\hline PJM & PJM Interconnection LLC (U.S. RTO) \\
\hline PLC & power line carrier \\
\hline PMU & phasor measurement unit \\
\hline PRODESEN & $\begin{array}{l}\text { Programa de Desarrollo del Sistema Eléctrico Nacional } \\
\text { (Program for Development of the National Electric System) }\end{array}$ \\
\hline PT & potential transformer \\
\hline PV & photovoltaic \\
\hline RAS & remedial action scheme \\
\hline $\mathrm{RE}$ & renewable energy \\
\hline REI & Redes Eléctricas Inteligentes (Smart Grid) \\
\hline RGD & Red General de Distribución (General Distribution Grid) \\
\hline RNMF & national grid phasor measurement \\
\hline RNT & Red Nacional de Transmisión (national transmission network) \\
\hline RTO & regional transmission organization \\
\hline SAIDI & system average interruption duration index \\
\hline SAIFI & system average interruption frequency index \\
\hline SCADA & supervisory control and data acquisition \\
\hline
\end{tabular}




$\begin{array}{ll}\text { SDG\&E } & \text { San Diego Gas and Electric } \\ \text { SEN } & \text { Sistema Eléctrico Nacional } \\ \text { SENER } & \text { Secretaría de Energía (Secretariat of Energy) } \\ \text { SIRENA } & \text { Colombian National Defense System against Large Scale Events } \\ \text { STATCOM } & \text { static synchronous compensator } \\ \text { T\&D } & \text { transmission and distribution } \\ \text { TCSC } & \text { thyristor-controlled series compensator } \\ \text { TSO } & \text { transmission system operator } \\ \text { TWh } & \text { terawatt-hour } \\ \text { UCTE } & \text { Union for the Co-ordination of Transmission of Electricity (EU) } \\ \text { UPFC } & \text { unified power flow controller } \\ \text { URDSM } & \text { unified real-time dynamic state measurement } \\ \text { VAR } & \text { volt-ampere reactive } \\ \text { VVO } & \text { volt/VAR optimization } \\ \text { WAM } & \text { wide-area monitoring } \\ \text { WAMPACS } & \text { wide-area monitoring, protection, and control systems } \\ \text { WAMS } & \text { wide-area monitoring system } \\ \text { WECC } & \text { Western Electricity Coordinating Council (United States) }\end{array}$




\section{Preface}

This report was prepared in compliance with the requirements of the Ley de Transición Energética (Energy Transition Law) of Mexico. ${ }^{1}$ The report was prepared for the Secretaría de Energía of Mexico (SENER) by the authors with the generous guidance of SENER and the National Renewable Energy Laboratory (NREL) in the United States. The report benefitted greatly from the helpful cooperation of Comisión Federal de Electricidad (CFE) and Centro Nacional de Control de Energia (CENACE). Finally, important contributions to the report were provided by members and staff of the International Smart Grid Action Network (ISGAN).

\footnotetext{
${ }^{1}$ See section of the Energy Transition Law titled Transitorios, Décimo Séptimo.
} 


\section{Acknowledgments}

The authors are extremely grateful for the support of Secretaría de Energía (SENER), Comisión Federal de Electricidad (CFE), Centro Nacional de Control de Energía (CENACE), and Comisión Reguladora de Energía (CRE). Specifically, the authors are grateful to Ing. Edmundo Gíl Borja and Ing. Telésforo Trujillo Sotelo of the General Direction for Distribution and Commercialization at SENER for their leadership and participation. 


\section{Executive Summary}

For the past four years, Mexico has been implementing its constitutional energy reform and transforming its electric power industry. Changes in law, regulation, and market structure are bringing forth new market participants and producing new levels of clean power with new technologies and expanded customer choices.

In making these power sector reforms, Mexico has understood and addressed the central importance of a modernized grid. The energy sector reform laws establish a Smart Grid Program, thus committing to making Mexico's power grid capable of meeting the country's lofty clean energy goals while improving efficiencies, maintaining system reliability, and increasing its security. This Report on the Implementation of Smart Grids in Mexico responds to and complies with the new law requirements, and it is written in service of the goal of Mexico having a Smart Grid-Redes Eléctricas Inteligentes — with all the benefits such an investment can bring.

This report comprises eight main sections, and it represents a compilation of data and information from many sources that document Mexico's progress in implementing a Smart Grid. The content for each section was developed with the participation of knowledge experts in each topic area, who are acknowledged above. Readers may want to view the report as a reference guide on the eight main topic areas that are presented. Before discussing each section of the report below, we offer an overall assessment:

Mexico is moving on a path with ambitious and growing goals of clean energy generation. To meet them, it has begun restructuring its power sector to make it more competitive, efficient, and responsive to consumers. Each aspect of the country's National Electric System (Sistema Eléctrico Nacional or SEN in Spanish)—from generation to the customer's premises - will be touched by the grid modernization called Smart Grid, and each aspect can benefit from smart grid investment. Careful planning and selection of smart grid measures will prove to be a cost-effective strategy that will ensure Mexico's success in its energy transformation. And, international experience shows that a smarter electric grid will bring many benefits to Mexico and will aid the country in achieving its lofty goals on a reasonable timeframe and at a reasonable cost.

Section 1 of the report sets the stage by reviewing the legislation that created the sectoral transformation now underway.

Section 2 reviews the state of technology in Mexico's power sector and the efforts undertaken to date with grid modernization by the country's biggest power sector players: the state-owned electricity utility, Comisión Federal de Electricidad (CFE), and the independent system operator, Centro Nacional de Control de Energía (CENACE). In later sections, these efforts are put into the context of some of the best international practices.

Section 3 reviews the state of policy in the power sector and describes the development of the Smart Grid Implementation Plan by the Ministry of Energy, Secretaría de Energía (SENER). As part of the policy review, we revisit and review recent work performed for SENER and the 
Energy Regulatory Commission, Comisión Reguladora de Energía (CRE), by consulting experts, including ESTA International (ESTA), the National Renewable Energy Laboratory (NREL), and the Regulatory Assistance Project.

Section 4 reviews the country's priorities for smart grid deployment. The eight drivers in Figure ES-1 express the Mexico-specific goals for Smart Grid. Section 4 also compares Mexico's drivers to the drivers of smart grids in the European Union and several other areas, including Asia, Africa, the Middle East, and other parts of Latin America. As shown in Figure ES-1, the drivers in Mexico match well with those of the European Union.

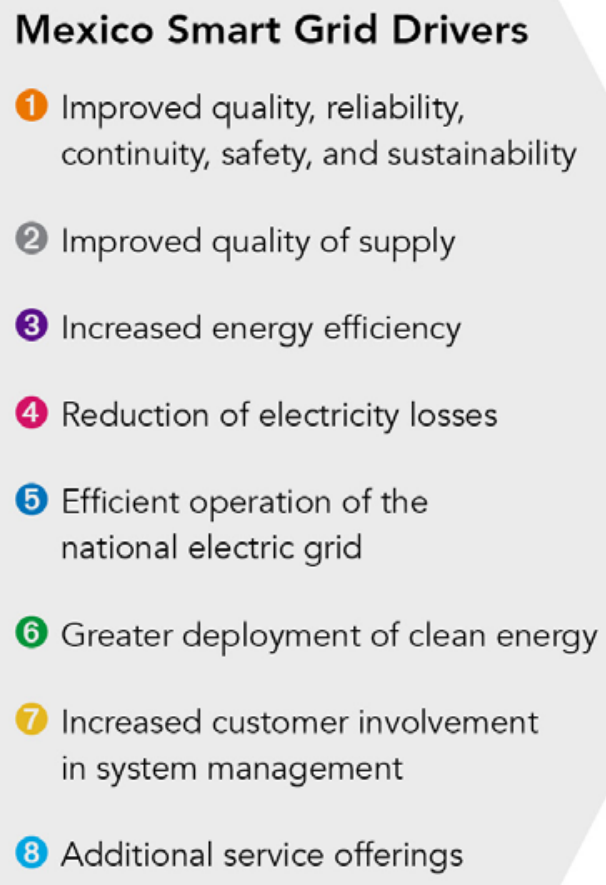

\section{EU Smart Grid Drivers}

- Sustainability

- Reduction of $\mathrm{CO}_{2}$ emissions 6

- System losses 4

- Transportation 8

- Integration of DER 6

- Competitiveness

- Increased market participation $(7)$

- Through aggregation of distributed generation, storage, demand response (3)

- Improved market transparency

- Interregional markets (harmonized)

- Security and quality of supply (2)

- Safe integration of large-scale renewable energy sources $(6$

- Cyberenergy and data protection

- Operational improvements 105

Figure ES-1. Comparison of Mexico's smart grid drivers with those of the European Union (EU)

The figure is by the authors, with content from SENER $(2016 a, 15)$ and European Commission $(2011,48)$.

Section 5 consists of an eight-page table that maps many smart grid measures to specific smart grid drivers. Though it is not exhaustive of all smart grid measures, the table serves as a "shortcut" to many actual and illustrative applications of Smart Grid that will assist Mexico in accomplishing the goals expressed in the drivers. Each of the eight smart grid drivers is addressed separately, with illustrative smart grid measures that could serve the driver and with applications in all aspects of the grid, including generation/supply, transmission, distribution, metering, customer premises, and "other/combined" aspects.

Section 6 is the most information-dense section of the report. In substantial detail, smart grid experts from the National Renewable Energy Laboratory (NREL) in the United States and from Swedish smart grid research centers describe smart grid measures that will assist Mexico's move to a cleaner, more-efficient grid. The section contains large amounts of technical information about these measures and taps the rich international experience of several other countries. As 
before, though, the expert opinions are always focused on Mexico's goals, tying the discussion to the specific smart grid drivers identified by SENER.

Section 7 discusses institutional policies that are recommended for smart grid growth. The discussion focuses on cost/benefit assessments that should be undertaken for each group of smart grid measures. This section also recalls the work described in other reports prepared for Mexico that have concluded the overall benefit/cost ratio for smart grid investments will be quite positive, assuming careful planning and deployment of smart grid measures occur.

Section 8 discusses some of the barriers to smart grid deployment, including cybersecurity concerns and consumer receptivity. The section reviews an approach to introducing dynamic pricing that may increase residential customer acceptance.

The References section lists the publications cited in the report as well as other monographs and articles that will help readers dive deeper into any given smart grid topic.

Finally, the appendices contain an excerpt summarizing a report on Smart Grid that ESTA International prepared for CRE, as well as SENER's Programa de Redes Eléctricas Inteligentes report. 


\section{Table of Contents}

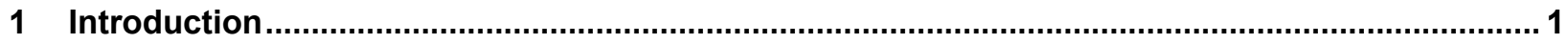

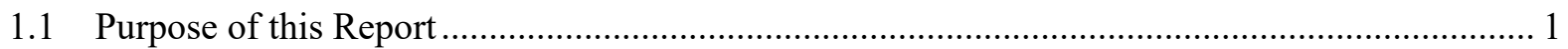

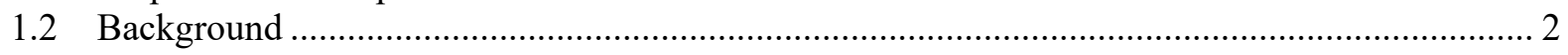

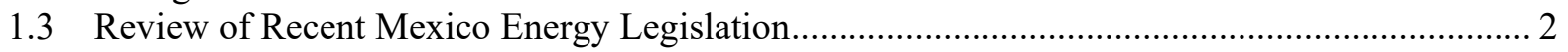

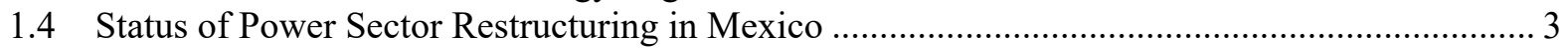

1.5 Definition of Smart Grid for Mexico Used in this Report......................................................... 5

2 Technology Landscape: Review of National and Regional Smart Grid Technologies in Mexico

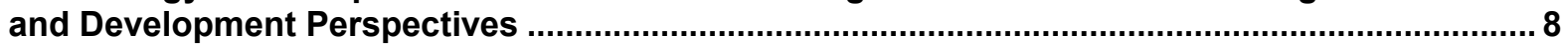

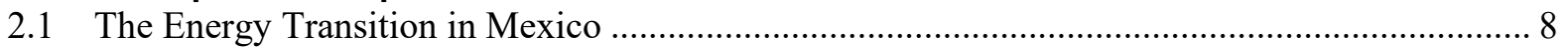

2.2 Strategic Objectives of Comisión Federal de Electricidad................................................ 8

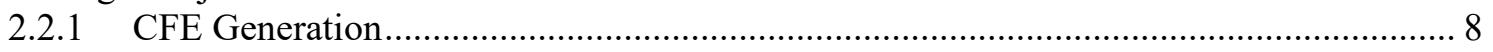

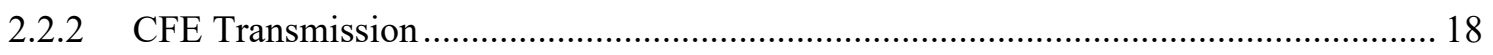

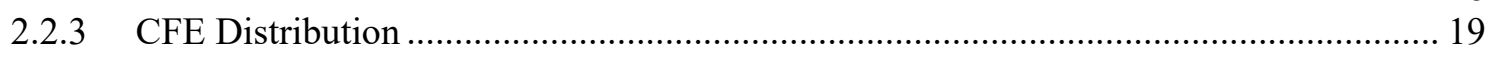

2.3 Centro Nacional de Control de Energía (CENACE) .......................................................... 22

2.4 Smart Grid Technology Players in Mexico, the Americas, and the World ............................... 24

3 Technology and Policy Landscape: Technologies and Policies Available for Mobilizing Smart

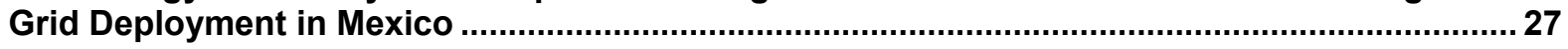

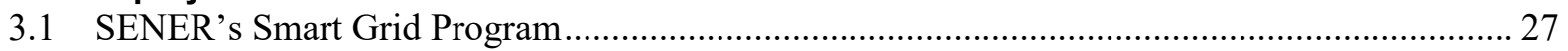

3.2 SENER'S Policies for the Deployment of Smart Grids ...................................................... 27

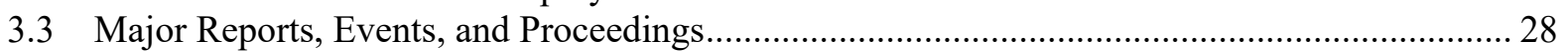

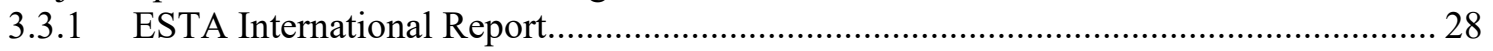

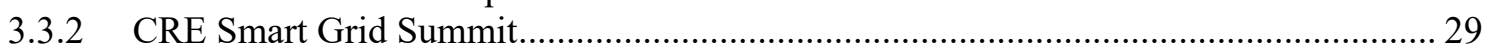

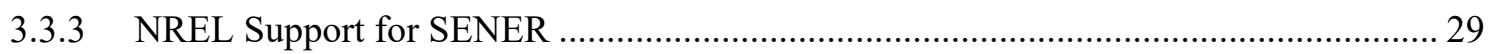

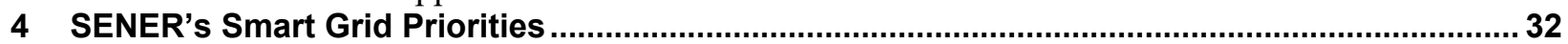

4.1 Review of Mexico's Smart Grid Priorities ................................................................................ 32

4.1.1 Improved Quality, Reliability, Continuity, Safety, and Sustainability........................ 34

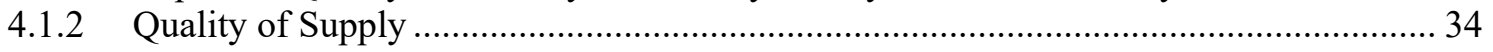

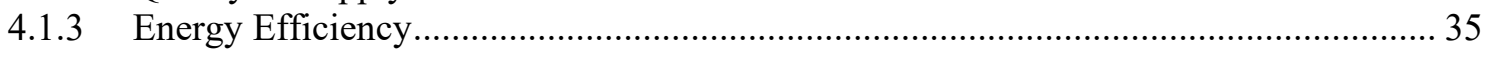

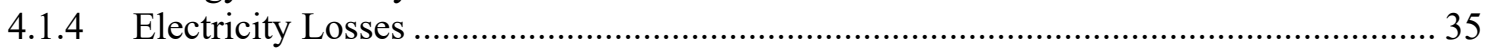

4.1.5 Efficient Operation of National Interconnected Electric Grid ................................... 37

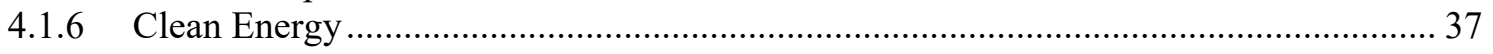

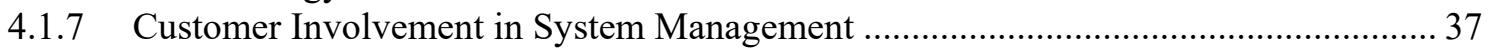

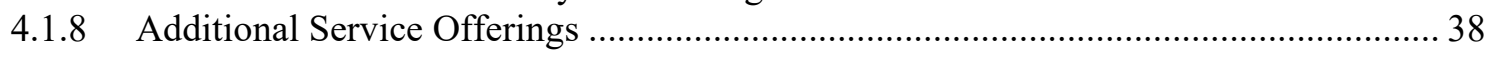

4.2 How Smart Grid Measures Can Serve Mexico's Energy Goals.............................................. 38

4.3 Survey of International Experience with Smart Grid Technologies....................................... 39

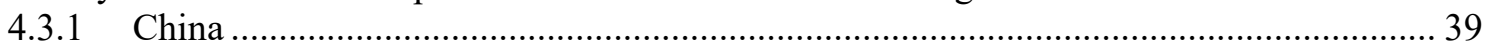

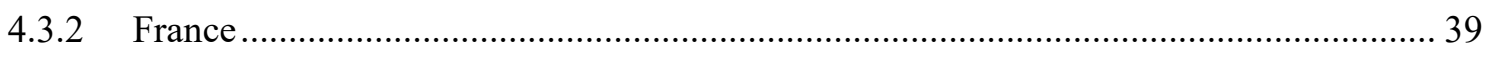

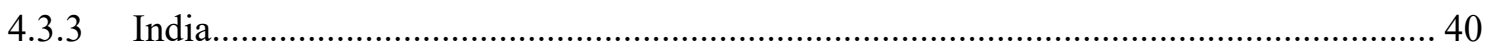

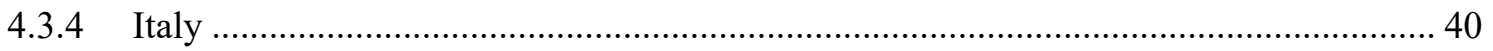

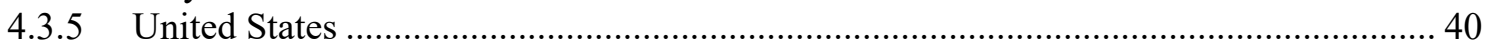

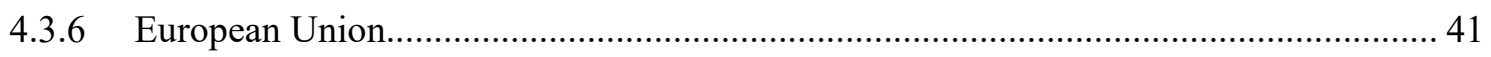

5 Mapping Smart Grid Measures to Key Drivers in Mexico ....................................................... 42

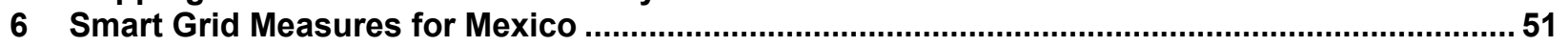

6.1 Driver 1: Quality, Reliability, Continuity, Safety, and Sustainability .................................... 51

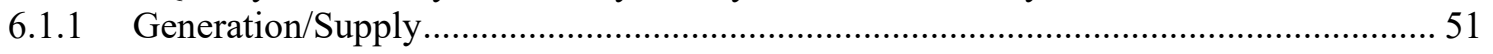

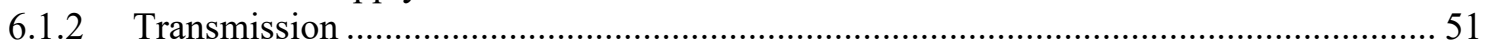

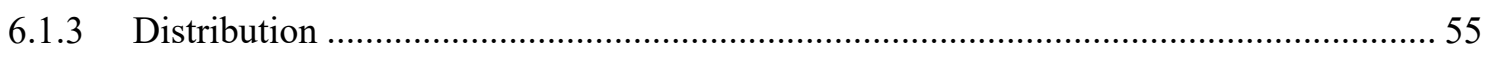

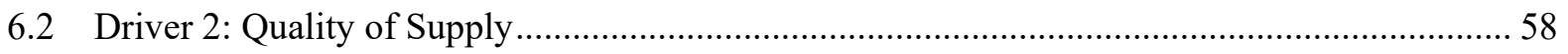

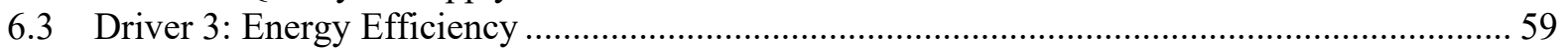




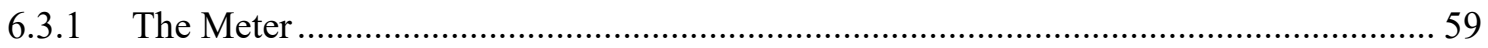

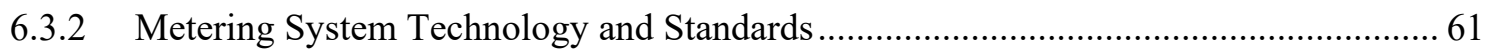

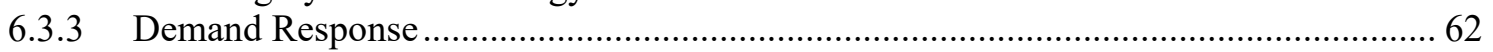

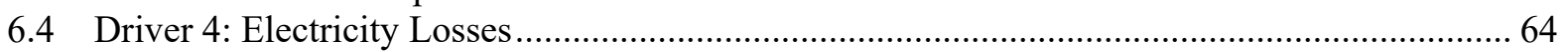

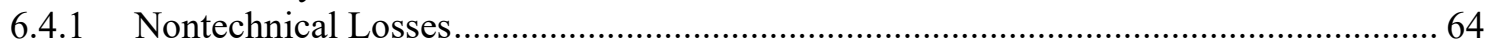

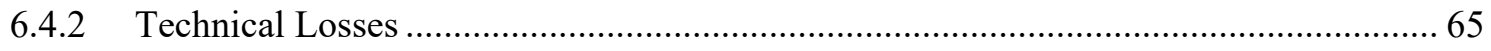

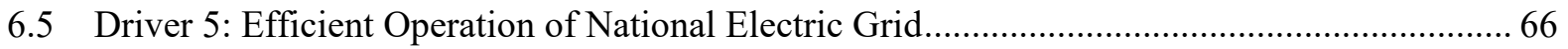

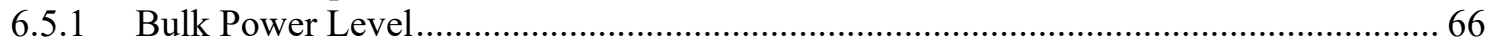

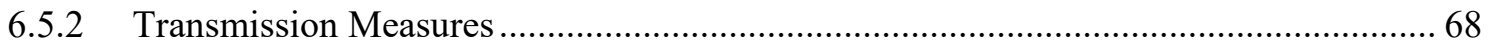

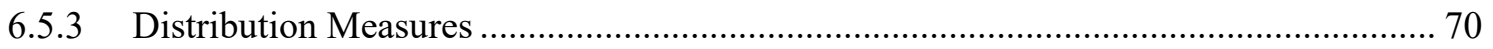

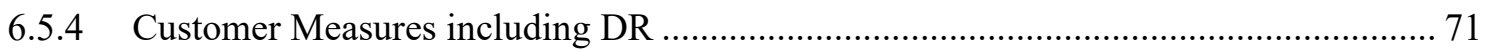

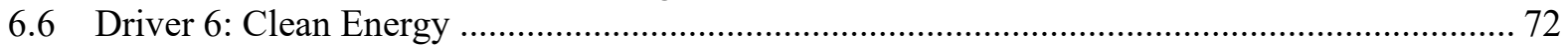

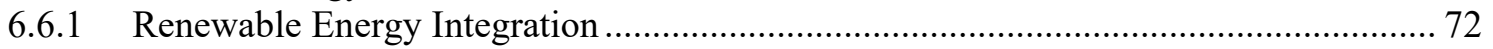

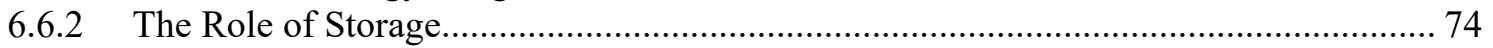

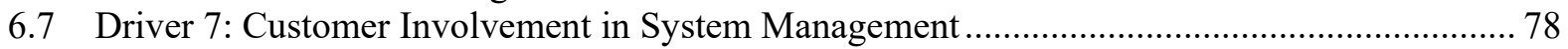

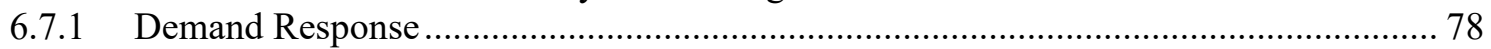

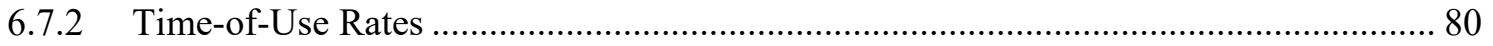

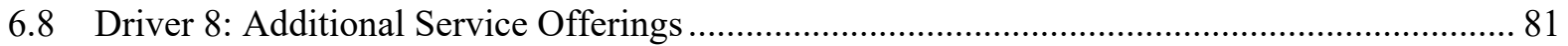

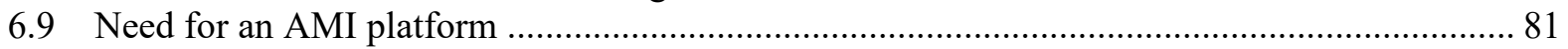

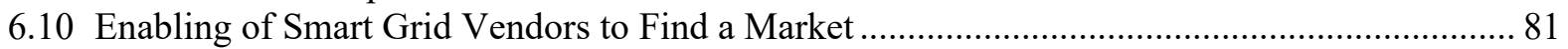

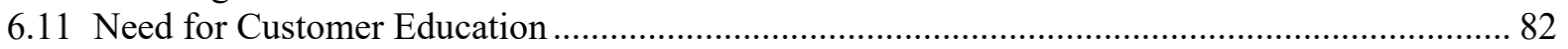

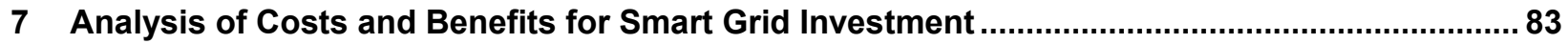

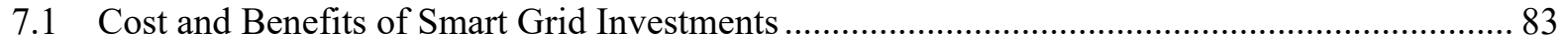

7.1.1 Cost-Benefit Analysis of Smart Grid as a High-Level Strategy.................................... 83

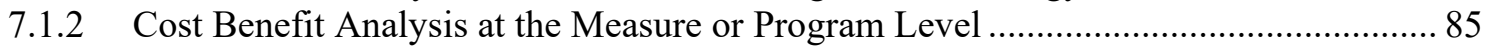

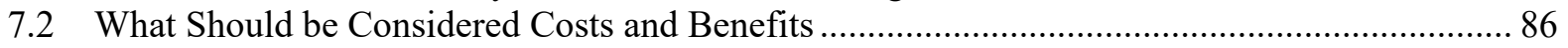

8 Obstacles to Implementation of Smart Grid Programs and Investment in Them ........................8 88

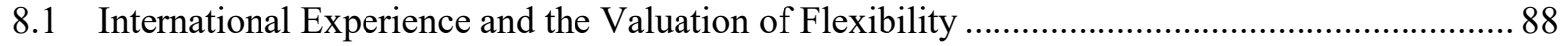

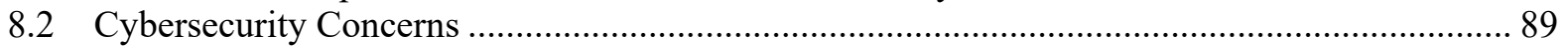

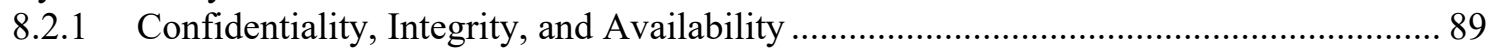

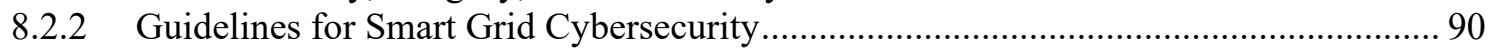

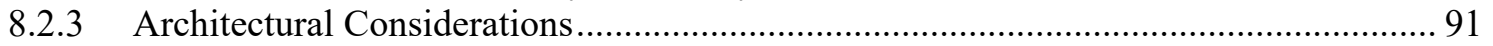

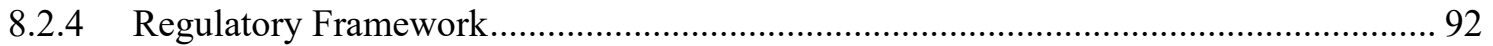

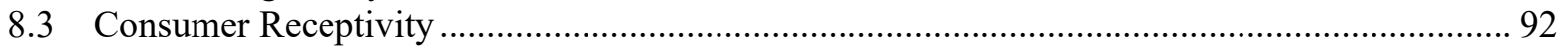

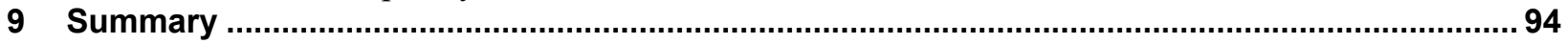

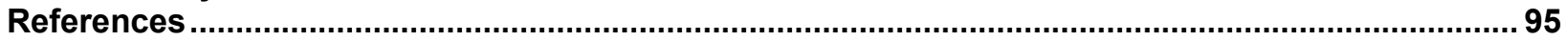

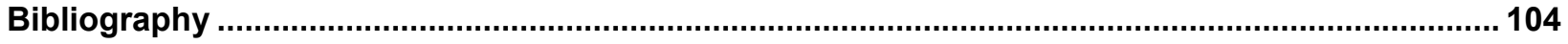

Appendix A. Summary of the ESTA International Report............................................................. 106

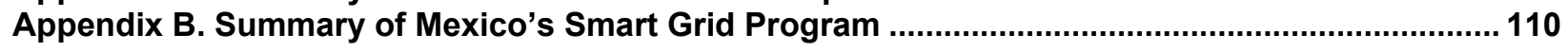




\section{List of Figures}

Figure ES-1. Comparison of Mexico's smart grid drivers with those of the European Union (EU) ........... 7

Figure 1. Pre-reform electric industry structure In Mexico ................................................................. 4

Figure 2. New (post-reform) electric industry structure in Mexico ….................................................... 5

Figure 3. Electricity use (megawatt-hours) by sector in Mexico, 2017 ............................................. 6

Figure 4. Residential electricity consumption by end use in Mexico, 2008 .......................................... 7

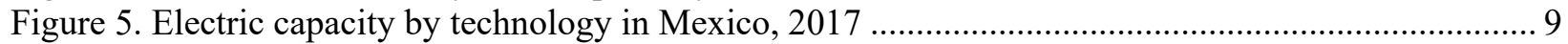

Figure 6. Energy generation by technology In Mexico, 2017 ......................................................... 9

Figure 7. Clean energy projects of the first and second auctions, by state ............................................. 10

Figure 8. Percentage of participation in the first and second auctions, by technology ............................ 12

Figure 9. Clean energy statistics from the Mexican energy auctions.................................................... 14

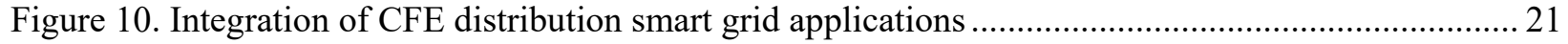

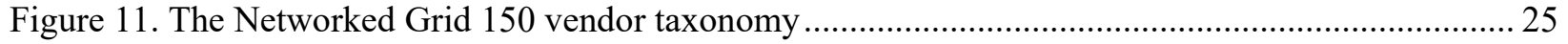

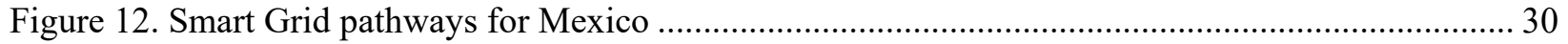

Figure 13. Comparison of smart grid drivers: Mexico and the EU ..................................................... 33

Figure 14. Trend of electricity losses (pérdidas) in the interior of Mexico, 2002-2015........................ 36

Figure 15. Trend of electricity losses (pérdidas) in the Valley of Mexico, 2002-2015 .......................... 36

Figure 16. Navigant ranking of residential demand response providers............................................. 71

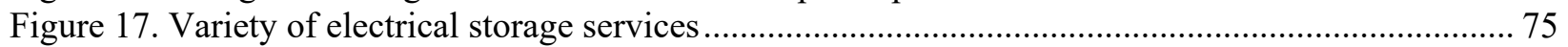

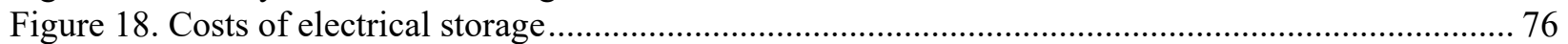

Figure 19. Supply curve for battery-provided regulation service ....................................................... 77

\section{List of Tables}

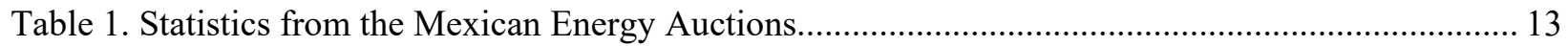

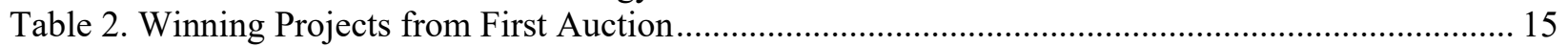

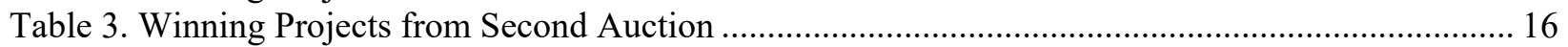

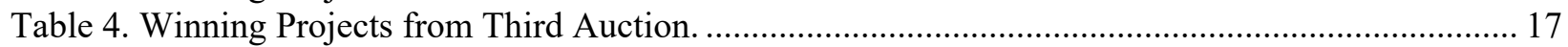

Table 5. FLISR Equipment Installed on the Medium Voltage Level, 2015 ....................................... 20

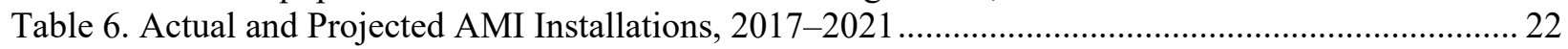

Table 7. CENACE'S New Smart Grid Projects, 2017 ....................................................................... 23

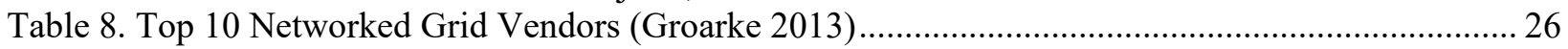

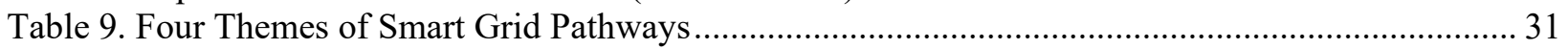

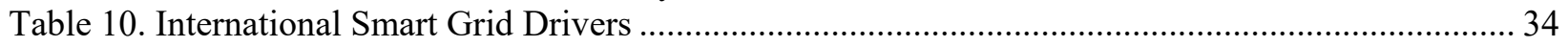

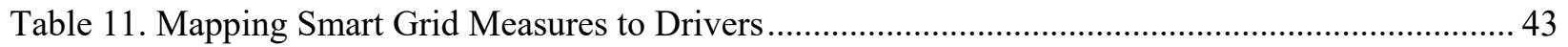

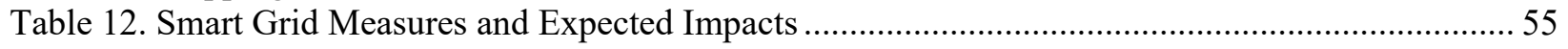

Table 13. Smart Grid Distribution Measures Affecting Power Quality ................................................... 59

Table 14. Demand Response Costs in Selected Nordic Countries........................................................ 63

Table 15. Report from IEA Task 17: Integration of DSM, Energy Efficiency, Distributed Generation and

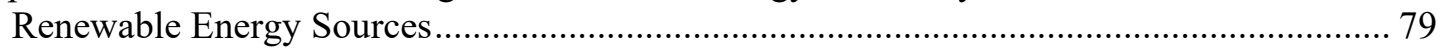

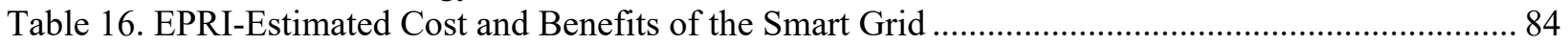

Table 17. EPRI-Estimated Distribution of Smart Grid Benefits ............................................................... 84 


\section{Introduction}

In December 2013, the Mexican government approved constitutional energy reform. Following this, it issued the Electrical Industry Law in August 2014 and the Energy Transition Law in December 2015. These pieces of sweeping legislation catapulted Mexico into the international energy spotlight for its leadership on energy policy reform. The new laws address all Mexican energy sectors, including power and hydrocarbons, transportation fuels, and energy efficiency. For the electric sector, the new laws make major changes, including (SENER 2017):

- Creation of a wholesale power market

- Establishment of an independent system operator, Centro Nacional de Control de Energía (CENACE)

- Creation of an incentive system for clean energy deployment using "clean energy certificates"

- Restructuring of the vertically owned utility by splitting the generation function of the Comisión Federal de Electricidad (CFE) into six competing and independent companies, and creating separate independent businesses for its transmission division, its distribution division, and its commercialization division.

- Endorsement of a Smart Grid program

- Assignment of increased policy responsibilities and regulatory powers, including on smart grid issues, to Secretaría de Energía (SENER) and Comisión Reguladora de Energía (CRE).

\subsection{Purpose of this Report}

The purpose of this report is to fulfill a requirement of the new law concerning Smart Grid in Mexico. The Energy Transition Law (Ley de Transición Energética-LTE) requires Mexico's Ministry of Energy, SENER, to provide a report concerning smart grid technologies in Mexico, as follows:

The Ministry of Energy (SENER), with the support of CENACE, CRE (Comision Reguladora de Energía), Transmission companies, Distributors and Suppliers shall develop and publish no later than August 2015 a report including: the benefits, costs and the technologies available for the implementation of Smart Grids in Mexico, the current status of smart grids in Mexico, at the national and regional level, and their development prospects. Also identify potential obstacles for implementation, as well as current and potential impacts for deployment of such technologies. ${ }^{2}$

The report fulfills this requirement by setting out the current state of smart grid investment in Mexico, reviewing the available technologies, and assessing the costs and benefits of pursuing various smart grid measures.

In addition to responding to the specific requirements of this section of the LTE, the report identifies smart grid measures — or drivers - that will most likely succeed in serving the eight

\footnotetext{
${ }^{2}$ Transitorios, Décimo Séptimo section of Ley De Transición Energética
} 
drivers for Smart Grid adopted by SENER in its smart grid policy statement (SENER 2016, 15). This guidance should provide SENER, CFE, CENACE, and CRE with information to make informed choices about the choice of smart grid architecture, the priority and timing of smart grid investments, and an estimate of the benefits Mexico will derive from smart grid investments.

\subsection{Background}

The era of power sector reform in Mexico dates to 1992, when it first became possible for non-government entities to own and operate electricity generation. This led to the entry of independent power producers (productores independientes de energía-PIEs) into the market. However, Mexico's state utility, CFE, remained the sole (monopsony) buyer of power produced by the PIEs.

In August 2013, the President of Mexico submitted a proposal for constitutional reforms of the energy sector of Mexico. The national legislature and most of the legislatures in the Mexican states passed this sweeping constitutional reform, making it effective in December 2013. Secondary implementing legislation was introduced in 2014; the 21 legislative measures enacted as a result include the Electricity Industry Act (Ley de la Industria Eléctrica-LIE), which complements the energy reform and gives better guidance to the different institutions and participants. ${ }^{3}$

Reform legislation has

catapulted Mexico into

the international energy

spotlight

The final important legislative piece of the power sector reform is the LTE and its regulation, which became law in December 2015 and May 2017 respectively, after protracted legislative consideration. The LTE addresses many issues, including Mexico's clean energy and energy efficiency commitments and the Smart Grid Program.

\subsection{Review of Recent Mexico Energy Legislation}

The LTE established an overall clean energy goal of $35 \%$ clean energy generation by 2024 , with intermediate goals of $25 \%$ by 2018 and a $30 \%$ by 2021, which Mexico committed to meeting at the 2015 United Nations Climate Change Conference or "Paris climate summit." The law also established energy efficiency goals and an annual process for promoting the penetration of clean energies, including distributed generation (DG). SENER is responsible for planning the transmission and distribution grids. SENER publishes on an annual basis its 15-year indicative electric system expansion plan through a document called PRODESEN (Program for Development of the National Electric System). In it, SENER presents its plans for expanding generation and works with CENACE and CFE to include the proposed expansion and

\footnotetext{
${ }^{3}$ Leyes Secundarias de la Reforma Constitucional en Materia Energética
} 
modernization of the national transmission grid and the general distribution networks, as well as recommendations for installing and retiring power plants.

SENER issued PRODESEN for the first time for 2015-2029 in July 2015; SENER subsequently issued PRODESEN for 2016-2030 in May 2016, for 2017-2031 in May 2017, and for 20182032 in May 2018. All subsequent PRODESEN reports must be issued in May of each year. The 2017-2031 PRODESEN document estimated that Mexico would have to (1) expand its transmission grid over the 15 -year period by 23,773 kilometers. This new transmission would bring the current 2018-2032 PRODESEN transmission total from 107,042 kilometers to 130,815 kilometers and (2) add transformers and reactive power sources, at a total cost of approximately USD 9.6 billion, in order to meet the demands of growth. Some of these new transmission projects are specific to meeting the clean energy goals in the Energy Transition Law. Mexico also would have to expand and modernize its distribution networks, at a total cost of approximately USD 7.7 billion over the 2018-2032 period. Funding for this expansion is expected to come from a mix of government and private sector investment.

The current PRODESEN calls for total installed capacity of 130 gigawatts (GW) by 2032, which includes $55 \mathrm{GW}$ of new capacity to cover the electricity demand for the coming 15 years. From the expected new capacity, approximately $34 \%$ is expected to come from conventional fossil fuel sources and $66 \%$ is to come from clean energy sources. This roadmap foresees new solar capacity of $11.4 \mathrm{GW}$ for this period. When the 2018-2032 PRODESEN was issued, solar capacity in Mexico was estimated to be only 214 MW (SENER 2018a).

The LTE also established the details of the program for clean energy certificates (certificados de energías limpias - CELs), which will be facilitated by the establishment of a public registry. The CEL program began in 2018 with an initial 5\% target.

\subsection{Status of Power Sector Restructuring in Mexico}

It is helpful to understand how the structure of the Mexican power sector has changed because of the reform efforts of the government. Figure 1 and Figure 2 present a "before-and-after" diagrams of the industry structure as presented by SENER: 


\section{Pre-Reform Industry Structure}

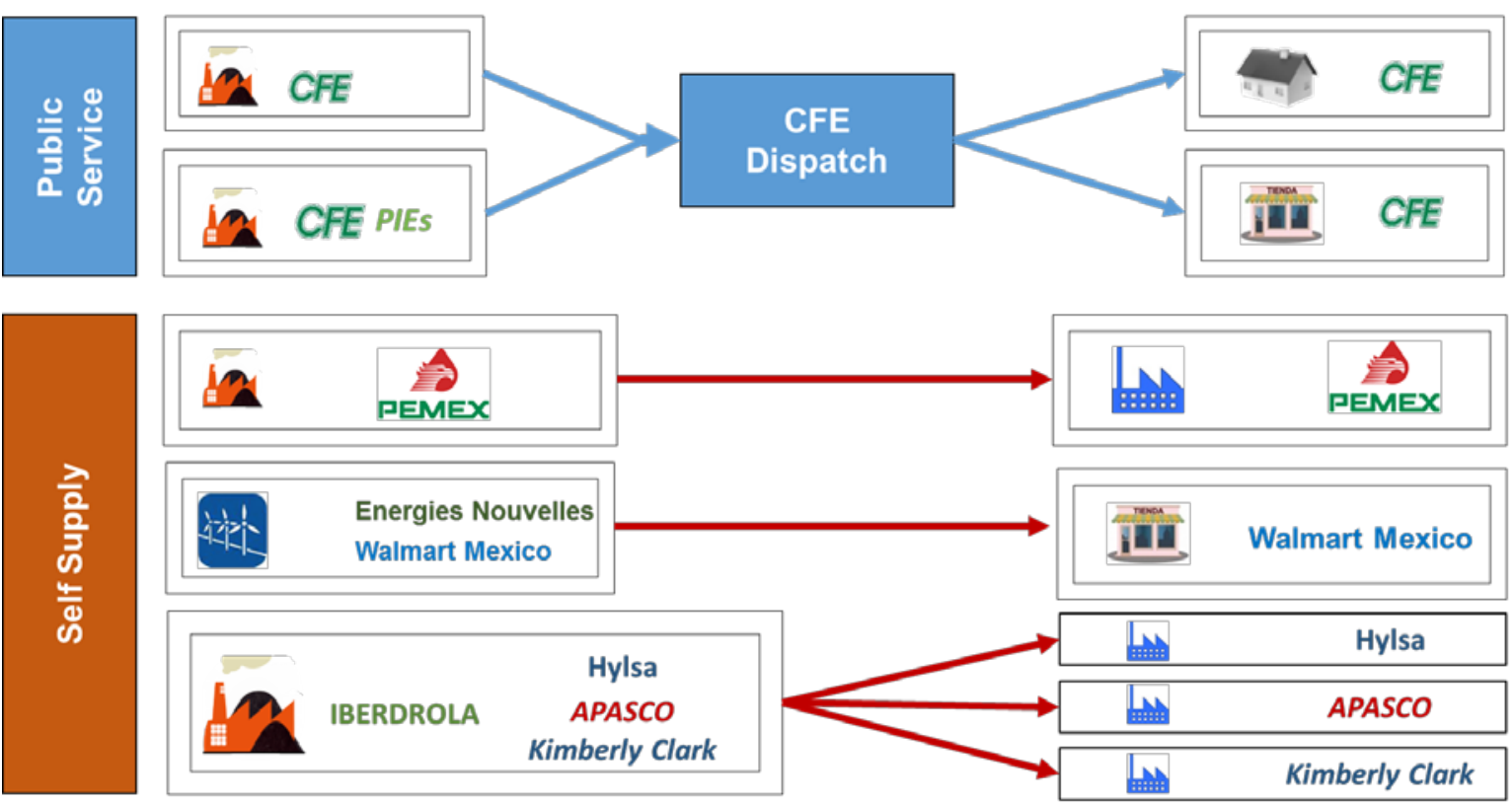

Figure 1. Pre-reform electric industry structure In Mexico

(Pavlovic n.d.)

Notable about the pre-reform industry is that for the public utility ("public service") function, $\mathrm{CFE}$ is the sole buyer and the sole seller of electricity for retail purposes. Under this structure, residential and business consumers had no choice other than buying from CFE. To serve such smaller customers, PIEs had to sell their power to CFE, the sole buyer for power delivered to residential and small commercial customers. Large commercial and industrial customers had certain additional options through a regime of self-supply. However, those activities were isolated and not integrated into the rest of the public service function. There was no market that would integrate the two regimes in a way that optimized production costs.

As illustrated by Figure 2, the reform changed the status quo in several ways. Separating CFE generation into competing companies modified the near-monopoly of CFE in generation. PIEs were placed on the same footing as the CFE generating subsidiaries so that all generators participated in a spot market administered by CENACE, formerly a CFE subsidiary. Capacity and energy auctions were created, in which retailers and qualified users may obtain capacity contracts. Finally, this structure permits the deregulation of wholesale electric prices. 


\section{New Industry Structure}

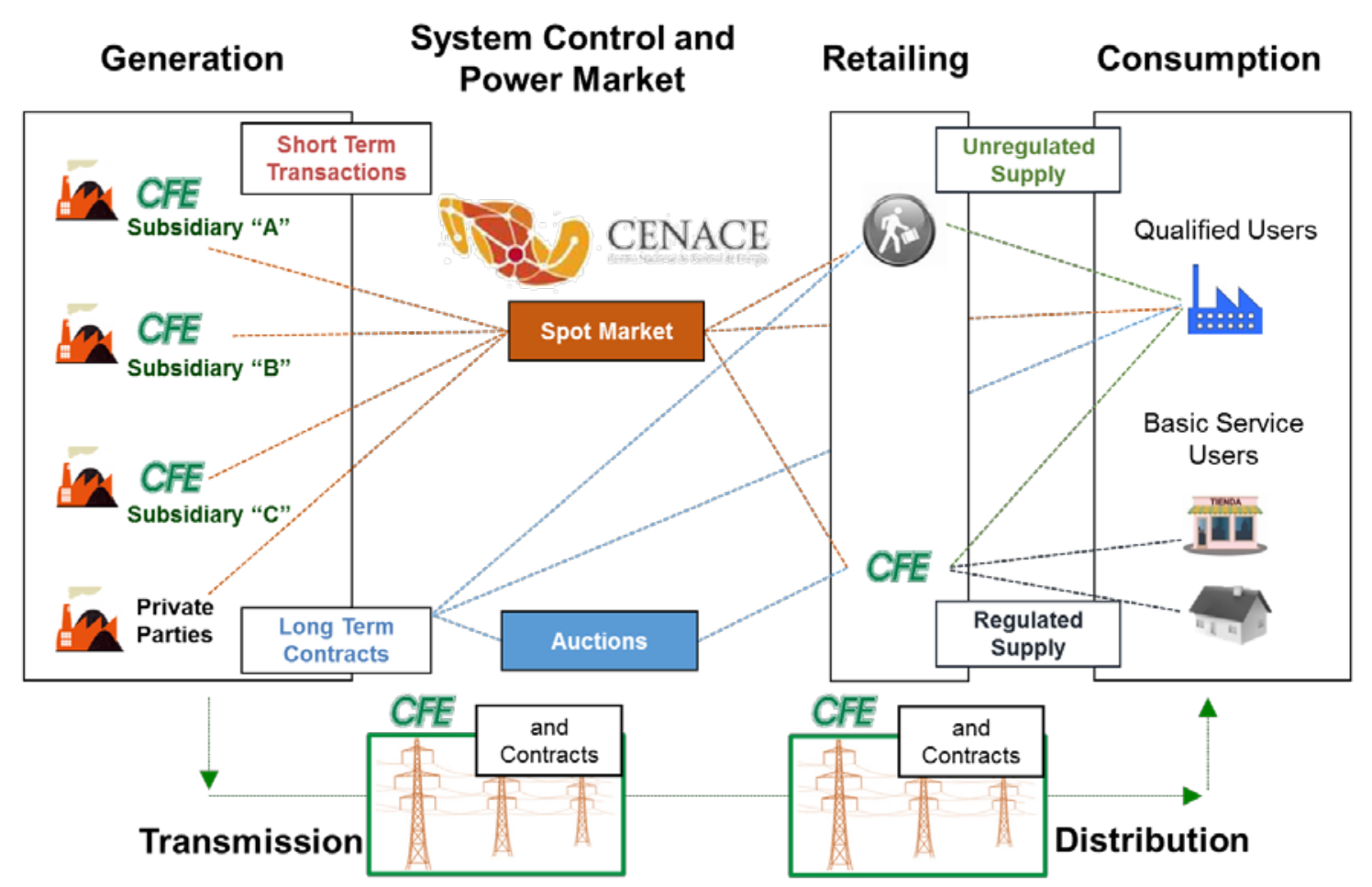

Figure 2. New (post-reform) electric industry structure in Mexico

(SENER n.d.)

\subsection{Definition of Smart Grid for Mexico Used in this Report}

The LTE addresses Smart Grid in Articles 37 and 38, brief statutory sections that describe the law's vision of a Smart Grid program for Mexico:

Article 37: The Smart Grid Program aims to support the modernization of the National Transmission Network and General Distribution Networks, to maintain a reliable and secure grid infrastructure to meet electricity demand in an economically efficient and sustainable manner. The Smart Grid program should also facilitate the incorporation of new technologies to achieve electricity cost reductions, the provision of additional services through the electric network, and promotion of Clean Energy and Clean Distributed Generation by allowing greater interaction between end user devices and the electrical system.

Article 38: The Smart Grid Program shall identify, evaluate, design, establish and implement strategies, actions and projects related to the electricity grid. ${ }^{4}$

\footnotetext{
${ }^{4}$ Ley de Transición Energética (LTE)
} 
Around the world, many definitions of smart grid have been proffered, and they have evolved over time. For this report, we use the definition contained in the law in Mexico:

A Smart Grid is one that integrates advanced technologies of measurement, monitoring, communication and operation, among others, to improve the Efficiency, Reliability, Quality or Security of the National Electric System.

\section{Essential Elements of a Smart Grid}

1) Applies information and communication technology to the electric power sector

2) Affects all segments of the electric power sector (e.g., generation, delivery, and consumption)

3) Can produce a variety of useful outcomes that improve the value of the electric grid.

Each country is different, and Smart Grid will mean different things for different countries. Among many differentiating factors is the final use of electricity by customers. Two factors may distinguish Mexico from other situations. First is the use of electricity by each customer class. Figure 3 shows that most electricity use in Mexico (56\%) is by medium and large industrial users (sector mediana industria and sector gran industria respectively). Residential electricity usage (sector residencial), which is often the focus of Smart Grid in popular literature, is the thirdlargest sector and constitutes only about a fourth of Mexico's electricity use.

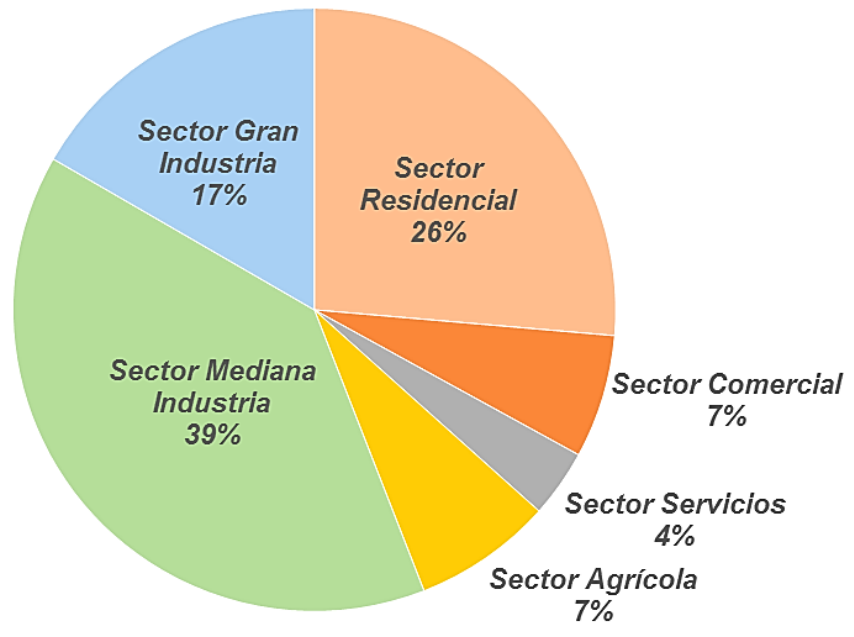

Figure 3. Electricity use (megawatt-hours) by sector in Mexico, 2017

(SENER 2016c)

A closer look at residential energy use (using 2008 data, shown in Figure 4) reveals that residential electricity use is mainly for refrigeration (refrigerador) and lighting (focos), followed by TV, air conditioning $(A / A)$, and ironing (plancha). 


\section{Consumo de electricidad de los aparatos en 2008}
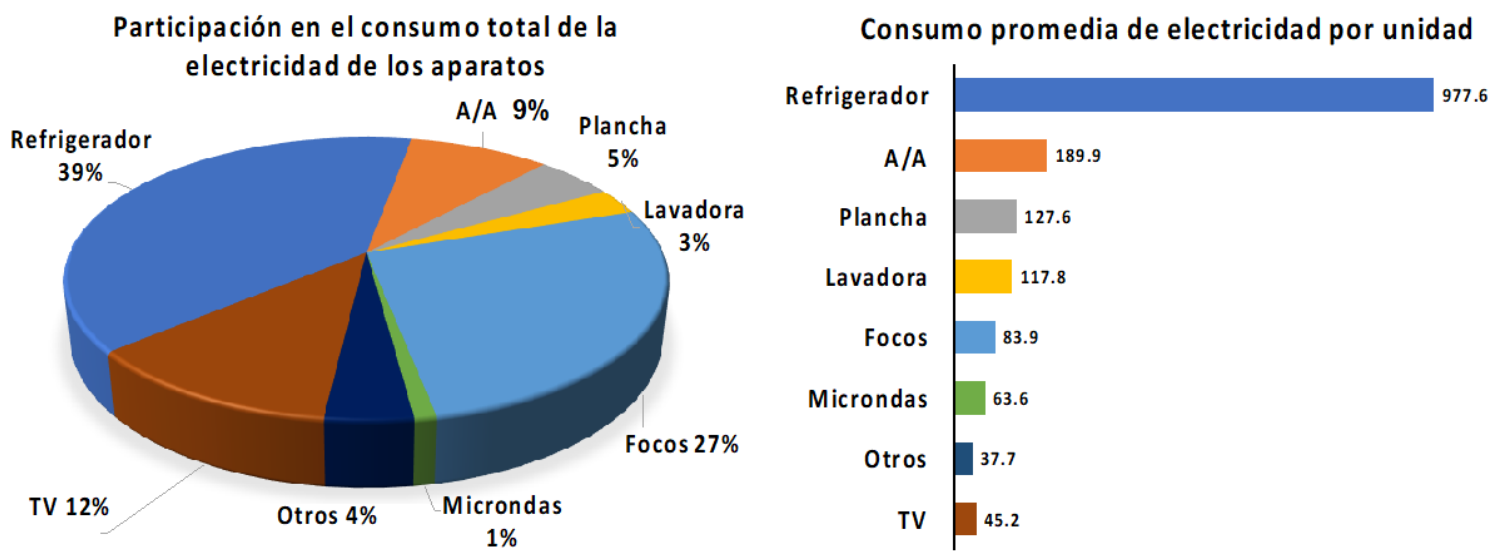

Figure 4. Residential electricity consumption by end use in Mexico, 2008

(SENER 2011, 94-95)

participation in the total consumption of electricity by appliance (left) and average power consumption per unit (right)

$\mathrm{A} / \mathrm{A}=$ aire acondicionado (air conditioning), focos = lighting, lavadora $=$ washing machine, microondas = microwave, plancha $=$ iron, refrigerador $=$ refrigerator, Otros $=$ other, including computer equipment, and hair dryers

Undoubtedly, this profile of residential usage will change as customer use evolves and national average income grows. It is reasonable to believe, for example, that the fraction of use dedicated to air conditioning (A/A) will grow. Energy efficiency programs and increasing appliance efficiency, especially for refrigeration and lighting, are also likely to change the balance of uses as existing appliances and lighting components are replaced by more efficient technologies.

These considerations (e.g., electricity use dominated by industrial customers and the changing profile of residential use) will be important factors in determining the pace and priority of "retail" smart grid investment. 


\section{Technology Landscape: Review of National and Regional Smart Grid Technologies in Mexico and Development Perspectives}

Before turning to the question of recommended smart grid solutions for Mexico, we describe the state of smart grid investment by three major power sector players: CFE Distribution, CFE Transmission, and CENACE.

\subsection{The Energy Transition in Mexico}

In December 2015, Mexico published the LTE. This law aims to regulate the sustainable use of energy; establish requirements for energy efficiency, clean energy deployment, and the reduction of polluting emissions of the electricity industry; and maintain the competitiveness of the productive sectors. The LTE includes a goal of implementing a total of $35 \%$ of energy generation from clean energy sources by the year 2024. Mexican policymakers recognized the challenges of achieving that goal under the then-current electrical industry structure. They concluded that major restructuring of the existing model - a vertically integrated system in which a single company-controlled generation, transmission, and distribution-would allow new and different players to produce electricity and compete in the newly created wholesale power market. With appropriate incentives and competitive markets, these players could help Mexico transition to cleaner energy and meet its energy efficiency and clean energy generation goals.

With increased variable renewable energy in the system comes increased need for system flexibility. And, the Mexican government determined that a key enabling element that could provide additional flexibility and help the transition succeed would be a Smart Grid that helps achieve interoperability between conventional and renewable systems to cushion or correct events affecting the grid.

\subsection{Strategic Objectives of Comisión Federal de Electricidad}

\subsubsection{CFE Generation}

Mexico's transition to a cleaner energy generation profile would be no easy task. At the end of 2017, the installed generation capacity in Mexico consisted mainly of combined cycle, thermal, carbon, and hydro plants, with a very small percentage of clean energy (PRODESEN 20182032), as shown in Figure 5. To accomplish the goal set by the LTE, Mexico saw that retrofitting existing power plants to natural gas would not be cost-effective. To expedite the process and entice new generation development, SENER worked with CRE to create and auction a CEL for each clean megawatt-hour (MWh) generated. These certificates could then be sold to consumers in the wholesale power market. SENER also implemented a minimum of CEL purchases for basic service providers, services suppliers, emergency suppliers, and large consumers that will increase over time, from 5\% through 2018, increasing to 5.8\% through 2019, 7.4\% through 2020 , $10.9 \%$ through 2021 , and $13.9 \%$ through 2022. 


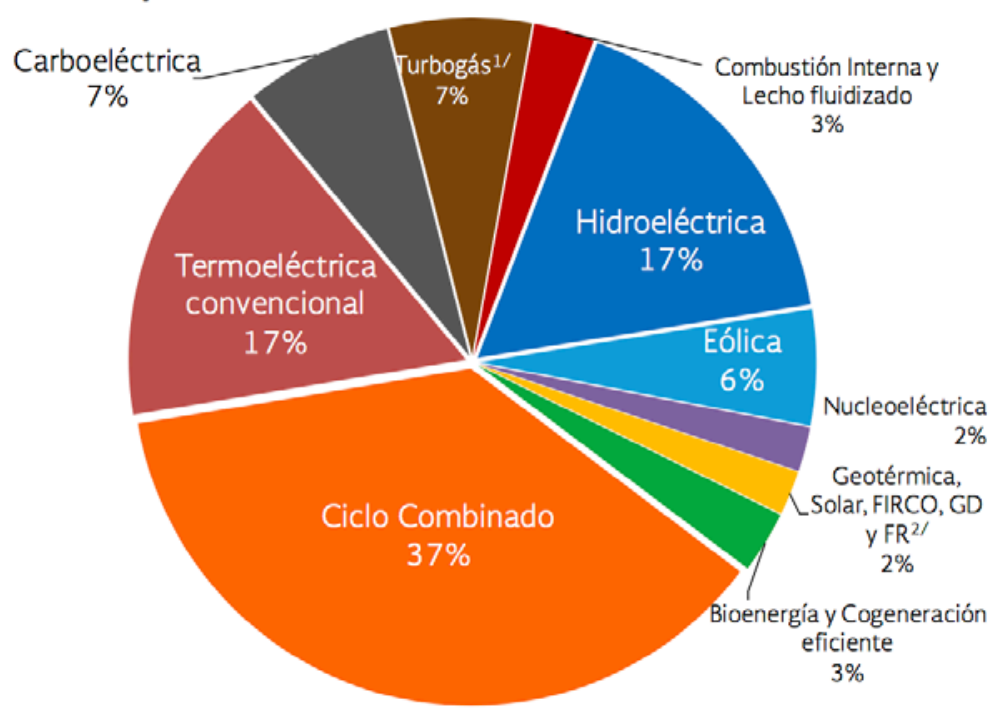

Figure 5. Electric capacity by technology in Mexico, 2017

(SENER 2018a, 19)

Turbogas $=$ gas turbine (Includes mobile generation plants), Combustión Interna y Lecho fluidizado $=$ internal combustion and fluidized bed, Hidroeléctrico $=$ hydroelectric, Eólica $=$ wind, Nucleoeléctrica $=$ nuclear, Geotérmico $=$ geothermal, Solar $=$ Solar, FIRCO $=$ Ministry of Agriculture Shared Risk Trust, GD = Distributed Generation, FR = Regenerative Brakes, Bioenergía y Cogeneración eficiente $=$ biomass and efficient cogeneration, Ciclo Combinado = combined cycle, Termoeléctrica convencional $=$ conventional thermal generation, Carboeléctrica $=$ coal generation

Figure 6 shows the corresponding percentage of Mexican energy production (GWh) produced by each generation technology.

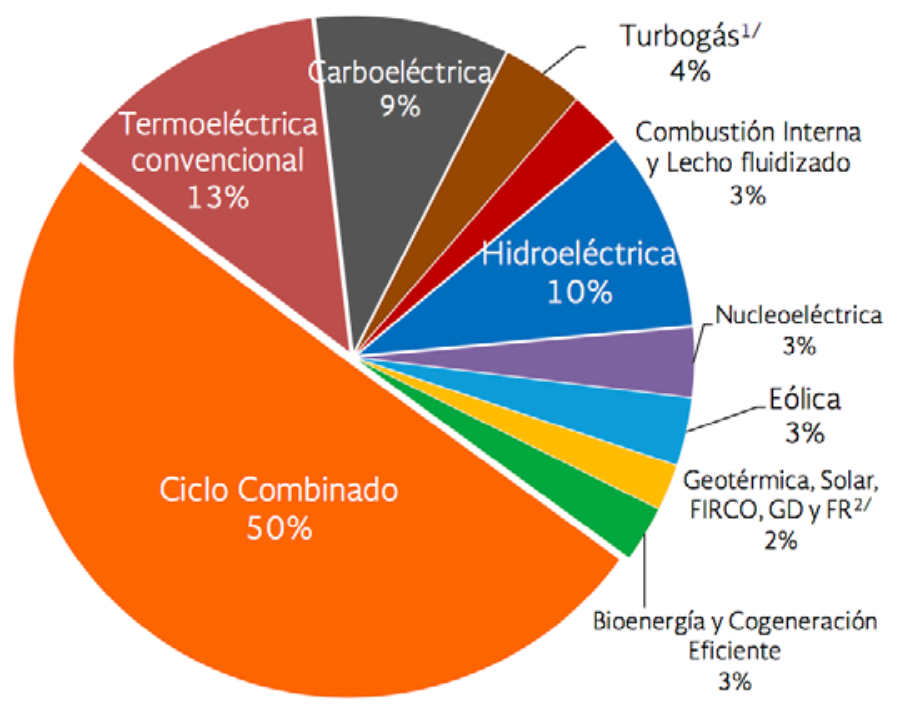

Figure 6. Energy generation by technology In Mexico, 2017

(SENER 2018a, 22)

See Figure 5 for English notations. 
New Models for Generation Deployment in Mexico Renewable Energy

Capacity Auctions

As of the end of 2017, Mexico had held three clean energy auctions, all directed by SENER in collaboration with CENACE. For the auctions, project developers could offer bids to provide power, clean energy certificates (CELs), or readily available capacity; however, only the clean energy projects could compete for the auctioned power and CELs, while any available technology could participate in the capacity offers.

The first and second auctions were held to allow CFE (the basic service provider) coverage of its requirements for clean energy generation through 15-year contracts and clean energy certificates through 20-year contracts. The results of the first two auctions in 2016 included $5 \mathrm{GW}$ of new renewable energy capacity, and the auctions were considered a success with a total expected investment of USD 6.6 billion in 15 Mexican states (Figure 7). Twenty different national and international companies representing 11 countries won awards, and they plan to provide new clean energy generation of 14,312 terawatt-hours (TWh)/yr and over 14 billion CELs/yr.
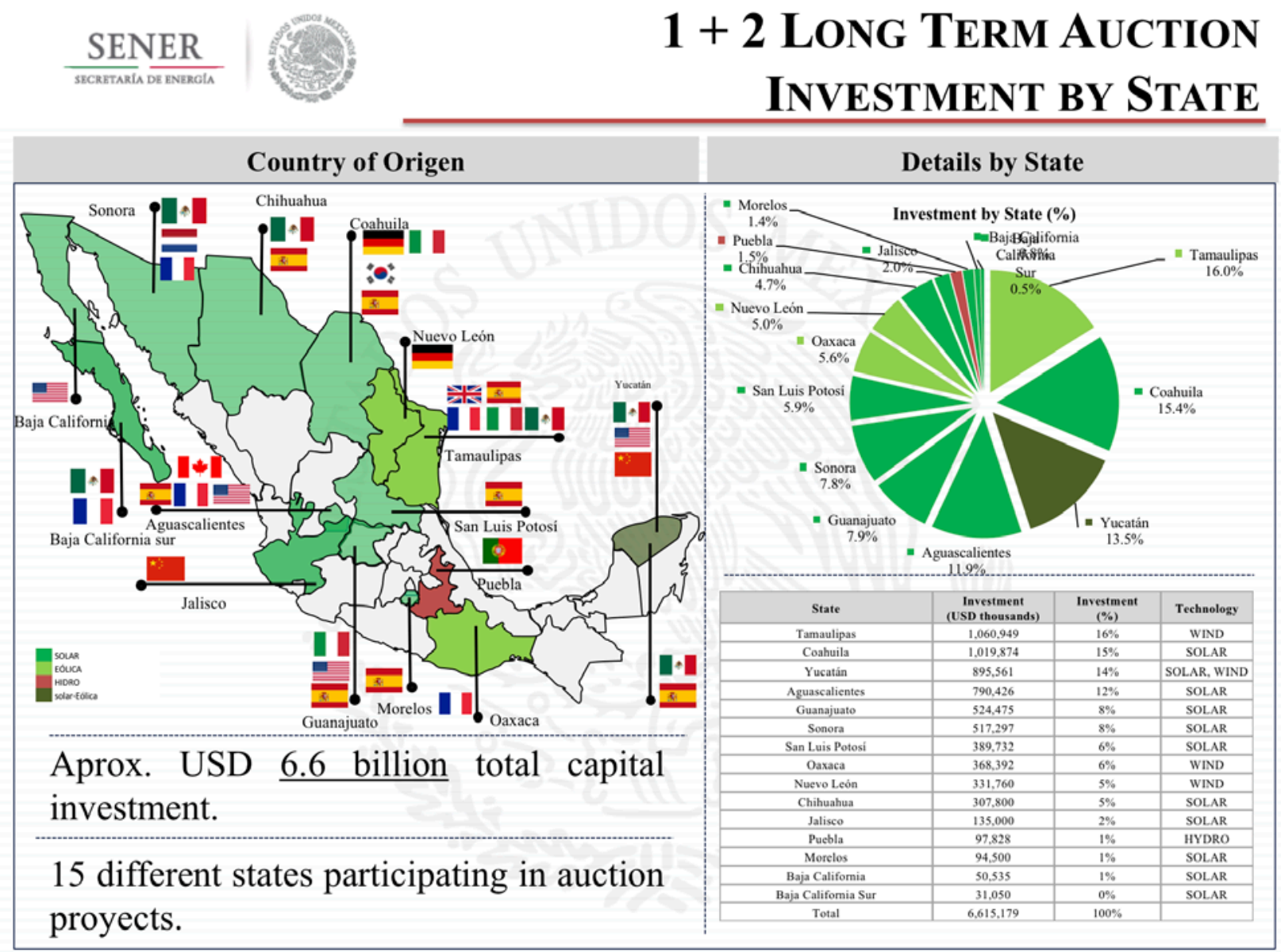

Figure 7. Clean energy projects of the first and second auctions, by state

(SENER 2017a) 
The auctions are focused on (1) bringing renewable energy projects to Mexico, particularly in areas with the greatest potential for renewable energy generation and (2) using a nodal price adjusting mechanism to discourage development near nodes where supply already exceeds demand while incentivizing development near nodes where generation is less available such as in the following states:

- Sonora

- Chihuahua

- Coahuila

- Nuevo León

- Tamaulipas

- Baja California

- Baja California Sur

- Yucatán

- San Luis Potosí

- Oaxaca

- Puebla

- Morelos

- Guanajuato

- Jalisco

- Aguascalientes

The northern portion of the country has the greatest potential for solar energy, as can be seen in the percentage of projects awarded in that area. The auctions' goal evolved to increase the types of technology available and integrate them into the evolving energy portfolio.

During the first two auctions, $61 \%$ of CELs were offered to solar photovoltaic (PV) projects, $36 \%$ to wind projects, $1 \%$ for geothermal, and $2 \%$ for hydro projects. The first auction resulted in projected energy generation per year of $4.0 \mathrm{TWh}$ from PV and 1.4 TWh from wind. The second auction resulted in projected energy generation of $4.84 \mathrm{TWh}$ from PV, 3.9 TWh from wind, and $0.2 \mathrm{TWh}$ from geothermal. Figure 8 and Table 1 provide information about the auction (subastas) results. 


\section{Subastas}

\section{Porcentaje de Participación por Tecnología}
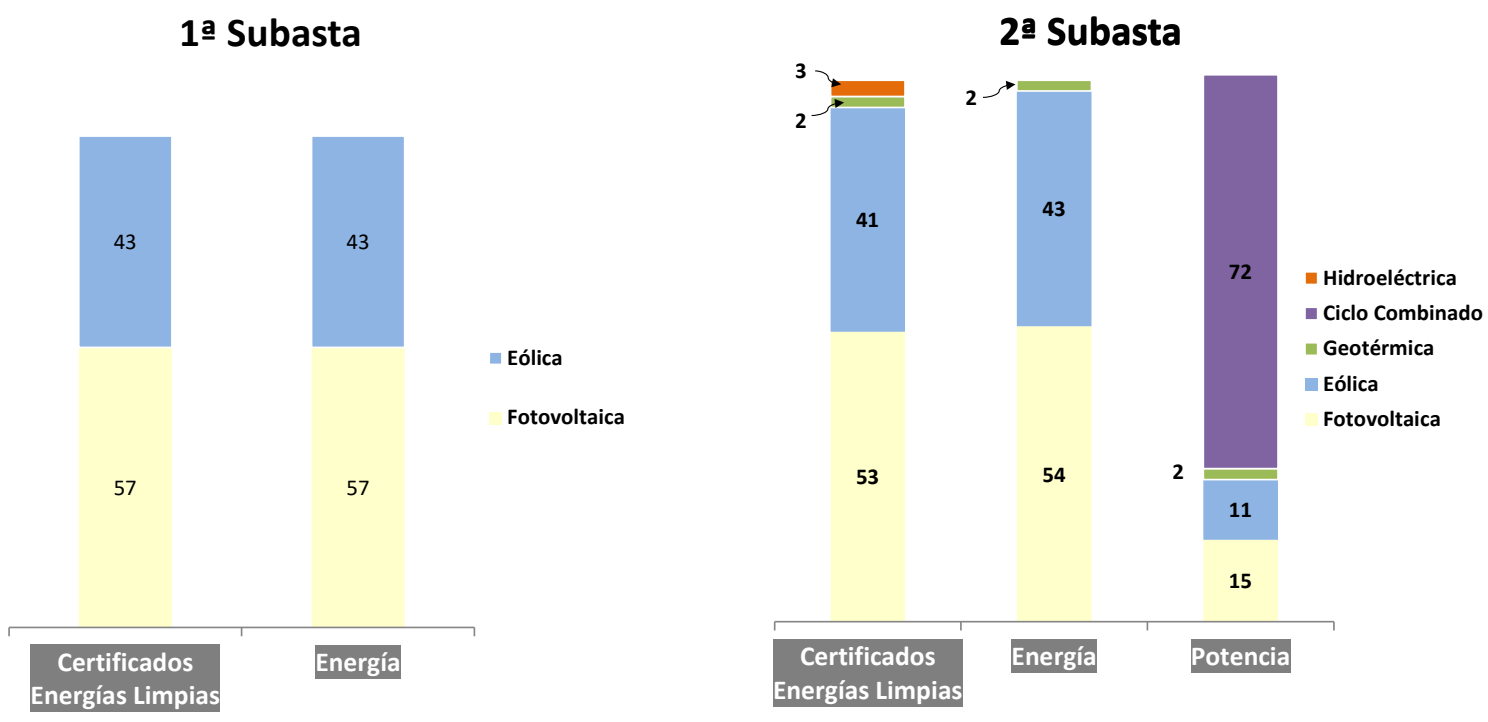

Figure 8. Percentage of participation in the first and second auctions, by technology.

(SENER 2017a)

Technology percentage participation in the $1^{\text {st }}$ (left) and $2^{\text {nd }}$ (right) auction

Certificados de Energías Limpias = clean energy certificates, Energía = energy, Potencia = capacity, Eólica = wind,

Fotovoltáica $=$ solar PV, Hidroeléctrica $=$ hydroelectric, Ciclo Combinado $=$ combined cycle, Geotérmica $=$ geothermal 
Table 1. Statistics from the Mexican Energy Auctions

(SENER 2017a)

\begin{tabular}{|c|c|}
\hline First Auction - March 2016 & Second Auction - September 2016 \\
\hline \multicolumn{2}{|l|}{ Number of Participants } \\
\hline 69 & 57 \\
\hline \multicolumn{2}{|c|}{ Winners } \\
\hline 11 & 23 \\
\hline \multicolumn{2}{|c|}{ Average Winning Price } \\
\hline USD 41.80/MWh & USD 33.47/MWh \\
\hline \multicolumn{2}{|c|}{ Clean Energy Certificates } \\
\hline $5,380,911$ & $9,000,000$ \\
\hline Representing $84.39 \%$ of the auctioned CELs & Representing $87.26 \%$ of the auctioned CELs \\
\hline \multicolumn{2}{|c|}{ Capacity } \\
\hline & 1,187 MW/year \\
\hline & Representing $80.05 \%$ of the auctioned capacity \\
\hline \multicolumn{2}{|c|}{ Investment in USD millions } \\
\hline \multicolumn{2}{|c|}{6,600} \\
\hline
\end{tabular}

Mexico's first two energy auctions attracted over 120 participating project proposals, with $27 \%$ moving forward as viable projects to meet the clean energy and demand requirements.

With the first auction, Mexico increased its renewable energy capacity by $37 \%$ of all the PV and wind energy installed in the previous 18 years. The second auction, held just six months later, added capacity equal to $98 \%$ of the PV and wind energy installed in the previous 18 years. With the overall installed capacity from both auctions, the Mexico energy sector has been able to cover $5.1 \%$ of the country's annual energy consumption with clean energy resources, as shown in Figure 9. 


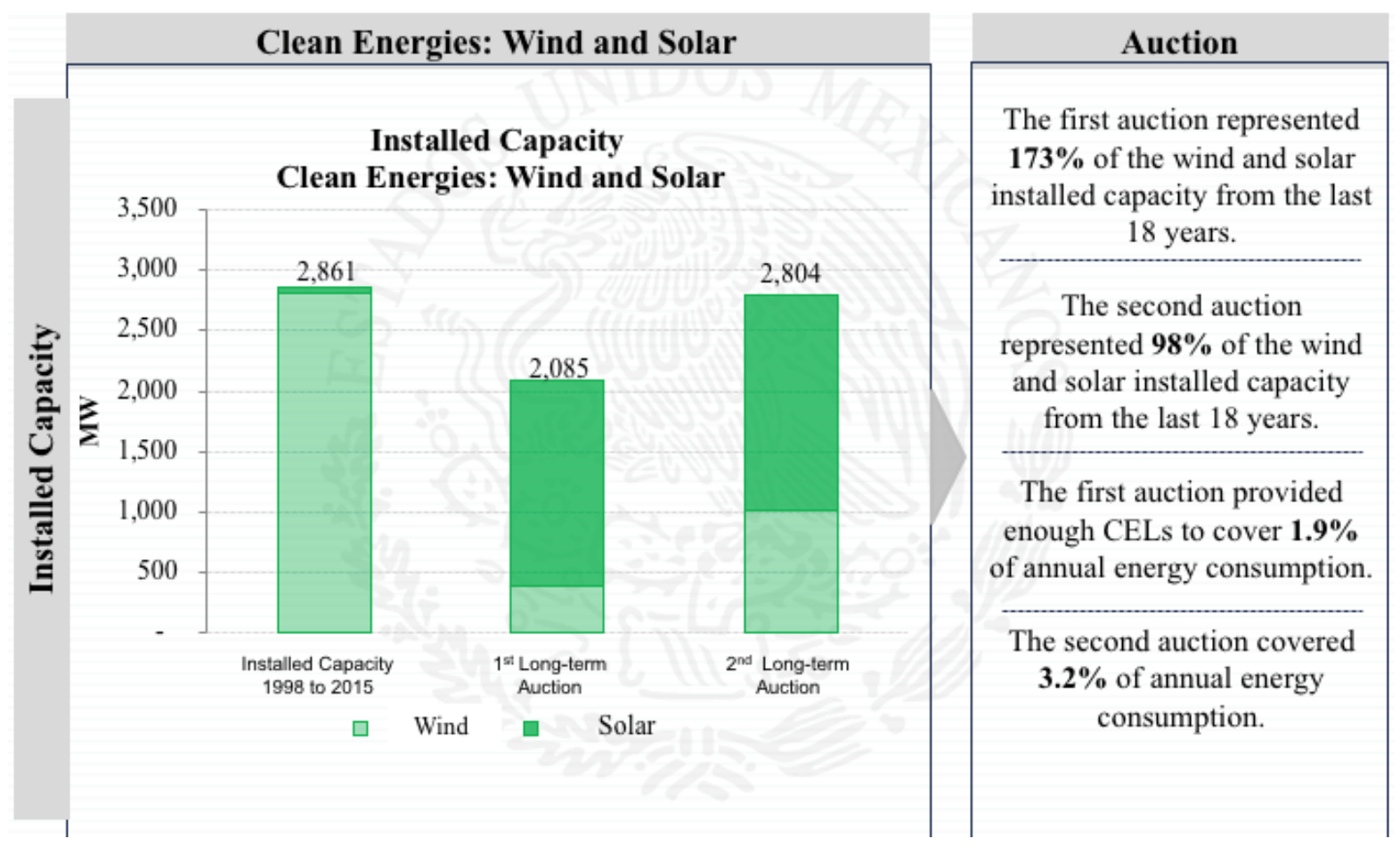

Figure 9. Clean energy statistics from the Mexican energy auctions.

(SENER 2017a)

The first auction took place in March 2016, with 11 companies from 7 countries ${ }^{5}$ investing approximately USD 2,615 million over three years and increasing generation capacity by a planned 2,085 MW. Selected bids covered $85 \%$ of the generation and CELs offered by CFE. Winning offers are detailed in Table 2 . The majority $(67 \%)$ of the proposed projects were awarded to PV and the rest were for wind. The projects were scheduled to come online by mid2018, and we do not have an update on their status.

${ }^{5}$ Mexico, China, India, Italy, Peru, Spain, and the United States 
Table 2. Winning Projects from First Auction

(CENACE 2016)

\begin{tabular}{|c|c|c|c|c|c|}
\hline \multicolumn{6}{|l|}{ Winning Sale Offers SLP/2015 } \\
\hline Company Name & Sale Offer & $\mathrm{MWH} / \mathbf{y r}$ & CELs/year & Technology & State \\
\hline SUNPOWER SYSTEMS - Guiajiro 2 & SLP2015010018-03 & 269,155 & 263,815 & SOLAR & Guanajuato \\
\hline ENEL GREEN POWER - Solar Villanueva & SLP2015010059-27 & 972,915 & 972,915 & SOLAR & Coahuila \\
\hline ENEL GREEN POWER - Solar Villanueva 3 & SLP2015010059-31 & 737,998 & 737,998 & SOLAR & Coahuila \\
\hline ENEL GREEN POWER - Solar Don José & SLP2015010059-45 & 539,034 & 539,034 & SOLAR & Guanajuato \\
\hline ENERGIA RENOVABLE DE LA PENINSULA & SLP2015010134-03 & 275,502 & 275,502 & WIND & Yucatan \\
\hline RECURRENT ENERGY - Aguascalientes Potencia 1 & SLP2015010148-01 & 140,970 & 140,970 & SOLAR & Yucatan \\
\hline ALDEASA ENERGIA - Eólico Chacabal & SLP2015010160-01 & 113,199 & 113,199 & WIND & Yucatan \\
\hline ALDEASA ENERGIA - Eólico Chacabal II & SLP2015010160-02 & 117,689 & 117,689 & WIND & Yucatan \\
\hline VEGA SOLAR 1 - Ticul 1 & SLP2015010319-01/02 & 740,135 & 725,450 & SOLAR & Yucatan \\
\hline JINKOSOLAR - Las Viborillas & SLP2015010331-01 & 277,490 & 277,490 & SOLAR & Jalisco \\
\hline JINKOSOLAR - Concunul & SLP2015010331-03 & 176,475 & 176,475 & SOLAR & Yucatan \\
\hline JINKOSOLAR - San Ignacio & SLP2015010331-06 & 48,748 & 48,748 & SOLAR & Yucatan \\
\hline PHOTOEMERIS SUSTENTABLE - Kambul & SLP2015010350-01 & 54,975 & 53,477 & SOLAR & Yucatan \\
\hline ENERGIA RENOVABLE DEL ISTMO II - PE El Cortijo & SLP2015010378-03/04 & 585,731 & 585,731 & WIND & Tamaulipas \\
\hline SOL DE INSURGENTES & SLP2015010445-03 & 60,965 & 60,518 & SOLAR & Baja California Sur \\
\hline ENERGIA LIMPIA - Eólico Tizimin & SLP2015010455-02 & 291,900 & 291,900 & WIND & Yucatan \\
\hline SUM & & $5,402,881$ & $5,380,911$ & & \\
\hline
\end{tabular}

The second long-term auction took place in September 2016, with 23 companies from 11 countries investing USD 4,000 million. Selected bids covered $84 \%$ of the generation offered, $87 \%$ of the CELs offered, and $80 \%$ of firm capacity offered by CFE. During the first auction, no capacity was awarded. Winning offers for the second auction are detailed in Table 3 . As in the first auction, most proposed projects (58.9\%) were awarded for PV generation. The rest of the winning bids were distributed as follows: $17.8 \%$ for wind, $10.7 \%$ for both combined cycle and hydroelectric, and $1.7 \%$ for geothermal. The projects are scheduled to come online by mid-2019. The countries that have actively participated in both auctions, other than Mexico, include China, France, Germany, Great Britain, Italy, Korea, Netherlands, Portugal, Spain, and the United States. During the second auction, CFE was able to contract 1,187 MW/yr of capacity, which during the first auction, it failed to do. Of the total capacity awarded, $337 \mathrm{MW}$ were won by clean energy projects, including $184 \mathrm{MW}$ from solar, $128 \mathrm{MW}$ from wind, and $25 \mathrm{MW}$ from geothermal (Table 3). 
Table 3. Winning Projects from Second Auction

(CENACE 2016)

\begin{tabular}{|c|c|c|c|c|c|}
\hline \multicolumn{6}{|l|}{ Winning Sale Offers SLP/2016 } \\
\hline Company Name & Sale Offer & MWH/year/year & CELs/year & Technology & State \\
\hline ZUMA ENERGIA - Quetzal Energia Sta Maria & SLP201610051-06/08 & 393,611 & 393,611 & SOLAR & Chihuahua \\
\hline ZUMA ENERGIA - Eólico Reynosa III & SLP201610123-01/05 & $1,613,416$ & $1,613,416$ & WIND & Tamaulipas \\
\hline EDF - Eólica de Oaxaca Gunaa Sicaru & SLP201610045-03 & 818,264 & 818,264 & WIND & Oaxaca \\
\hline BLUEMEX POWER - & SLP201610245-01 & 249,982 & 249,982 & SOLAR & Sonora \\
\hline CUBICO - Eólico El Mezquite & SLP201610151-10/11 & 820,635 & 774,938 & WIND & Nuevo Leon \\
\hline CUBICO - ALTEN & SLP201610233-03-07 & 722,042 & 812,417 & SOLAR & Aguascalientes \\
\hline FOTOWATIO RENEWABLE - Potosi Solar & SLP201610206-01/02 & 779,161 & 779,161 & SOLAR & San Luis Poyosi \\
\hline ENGIE - El Trompezon & SLP201610189-01 & 342,629 & 338,851 & SOLAR & Aguascalientes \\
\hline TRACTEBEL ENERGIA - Tres Mesas III & SLP201610203-04 & 223,010 & 223,010 & WIND & Tamaulipas \\
\hline X-ELIO ENERGY - EI Conejo & SLP201610128-04 & 193,771 & 193,771 & SOLAR & Chihuahua \\
\hline X-ELIO ENERGY - Xoxocotla & SLP201610128-07 & 169,365 & 169,365 & SOLAR & Morelos \\
\hline CONSORCIO SMX - Tepezala II & SLP201610193-05/06 & 278,357 & 285,606 & SOLAR & Aguascalientes \\
\hline ACCIONA - AT Solar & SLP201610030-23/24 & 478,261 & 478,260 & SOLAR & Sonora \\
\hline GREEN HUB - Sn Miguel Allende & SLP201610255-01 & 72,919 & 72,919 & SOLAR & Guanajuato \\
\hline ENEL GREEN POWER - Salitrillos & SLP201610040-08 & 399,130 & 399,130 & WIND & Tamaulipas \\
\hline FISTERRA - KAMET ENERGIA - Orejana & SLP201610124-01 / 02 & 353,466 & 353,466 & SOLAR & Sonora \\
\hline IENOVA - Rumorosa Solar & SLP201610032-07/08 & 114,116 & 117,064 & SOLAR & Baja California \\
\hline OPDE - Coahuila Anda Lucia II & SLP201610096-01/02 & 213,655 & 213,655 & SOLAR & Coahuila \\
\hline OPDE - Aguascalientes Sur I & SLP201610096-07/08 & 75,854 & 75,853 & SOLAR & Aguascalientes \\
\hline HANWHA - HQ HOLD - & SLP201610217-06/07 & 252,444 & 252,444 & SOLAR & Coahuila \\
\hline CFE - Azufres 3 Phase 2 & SLP201610066-01 & 198,764 & 198,764 & GEOTHERMAL & Michoacan \\
\hline GREENERGY GUANAJUATO - Mexsolar I \& II & SLP201610126-03 & 146,957 & 146,957 & SOLAR & Guanajuato \\
\hline GENERADORA FENIX - Necaxa 1,6,7,8,10 - Patia 2 & SLP201610103 & 0 & 314,631 & HIDRO & Puebla \\
\hline SUM & & $8,909,809$ & $9,275,535$ & & \\
\hline
\end{tabular}

The first long-term two auctions were developed to provide CFE with a vehicle for contracting its estimated amount of clean energy generation and certificates needed to meet its initial requirements. For the third auction, which was convened in 2017, the government of Mexico used its Camara de Compensación (Clearinghouse) for the first time. The clearinghouse is now the intermediary between the qualified offtakers and the auction projects, which provides a way for entities outside CFE to participate in the auctions. This time, apart from CFE basic service providers, two other corporations-Menkent (CEMEX) and Iberdrola - participated in the auction, and together they contracted $534 \mathrm{GWh} / \mathrm{yr}$ of power, and 534,000 CELs/yr. The third auction also awarded projects in two additional states of Mexico, bringing the total number of states participating to 17 .

From the third auction, the 14 new clean energy projects selected can provide $689 \mathrm{MW}$ of additional wind and 1,323 MW of additional solar capacity. These new projects represent additional contracts for $5.49 \mathrm{TWh} / \mathrm{yr}$ of renewable energy generation and 5.9 million additional 
CELs/yr. The new contracted energy and CELs represent $90.20 \%$ and $97.75 \%$ of the offered amounts respectively. Winning offers are detailed in Table 4.

\section{Table 4. Winning Projects from Third Auction.}

(CENACE 2017)

\begin{tabular}{|c|c|c|c|c|c|}
\hline \multicolumn{6}{|l|}{ Winning Sale Offers SLP/2017 } \\
\hline Company Name & Sale Offer & MWH/year/year & CELs/year & Technology & State \\
\hline X-ELIO ENERGY, S.L - Bacabachi I & SLP2017010076-002 & 435,354 & 483,727 & SOLAR & Sonora \\
\hline NEOEN INTERNATIONAL, S.A.S - Pachamama & SLP2017010093-002 & 616,692 & 770,864 & SOLAR & Aguascalientes \\
\hline CANADIAN SOLAR ENERGY MEXICO - Horus Solar & SLP2017010102-009 & 206,017 & 247,220 & SOLAR & Aguascalientes \\
\hline CANADIAN SOLAR ENERGY MEXICO - Tastiota & SLP2017010102-004 & 235,640 & 265,095 & SOLAR & Sonora \\
\hline CANADIAN SOLAR ENERGY MEXICO - EI Mayo & SLP2017010102-011 & 210,426 & 252,511 & SOLAR & Sonora \\
\hline CONSORCIO ENGIE EOLICA & SLP2017010111-056 & 362,935 & 391,805 & WIND & Sonora \\
\hline CONSORCIO ENGIE SOLAR 1 - Abril 99 & SLP2017010115-014 & 280,055 & 302,332 & SOLAR & Sonora \\
\hline CONSORCIO ENGIE SOLAR 1 - Calpulalpan & SLP2017010115-026 & 486,313 & 524,997 & SOLAR & Tlaxcala \\
\hline CONSORCIO ENGIE SOLAR 4 - Villa Ahumada & SLP2017010117-002 & 379,603 & 434,486 & SOLAR & Chihuahua \\
\hline ENEL RINNOVABILE S.A. DE C.V - Amistad II & SLP2017010122-004 & 373,017 & 373,016 & WIND & Coahuila \\
\hline ENEL RINNOVABILE S.A. DE C.V - Amistad III & SLP2017010122-007 & 357,032 & 357,031 & WIND & Coahuila \\
\hline ENEL RINNOVABILE S.A. DE C.V - Amistad IV & SLP2017010122-011 & 510,680 & 510,680 & WIND & Coahuila \\
\hline ENEL RINNOVABILE S.A. DE C.V - Eólica Dolores & SLP2017010122-063 & 848,883 & 848,883 & WIND & Nuevo León \\
\hline MITSUI \& CO LTD - TRINA SOLAR (Netherlands) Solar Calera & SLP2017010123-001 & 189,928 & 189,928 & SOLAR & Zacatecas \\
\hline SUM & & $5,492,575$ & $5,952,575$ & & \\
\hline
\end{tabular}

The Camara de Compensación, or clearinghouse, was originally included in the wholesale market rules, but it was during the third auction that it was finally instituted and allowed nonCFE offtakers to participate as potential buyers in the auction. The clearinghouse manual includes various mechanisms for mitigating potential risks with the winning projects.

Lessons learned from the initial three auctions include that clean energy, specifically wind and solar, can be competitive in today's market as indicated by the very low prices of the winning offers. Weighted average prices by technology as well as weighted average prices for all projects combined during the first auction were considered some of the lowest in the world, and they have continued to decline in subsequent auctions. During the first auction, weighted average prices for solar and wind, which include generation and CELs, were USD 45/MWh and USD $55 / \mathrm{MWh}$ respectively. For all projects combined, the average contracted price was USD 47.6/MWh. Although these prices were considered low, the second auction resulted in even lower prices: the government contracted at 30\% lower prices, at USD 33.5/MWh on average. Solar average prices declined to USD 31.9/MWh (-29\%), while wind declined to USD 35.8/MWh (-35\%) and geothermal, which was the first time it won projects in an auction, had prices of USD 37.3/MWh. The small hydro projects were only awarded CELs at USD 7.3/MWh.

Another lesson learned is that the government of Mexico could successfully incentivize projects to be developed where the system most needs them. By applying adjustments to the nodal marginal prices, the government has discouraged projects near nodes where supply exceeds demand, and it has promoted projects near nodes where generation is less available. During the 
first auction, these nodal adjustments for the National Interconnected System (SIN) had a wide range and varied between USD/MWh +10 and -22 depending on the node. As a result of these adjustments, almost half the first auction projects were awarded to Yucatán, the state with the highest local discounts.

Interestingly, during the second and third auctions, nodal price adjustments did not show such a wide variance between nodes. In the second auction the adjustment range for the SIN was just $\mathrm{USD} / \mathrm{MWh}+0.06$ and -0.06 , while for the third auction, the range for nodes in the SIN was USD/MWh +2.9 to -3.6 - both times, the ranges were significantly lower than they were in the first auction. The result was a much lower impact on the locations of the winning bids. In fact, the reduced adjustments are assumed to push developers to lower their bids to remain competitive, and as a result, several selected projects were chosen in states with unfavorable nodal price adjustments. During the third auction, the weighted average prices were USD 20.8/MWh for solar, USD 18.6/MWh for wind, and USD 19.8/MWh for wind and solar combined. Average auction prices represented a decline of $41 \%$ over the second auction results, and they were $58 \%$ lower than those of the first auction.

\section{Cleaner Generation and Smart Grid}

Mexico's first three auctions indicate that significant potential for Mexico to add more clean energy to its electricity generation mix. As Mexico adds higher percentages of variable renewable energy to its portfolio of power system generation, it will need to identify and incorporate new sources, and better utilize existing sources, of power system flexibility to ensure system reliability and cost-effective management. Smart grid technologies enable communication and coordination among all parts of the electricity system, which allow the overall system to cost effectively deploy all the flexibility resources that are available. Sections below will detail smart grid investments that Mexico should consider as it transitions to cleaner electricity generation.

\subsubsection{CFE Transmission}

CFE's transmission division will begin making smart grid investments in communication and automation improvements so that they can better visualize the current state of the transmission grid. These investments will improve the response time in case of an event and will provide condition monitoring for equipment in the field. In line with this goal, CENACE and CFE Transmission are proposing the use of phasor measurement units (PMUs) and Flexible AC Transmission Systems (FACTS). The immediate effect will be to (1) help with improved grid performance by providing power flow and angular calculations and (2) serve as an alarm or indicator in case of an event.

The vision for the PMUs is that they will provide real-time state estimation to help with generation and load shedding to improve power reliability and quality. They will also serve as a window to help identify the locations of faults in the system and to help consolidate and reduce downtimes in affected areas. The FACTS systems will improve control of grid performance for reliability and increase power transfer capability. The objective is to automate at least $80 \%$ of 
existing substations and $100 \%$ of new substations to IEC $61850^{6}$ by 2024 to assist with the protection and interoperability of the grid. This will serve to minimize technical losses and improve productivity (SENER 2017).

The goal is that all this information and interconnection will allow grid operators to develop realtime visualization applications of the dynamic behavior of the grid and better understand the protection schemes required during corrective actions. Currently, CFE is working with the implementation of a power quality monitoring system (SIMOCE for its acronym in Spanish) that will acquire the information from all field devices, perform the analysis, and make the correction to comply with the strict power quality requirements of the end user.

\subsubsection{CFE Distribution}

CFE Distribution is responsible for providing energy to 41 million customers with a total annual energy use of 218,072 GWh (as of the end of 2016). Mexico predicts energy consumption will grow $2 \%$ annually for the next few years (SE 2016). With that in mind, CFE's main goal is to continue to improve the quality of service and reduce technical and nontechnical losses.

As of the end of $2016,1.42 \%$ of the country's population did not have access to the grid. Mexico has a goal of providing electrification either by extending the grid or through DG and microgrid solutions. For areas that are marginal or islanded, the plan is to use alternative methods giving priority to renewable energy. The goal is to have $99.2 \%$ coverage in five years.

To enable these service improvements, $\mathrm{CFE}$ is working on various projects that would enable end users to be informed and able to make educated decisions regarding their energy consumption, and to have DG systems. To improve the service, CFE initially began working to implement the Common Information Model and the Business Process Model to accomplish the interoperability of the various systems used for energy delivery. It is hoped that this effort will make the system more efficient and capable of meeting growing energy demand.

Implementation of the Common Information Model and Business Process Model allows CFE to take advantage of the fault location isolation and restoration (FLISR) system. The goal of FLISR is to "instrument" the medium voltage grid so that in case of an event that affects 1,000 or more customers, CFE can isolate the affected customers in 1-2 minutes automatically or in 3-5 minutes manually and restore or reroute power to the portions of the grid that are affected.

By the end of 2016, 47.1\% of the Valley of Mexico (Valle de Mexico), a central region in which Mexico City lies, and $33.2 \%$ of the interior of the country were equipped with the required monitoring to participate in the FLISR program (Table 5). With the implementation of this program, the interruption time has improved by $40 \%$, with average outage times of 58.2 minutes in 2011 and 31.7 minutes in 2016.

\footnotetext{
${ }^{6}$ IEC 61850 is a standard issued by the International Electrotechnical Commission (IEC) that defines the communication between intelligent electronic devices (IEDs) in the substation and the related system requirements. See "Core IEC Standards," IEC, http://www.iec.ch/smartgrid/standards/.
} 
Table 5. FLISR Equipment Installed on the Medium Voltage Level, 2015

(SENER, 2015, 22)

\begin{tabular}{|c|c|c|}
\hline Distribution Branches & $\begin{array}{l}\text { Remaining for } \\
\text { Completion }\end{array}$ & $\begin{array}{l}\text { Installed as of } \\
\text { December } 2016\end{array}$ \\
\hline \multicolumn{3}{|l|}{ Interior } \\
\hline Baja California & 693 & 799 \\
\hline Noroeste & 3,645 & 1,014 \\
\hline Norte & 2,443 & 1,279 \\
\hline Golfo Norte & 4,320 & 2,400 \\
\hline Golfo Centro & 2,719 & 774 \\
\hline Bajío & 2,293 & 1,586 \\
\hline Jalisco & 3,167 & 1,080 \\
\hline Cento Occidente & 2,472 & 1,684 \\
\hline Centro Sur & 2,527 & 1,724 \\
\hline Centro Oriente & 1,732 & 1,323 \\
\hline Oriente & 2,086 & 1,516 \\
\hline Sureste & 3,687 & 743 \\
\hline Peninsula & 1,902 & 836 \\
\hline Subtotal & 33,686 & 16,758 \\
\hline \multicolumn{3}{|l|}{ Valle de Mexico } \\
\hline Valle de Mexico Norte & 894 & 1,400 \\
\hline Valle de Mexico Centro & 1,524 & 1,814 \\
\hline Valle de Mexico Sur & 2,344 & 1,410 \\
\hline Centro Sur & 145 & 612 \\
\hline Centro Oriente & 702 & 147 \\
\hline Subtotal & 5,609 & 4,993 \\
\hline Total & 39,295 & 22,141 \\
\hline
\end{tabular}

At the operational level, the Common Information Model and Business Process Model uses the coexistence and information exchange of the applications. To expedite a response during a power interruption event, CFE is working to have available the integrated distribution management system (DMS), visualization capabilities, geographic information system (GIS) reporting, and workforce management GIS applications. For example, if the supervisory control and data acquisition (SCADA) system detects a fault, it immediately generates an alarm for the operator with the information about the affected area and devices. At the same time, the system uses GIS information for the affected area to visualize and identify the affected customers, so the operator can focus on restoring power. When the event is confirmed, the system generates a report to notify all affected repair personnel. The workforce management GIS helps identify the crews 
that are available to help restore power. Figure 10 illustrates the type of information that this combination of systems provides to the operator.

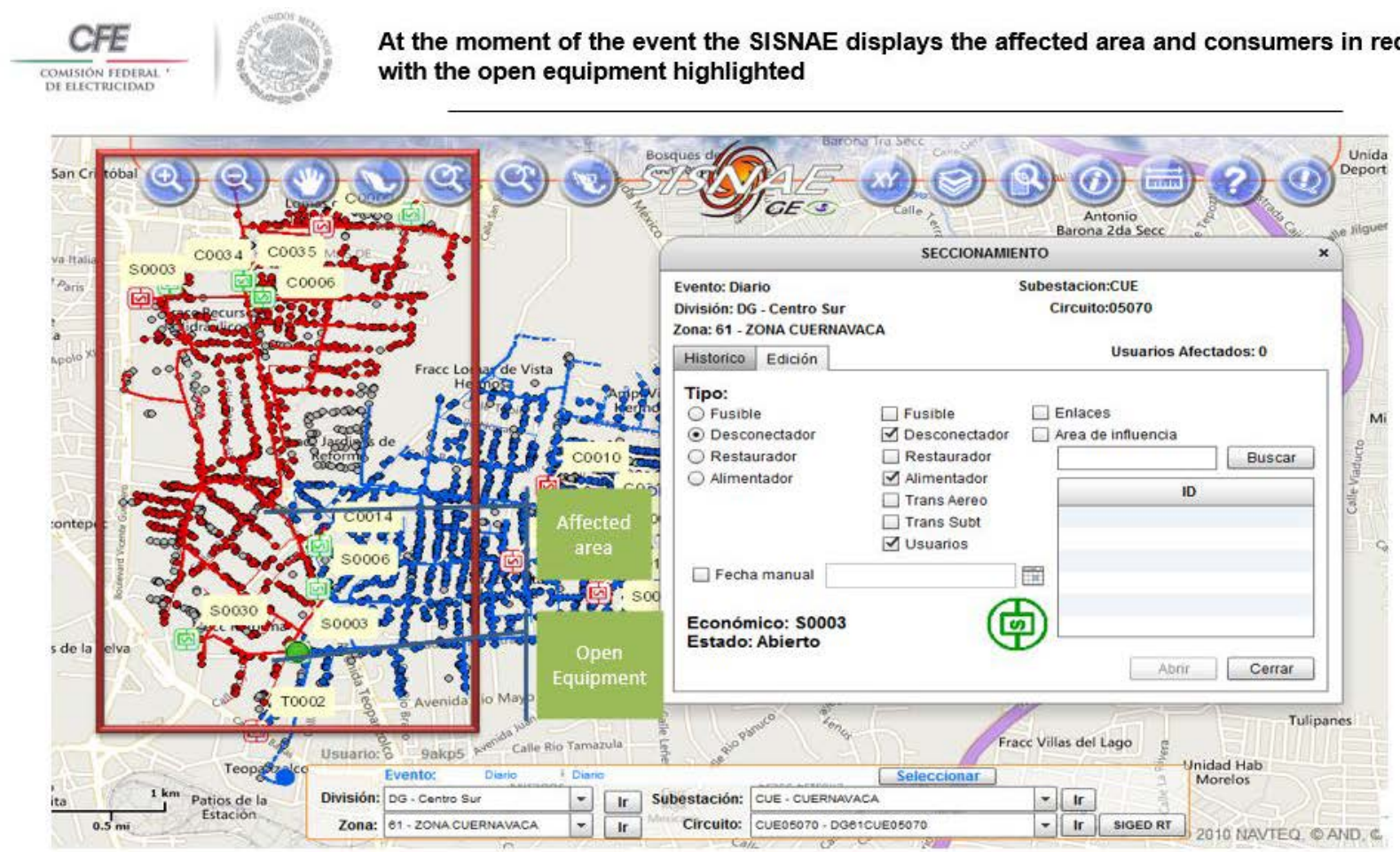

The operator and who ever has access to the SISNAE-GEO would have an automatic visual alert of the affected area, with the advantage that the operator could restore the system with the ability to open and close certain sections and everything that happens can be seen in the SCADA/SISE system.

Figure 10. Integration of CFE distribution smart grid applications

SISNAE-GEO = Sistema Nacional Para La Atención de Emergencias de CFE = National System for the Attention of CFE Emergencies

(CFE 2016)

In 2016, CFE Distribution calculated a total loss of $14.74 \%$, including $8.44 \%$ nontechnical losses and $6.29 \%$ technical losses. With substantial effort, CFE has decreased its losses by $1 \%$ per year in its distribution system the last couple of years, and it has a goal of decreasing its losses to $11 \%$ total by 2018 .

Advance metering infrastructure (AMI) has been deployed in various regions of the country to try to address some of the losses. The objective of AMI has been to have reliable and timely supply records to reduce losses and help engage consumers. Five AMI pilot projects have already been completed, and 11 AMI projects were being implemented at the end of 2016. As shown in Table 6, Mexico's goal is to install 4,690,266 smart meters by 2021. CFE calculates an internal rate of return of $24.4 \%$ on the investment; exceeding the threshold internal rate of return of $12 \%$ means the AMI investment is viable.

Table 6 shows the planned installation of AMI meters from 2017 to 2021. 
Table 6. Actual and Projected AMI Installations, 2017-2021

(SENER 2015, 22)

\begin{tabular}{|c|c|c|c|c|c|c|c|}
\hline \multirow{2}{*}{$\begin{array}{l}\text { Distribution } \\
\text { Branches }\end{array}$} & \multicolumn{2}{|l|}{ Actual } & \multicolumn{5}{|l|}{ Projected } \\
\hline & 2015 & 2016 & 2017 & 2018 & 2019 & 2020 & 2021 \\
\hline Baja California & 19,339 & 19,339 & 19,339 & 19,339 & 19,339 & 19,339 & 19,339 \\
\hline Noroeste & 16,067 & 21,130 & 40,716 & 59,638 & 80,452 & 103,346 & 128,530 \\
\hline Norte & 7,574 & 16,425 & 30,389 & 44,353 & 59,713 & 76,609 & 95,195 \\
\hline Golfo Norte & 11,440 & 11,440 & 31,235 & 51,030 & 72,805 & 96,758 & 123,105 \\
\hline Centro Occidente & 10,246 & 10,246 & 10,246 & 10,246 & 10,246 & 10,246 & 10,246 \\
\hline Centro Sur & 87,584 & 89,551 & 125,723 & 147,814 & 172,113 & 198,843 & 228,245 \\
\hline Oriente & 683 & 21,139 & 44,383 & 69,349 & 94,917 & 123,040 & 153,976 \\
\hline Sureste & 3,118 & 3,118 & 244,491 & 298,047 & 356,958 & 421,759 & 493,040 \\
\hline VM Norte & 224 & 88,944 & 504,082 & 514,336 & 525,616 & 538,023 & 551,671 \\
\hline VM Centro & 52,509 & 352,558 & 549,900 & 691,320 & 702,539 & 714,880 & 728,454 \\
\hline VM Sur & 306 & 20,496 & 643,928 & $1,128,793$ & $1,144,840$ & $1,162,492$ & $1,181,910$ \\
\hline Bajío & 11,585 & 70,612 & 88,824 & 107,036 & 127,069 & 149,106 & 173,346 \\
\hline Golfo Centro & 4 & 4 & 18,646 & 37,288 & 57,794 & 80,352 & 105,164 \\
\hline Centro Oriente & 6,749 & 6,749 & 54,878 & 103,007 & 155,949 & 214,184 & 278,242 \\
\hline Peninsular & 16,423 & 16,423 & 128,576 & 147,488 & 168,292 & 191,175 & 216,347 \\
\hline Jalisco & 24,227 & 24,227 & 56,000 & 87,773 & 122,722 & 161,166 & 203,456 \\
\hline Meters/Year & 268,078 & 772,401 & $2,591,356$ & $3,516,857$ & $3,871,364$ & $4,261,318$ & $4,690,266$ \\
\hline
\end{tabular}

\subsection{Centro Nacional de Control de Energía (CENACE)}

CENACE serves as an independent system operator (ISO) for Mexico's national grid and the wholesale electricity market. Its duties are to coordinate, control, and monitor the grid and guarantee access to the transmission and distribution networks. Furthermore, CENACE operates the wholesale power market to guarantee fair designation and dispatch to satisfy the energy demand of the national grid. CENACE has the responsibility to formulate projects to help improve and enhance the national grid.

CENACE is currently working on demonstration projects to investigate the performance of energy storage resources and understand how storage can contribute to operational security. Another project is the development of calculation tools that can provide information about line carrying capacity based on current thermal limits, potentially providing greater ability to integrate variable resources. In terms of power quality, CENACE is implementing tools for optimal dispatch of reactive resources in different time frames (e.g., seasonal, day-ahead, and real-time). 
CENACE recently completed a short-term smart grid project to improve their statistical weather and demand forecasting to a two-hour in-advance window with 15-minute resolution, which has improved the reliability and operational performance of energy generation. The long-term goals are to (1) develop and deploy advanced tools for forecasting from current output up to weekahead forecasting at sufficient spatial and temporal resolution and (2) understand the potential benefits and risks of probabilistic forecasts in operations. Table 7 displays the most recent listing of CENACE's new smart grid priorities (SENER 2017).

Table 7. CENACE'S New Smart Grid Projects, 2017

(CENACE 2017)

\begin{tabular}{|c|c|}
\hline Project & Project Tasks \\
\hline $\begin{array}{l}\text { Energy storage, deployment, } \\
\text { and control }\end{array}$ & $\begin{array}{l}\text { Implement demonstration projects to investigate the performance of } \\
\text { energy storage resources and understand how storage can } \\
\text { contribute to operational security }\end{array}$ \\
\hline $\begin{array}{l}\text { Wind and solar } \\
\text { power forecasting }\end{array}$ & $\begin{array}{l}\text { Develop and deploy advanced tools for forecasting from current } \\
\text { output up to week-ahead forecasting at sufficient spatial and temporal } \\
\text { resolution } \\
\text { Investigate potential for new sensors to be deployed (e.g., sky } \\
\text { imagers and lidar) } \\
\text { Understand potential application of probabilistic forecasts in } \\
\text { operations }\end{array}$ \\
\hline $\begin{array}{l}\text { Next-generation phasor } \\
\text { measurement network }\end{array}$ & $\begin{array}{l}\text { Build out a phasor measurement network to enable applications } \\
\text { envisioned by CENACE and CFE; Phase I will define the future } \\
\text { applications, determine the requirements for the network, and } \\
\text { evaluate the existing network. }\end{array}$ \\
\hline Thermal limit calculation tools & $\begin{array}{l}\text { Develop an operational tool that can provide information about } \\
\text { current thermal limits of transmission lines based on wind/solar based } \\
\text { generation and load, as well as online resources } \\
\text { Demonstrate tool in several locations to improve flexibility of the } \\
\text { system to integrate wind and solar }\end{array}$ \\
\hline $\begin{array}{l}\text { Real-time operational security } \\
\text { assessment tool }\end{array}$ & $\begin{array}{l}\text { Develop an online tool that uses SCADA, PMUs, and other } \\
\text { information tools to determine current operating limits } \\
\text { Analyze potential changes in wind and solar output and determine } \\
\text { whether mitigating strategies are required } \\
\text { Consider inertia levels on the system as well as reactive control } \\
\text { Link this operational assessment tool with needs for operating } \\
\text { reserves }\end{array}$ \\
\hline $\begin{array}{l}\text { Incorporation of risk-based } \\
\text { methods and flexibility in } \\
\text { planning process }\end{array}$ & $\begin{array}{l}\text { Implement probabilistic methods in planning processes to ensure } \\
\text { transmission system build-out considers costs and reliability } \\
\text { appropriately } \\
\text { Consider flexibility needs in the transmission build-out }\end{array}$ \\
\hline $\begin{array}{l}\text { Optimal dispatch of } \\
\text { reactive power }\end{array}$ & $\begin{array}{l}\text { Implement tools for optimal scheduling of reactive power resources in } \\
\text { different time frames (seasonal, day-ahead, and real-time) }\end{array}$ \\
\hline $\begin{array}{l}\text { Implementation of intelligent } \\
\text { tools to guide system } \\
\text { restoration }\end{array}$ & Implement tools for optimal system restoration during faults \\
\hline
\end{tabular}




\begin{tabular}{|l|l|}
\hline Project & Project Tasks \\
\hline $\begin{array}{l}\text { Investigation of the use of new } \\
\text { technologies to assist black- } \\
\text { start process }\end{array}$ & $\begin{array}{l}\text { Research the use of energy storage, voltage source converter HVDC } \\
\text { (high-voltage direct current), DG }\end{array}$ \\
\hline $\begin{array}{l}\text { Response to the operation of } \\
\text { the network }\end{array}$ & $\begin{array}{l}\text { Implement various tools to adequately analyze the behavior of } \\
\text { different types of load in Mexico } \\
\text { From the analysis, identify the demand response functions that can } \\
\text { be used to maintain reliability and increase the efficiency of the SEN }\end{array}$ \\
\hline
\end{tabular}

\subsection{Smart Grid Technology Players in Mexico, the Americas, and the World}

Mexico has access to numerous international firms providing smart grid services, including several Mexican firms whose products compete in the international marketplace. Figure 11 and Table 8 list the major players in Smart Grid around the world. 


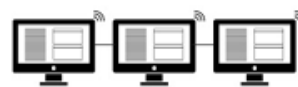

Integrated Enterprise-Wide Advanced Control Systems
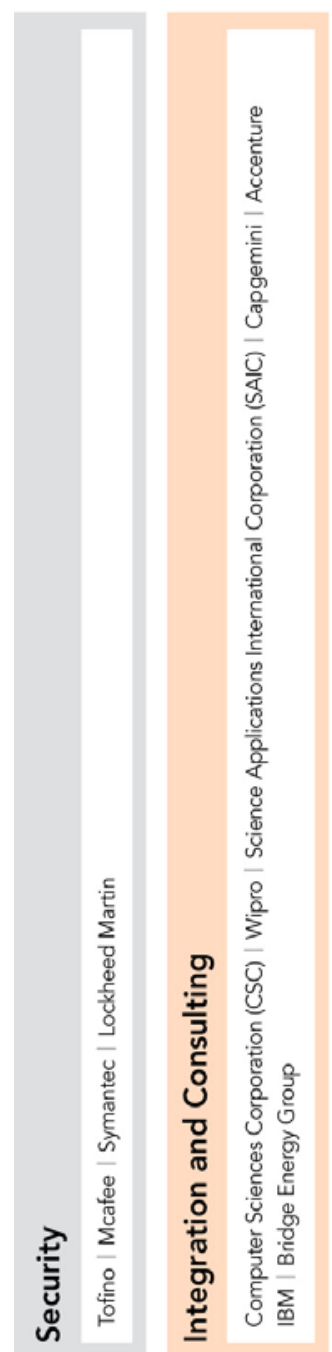

Soft Grid: Data Storage and Analytics

Rackspace | SAS | Oracle | EcoFactor | Cisco | IBM | Teradata

VMware | EMC $^{2}$ | SpaceTime Insight
.

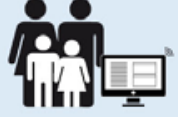

Consumer Energy Management Systems and Networks

\section{Application Layer}

Grid Support: Managing distributed energy Xtreme Power | A123 Systems | NGK Insulators | ClipperCreek AeroVironment | Beacon Power | ECOtality | Coulomb Technologies Better Place | Ice Energy

Network Operations:

Network monitoring and control

Schneider Electric | Ventyx | Siemens | Open Systems International

Alstom | Electrical Transient Analyzer Program (ETAP) | GE

Transmission: Wide area controls and applications Schweitzer Engineering Laboratories (SEL) | ABB | Alstom

Siemens | GE

Distribution Automation: Reliability, real-time monitoring, and intelligent control

ABB | Cooper Power Systems | Schneider Electric | Tavrida Electric Xian Electric Group (XD Group) | Efacec | Hitachi | Alstom S\&C Electric Company | Schweitzer Engineering Laboratories (SEL) Siemens | Crompton Greaves | Mitsubishi Electric | Eaton | GE

AMI Infrastructure: Manage distributed energy

Demand Side Management:

Energy

management

systems, portals,

and apps

Enernoc

Comverge

Constellation Energy

Viridity Energy

Honeywell

Alektrona

Opower

EnergyHub

Tendril

Ecofactor

Johnson Controls

Verdiem

Sentilla

eMeter (A Siemens Business) | Itron | Aclara | Ecologic Analytics

Oracle | OSlsoft | Silver Spring Networks | Trilliant | Cisco | Telvent

EnergylCT (An Elster Group Company) | ElectSolve Technology

Solutions \& Services, Inc. | Northstar | Landis+Gyr | Sensus | Elster

\section{Communications: Networking platform}

Current | Elster | Proximetry | AT\&T | Verizon | Cisco | Sensus

Ericsson | Ruggedcom | Alcatel-Lucent | Huawei | Ambient

S\&C Electric Company | Tropos

$\begin{array}{lll}\text { Communication Layer } & \text { Network } & \text { Smart Meter } \\ \text { (H/W, S/W/Control) } & \text { Gateway } & \text { and Broadband }\end{array}$

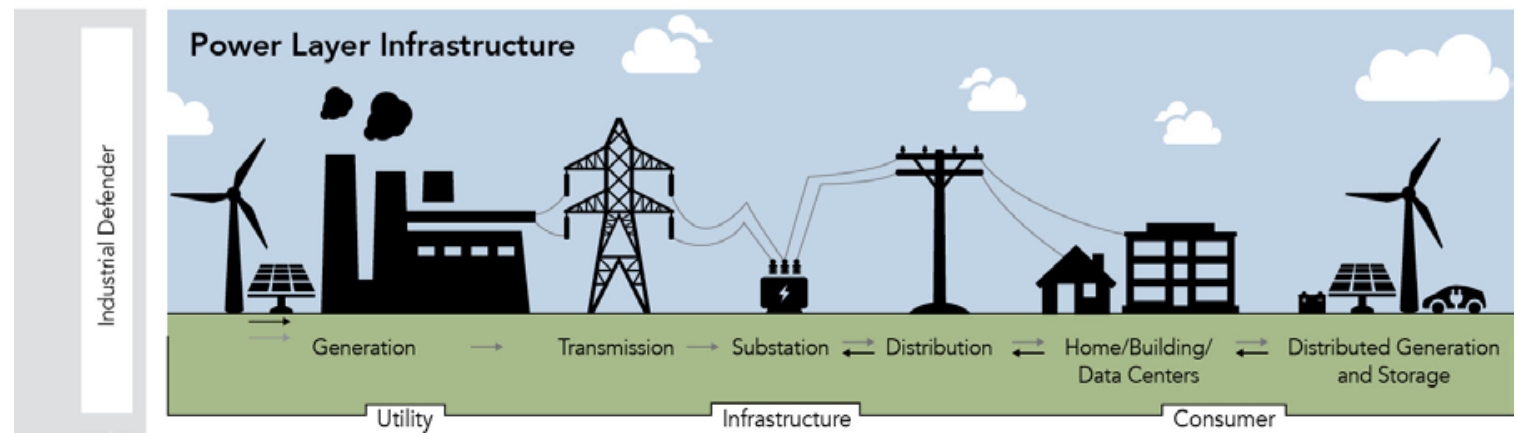

Figure 11. The Networked Grid 150 vendor taxonomy

(GTM 2013) 
Table 8. Top 10 Networked Grid Vendors (Groarke 2013)

\begin{tabular}{|l|l|}
\hline Networked Grid Vendor & Submarket \\
\hline ABB & Transmission and Distribution Automation \\
\hline IBM & Communications \\
\hline Itron & Integration and Consulting \\
\hline Siemens & AMI Infrastructure \\
\hline S\&C & Transmission and Distribution Automation \\
\hline Schneider Electric & Distribution Automation/Grid Support \\
\hline Opower & Distribution Automation \\
\hline Silver Spring Networks & Communications \\
\hline Tendril & Home Energy Management \\
\hline
\end{tabular}




\section{Technology and Policy Landscape: Technologies and Policies Available for Mobilizing Smart Grid Deployment in Mexico}

\subsection{SENER's Smart Grid Program}

SENER's statement of its view of Smart Grid is contained in Programa de Redes Eléctricas Inteligentes (Smart Grids Program) (SENER 2016d). Key elements of the implementation plan include:

1. Intelligent electrical networks projects

2. Program pillars - to be developed or strengthened by CENACE, CFE Transmission, and CFE Distribution

3. Candidate smart grid projects - to be developed by CENACE

4. Candidate smart grid projects - to be developed by the carrier

5. Candidate smart grid projects - to be developed by the distributor.

For details about these projects, see Appendix B.

\subsection{SENER'S Policies for the Deployment of Smart Grids}

SENER'S policies for the deployment of smart grids include the following, according to SENER (2017):

1. Promote interagency cooperation among agencies in the energy sector so that, within the scope of their powers, they contribute to the planning and implementation of the Red Eléctrica Inteligente (REI, or Smart Grid) in the SEN

2. Reduce the level of energy losses to $13.38 \%$ for 2018 , thus increasing the efficiency of the SEN

3. Incorporate strategies for the dissemination of REI projects, initiatives, and actions to promote active participation of members of the electricity industry and end users

4. Promote interoperability of the SEN systems and equipment, using standards and protocols to ensure compatibility of the technological infrastructure

5. Ensure system cybersecurity to maintain the operation of the SEN with criteria of reliability and safety

6. Promote the development of REI, using open source codes

7. Maintain the security and integrity of the information of the participants and users, guaranteeing the legitimate and controlled treatment of information

8. Promote training programs, innovation centers, and other initiatives under the concept of value chain development and training of human resources specialized in REI 
9. Promote the use of REI in the modernization of the national transmission network and general distribution networks to increase flexibility, resilience, reliability, efficiency, safety, and sustainability

10. Prioritize the use of REI technologies for the operation and operational control of the SEN that are aimed at improving reliability, continuity, efficiency, and security

11. Reduce curtailment of economically dispatched energy due to technical and operational limitations of SEN, to contribute to the efficient operation of the Mexican wholesale electricity market (MEM)

12. Ensure ISO (CENACE) has access to the information of distribution and transmission systems for monitoring SEN

13. Promote the use of electric vehicles and their incorporation into SEN management

14. Include intelligent technologies that facilitate the efficient integration of clean energy and DG in the expansion and modernization of the SEN

15. Promote participation of end users in schemes of controllable demand, provision of additional services, or management of consumption to encourage maximum use of the SEN infrastructure

16. Include REI projects in the expansion and modernization programs when they present an advantageous cost-benefit ratio and thus help improve SEN efficiency, quality, reliability, continuity, security, and sustainability.

\subsection{Major Reports, Events, and Proceedings}

\subsubsection{ESTA International Report}

In 2012, CRE began exploring the potential to implement smart grid solutions in Mexico and authorized the development of a regulatory roadmap for implementation. CRE envisioned the outcome of the exploration to be guide to a regulatory framework under which implementation and operation of the Smart Grid would be permitted and encouraged.

ESTA International (ESTA), an expert smart grid consultant, was selected in October 2012 to begin developing the implementation roadmap. During 2013 and in early 2014, ESTA worked with the major stakeholders in Mexico - including SENER, CFE, CRE, CENACE, and othersto research and develop the roadmap. Work on the roadmap was enhanced by the assistance of these agencies and the commitment of time from the CRE Chairman, commissioners, and staff.

The final report of the roadmap was completed by ESTA in September 2014 and presented to CRE for its consideration. Subsequently, official Spanish and English versions of the report were released. Appendix A contains information about the roadmap.

The ESTA project proceeded in seven phases:

1. Review of international experiences and feasibility of development

2. Development of the regulatory roadmap

3. Evaluation of investment opportunities

4. Preliminary assessment of environmental impact and development 
5. Economic analysis and implementation plan

6. Initial exploration on financing possibilities for implementation

7. Preparation of the final report and recommendations.

Upon completion, the ESTA-produced roadmap contained 91 recommendations for smart grid implementation for Mexico's consideration. They addressed mainly actions that could be taken by CRE but also areas in which CFE or SENER would have primary responsibility to act. The ESTA report (ESTA 2017) also identified areas in which best practices regulation from other countries implied that additional legislation would be needed in Mexico to provide certain additional authority to CRE or other agencies. Many of the ESTA report recommendations were used by CRE while Mexican energy reform was enacted. Subsequently, Mexican law was amended to give CRE a major role in the development of Smart Grid.

One of the most significant recommendations in the ESTA report was the creation of a multiparty council to guide the development of Smart Grid. ESTA noted that this group should eventually include Mexican government agencies as well as representatives of academia and the private sector involved in Smart Grid development.

When the Grupo Nacional de Redes Eléctricas Inteligentes (Grupo Nacional) was initially formed, it consisted of representatives of SENER, CRE, CFE, and CENACE. It was later expanded to include the representatives of National Electricity Institute and the National Energy Efficiency Commission. Ultimately, the Grupo Nacional was superseded by the Smart Grid Consultative Committee, which was established by the 2015 Energy Transition Law.

Membership of the Consultative Committee includes SENER and representation from all of the government of Mexico, electricity and energy efficiency organizations, industrial and smart grid associations, and electric-sector research institutions.

\subsubsection{CRE Smart Grid Summit}

On February 24, 2015, more than one 100 energy policymakers, industry leaders, and other stakeholders gathered in Mexico City to discuss the future of Smart Grid in Mexico. The meeting — titled The Regulatory Roadmap for Smart Grids in Mexico: Next Steps-marked another step in the country's progress toward reform of the energy sector and the introduction of technologies that will modernize the electric grid, improve its operations, and empower consumers. The meeting was hosted by the Grupo Nacional and was facilitated by CRE and the 21 st Century Power Partnership. ${ }^{7}$

\subsubsection{NREL Support for SENER}

Since early 2014, the 21st Century Power Partnership has been providing technical assistance to SENER on the development of public policies needed to move forward with Smart Grid. NREL commissioned the Regulatory Assistance Project and Public Policy Consulting to develop a selection of potential pathways for implementing Smart Grid. Each pathway consisted of a set of recommendations for policies that SENER should consider in promoting Smart Grid development in Mexico. In September 2015, the 21st Century Power Partnership, the Regulatory Assistance Project, and Public Policy Consulting made a presentation to the Subgroup on

\footnotetext{
${ }^{7}$ The 21 st Century Power Partnership is an initiative of the Clean Energy Ministerial and is managed by NREL.
} 
Policies of the Grupo Nacional that outlined five potential "pathways" in which public policies on Smart Grid could be developed. Development of the pathways depended significantly on the two predecessor documents discussed above:

1. The ESTA Smart Grid Regulatory Framework (September 2014), which provides a comprehensive vision of electricity sector reform and Smart Grid development

2. The Regulatory Roadmap for Smart Grid in Mexico: Next Steps (February 2015), which captures stakeholder conversations discussing implementation of the 91 recommendations included in the Smart Grid Regulatory Framework.

The September 2015 presentation emphasized there are several possible pathways in moving toward and ultimately achieving the energy reform goals through Smart Grid deployment. The presenters used research presented in Power Systems of the Future: A 21 st Century Power Partnership Thought Leadership Report (Zinaman et al. 2015) to organize and articulate the range of pathways. Figure 12 illustrates how the five pathways differ in their comprehensiveness and the speed of change that would follow their selection for the path forward.

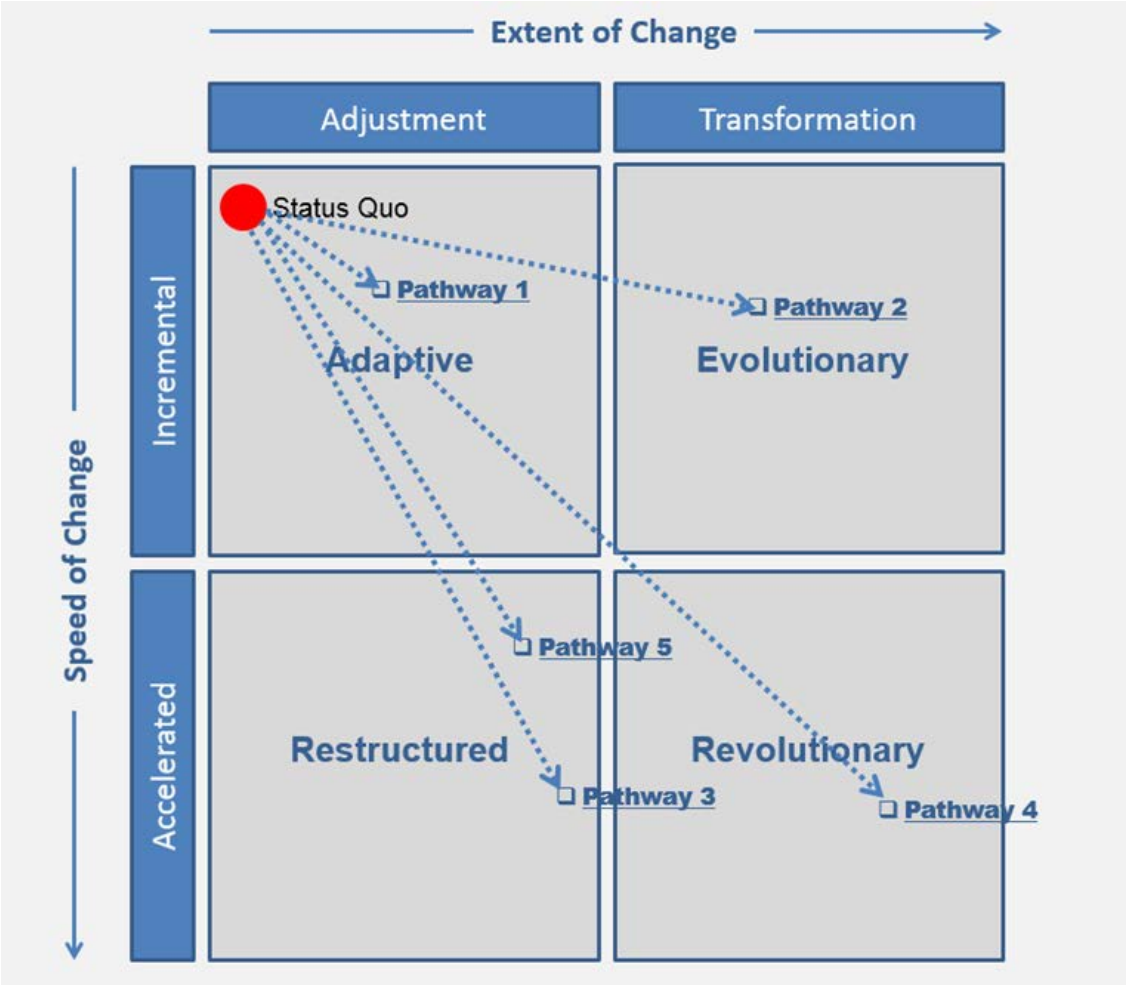

Figure 12. Smart Grid pathways for Mexico

(Linvill, Binz, and Bracho 2016) 
Pathways 1-4 can be characterized thematically by the main impact each would have on the developing energy sector in Mexico. Table 9 lists the four themes.

Table 9. Four Themes of Smart Grid Pathways

(Linvill, Binz, and Bracho 2016)

\begin{tabular}{|l|l|}
\hline Pathway & Theme \\
\hline Pathway 1 & Improve Status Quo and Reliability \\
\hline Pathway 2 & Improve Customer Choice \\
\hline Pathway 3 & Move Utility toward Platform Role \\
\hline Pathway 4 & Enable Competitive Markets \\
\hline
\end{tabular}

Pathways 1-4 align with four distinct approaches described in Zinaman et al. 2015: Adaptive, Evolutionary, Restructured and Revolutionary. Pathway 5- the Optimal Feasible Pathwaywas constructed to be a "middle" pathway to change. From Linvill, Binz, and Bracho (2016), here are the elements of Pathway 5:

- Complete wholesale smart grid investment; proceed to retail smart grid applications

- Plan and implement selective smart meter installation

- Develop and implement smart grid standards

- Streamline interconnection processes

- Undertake consumer education on energy use

- Improve regulation, adding performance incentives

- Implement full wholesale market unbundling and competition

- Apply dynamic pricing for customers with smart meters; facilitate commercial and industrial self-provision tariffs

- Establish shared renewable programs

- Enable third-party role in smart grid services

- Develop data sharing for customer usage data

- Allow retail customer aggregation.

As we will see, this list of actions along Pathway 5-the Optimal Feasible Pathway-is consistent with the recommendations of the international experts tapped for their contributions to this report. 


\section{SENER's Smart Grid Priorities}

\subsection{Review of Mexico's Smart Grid Priorities}

The Smart Grid Program (SENER 2016d) identifies the drivers of Smart Grid in Mexico. In this section, we review each of the eight identified drivers listed in that report:

1. Improved quality, reliability, continuity, safety, and sustainability

2. Improved quality of supply

3. Increased energy efficiency

4. Reduced electricity losses

5. Efficient operation of the national electric grid

6. Greater deployment of clean energy

7. Increased customer involvement in system management

8. Additional service offerings.

This list of drivers is specific to Mexico, but it shows a relationship to other lists of smart grid drivers. For example, the European Union (EU) identifies seven drivers in three major categories: sustainability, competitiveness, and security and quality of supply (EU 2011, 48):

- Sustainability

○ Reduction of carbon dioxide emissions

- System losses

- Transportation

- Integration of distributed energy resources (DER)

- Competitiveness

- Increased market participation

- Through aggregation of DG, storage, and demand response

- Improved market transparency

○ Interregional markets (harmonized)

- Security and quality of supply

- Safe integration of large-scale renewable energy sources

- Cyber security and data protection

○ Operational improvements. 
The drivers for Mexico correspond closely with those selected by the European Union, as seen in Figure 13.

\author{
Mexico Smart Grid Drivers \\ (1) Improved quality, reliability, \\ continuity, safety, and sustainability \\ (2) Improved quality of supply \\ (3) Increased energy efficiency \\ 4 Reduction of electricity losses \\ (5) Efficient operation of the \\ national electric grid \\ 6 Greater deployment of clean energy \\ (7) Increased customer involvement \\ in system management \\ 8 Additional service offerings
}

\section{EU Smart Grid Drivers}

- Sustainability

- Reduction of $\mathrm{CO}_{2}$ emissions 6

- System losses 4

- Transportation 8

- Integration of DER 6

- Competitiveness

- Increased market participation (7)

- Through aggregation of distributed generation, storage, demand response 38

- Improved market transparency

- Interregional markets (harmonized)

- Security and quality of supply 2

- Safe integration of large-scale renewable energy sources 6

- Cyberenergy and data protection

- Operational improvements 15

\section{Figure 13. Comparison of smart grid drivers: Mexico and the EU}

(SENER 2016d, 15); (European Commission 2011, 48)

In 2012, ESTA surveyed countries around the world on Smart Grid drivers. The results (Table 10) indicate the top five motivations for Smart Grid by region. Once again, we see that Mexico's drivers generally correspond with the identified drivers in other regions. 
Table 10. International Smart Grid Drivers

(ESTA 2014)

\begin{tabular}{|l|l|l|l|l|}
\hline & $\begin{array}{l}\text { Latin America and } \\
\text { the Caribbean }\end{array}$ & Europe and Eurasia & $\begin{array}{l}\text { Middle East and } \\
\text { Africa }\end{array}$ & Asia \& Oceania \\
\hline $\mathbf{1}$ & $\begin{array}{l}\text { Reliability } \\
\text { Improvements }\end{array}$ & $\begin{array}{l}\text { Integration with } \\
\text { Renewable Energy }\end{array}$ & $\begin{array}{l}\text { Optimizing Energy } \\
\text { Consumption }\end{array}$ & $\begin{array}{l}\text { Reliability } \\
\text { Improvements }\end{array}$ \\
\hline $\mathbf{2}$ & $\begin{array}{l}\text { Power Quality } \\
\text { Improvements }\end{array}$ & $\begin{array}{l}\text { Demand Response } \\
\text { and Management }\end{array}$ & $\begin{array}{l}\text { Reducing Operating } \\
\text { and Maintenance } \\
\text { Costs }\end{array}$ & $\begin{array}{l}\text { Power Restoration } \\
\text { Improvements }\end{array}$ \\
\hline $\mathbf{3}$ & $\begin{array}{l}\text { Improving revenue } \\
\text { collection and } \\
\text { assurance; reduction } \\
\text { of commercial losses }\end{array}$ & $\begin{array}{l}\text { Reducing Operating } \\
\text { and Maintenance } \\
\text { Costs }\end{array}$ & Reducing Losses & $\begin{array}{l}\text { Optimizing Energy } \\
\text { Consumption }\end{array}$ \\
\hline $\mathbf{4}$ & $\begin{array}{l}\text { Power System } \\
\text { Restoration } \\
\text { Improvements }\end{array}$ & $\begin{array}{l}\text { Integration of } \\
\text { Distributed Energy } \\
\text { Resources }\end{array}$ & $\begin{array}{l}\text { New and Improved } \\
\text { Services for the } \\
\text { Customer }\end{array}$ & $\begin{array}{l}\text { Reducing Operating } \\
\text { and Maintenance } \\
\text { Costs }\end{array}$ \\
\hline $\mathbf{5}$ & $\begin{array}{l}\text { Energy Efficiency } \\
\text { Power Quality }\end{array}$ & $\begin{array}{l}\text { Improved Revenue } \\
\text { Collection and } \\
\text { Assurance }\end{array}$ & $\begin{array}{l}\text { Power Quality } \\
\text { Improvements }\end{array}$ \\
\hline
\end{tabular}

\subsubsection{Improved Quality, Reliability, Continuity, Safety, and Sustainability}

The first driver of Smart Grid in Mexico concerns the overall performance of the electric system. As we will see, this is an area in which smart grid technologies can play a significant role.

The LIE provides that transmission and distribution of electric power will be subject to the rules issued by the CRE in terms of quality, reliability, continuity, safety, and sustainability. For transmission and distribution service, the relevant parameters are:

- Voltage

- Availability of network elements

- Power interruptions

- Harmonic components

- Electricity losses

- Any other technical aspect that the CRE deems necessary.

When adopting the appropriate standards for each of these parameters, CRE must consider the associated economic aspects. Similarly, the operation of the wholesale electricity market is subject to the electricity market rules, which apply to all market participants. These rules provide operating procedures concerning security dispatching, reliability, quality, continuity, and efficiency of the wholesale electricity market, and they include rules to be applied in case of emergency.

\subsubsection{Quality of Supply}

Parameters related to the quality of supply are also relevant for transmission and distribution service, and it is important to take actions to increase the quality of supply that is provided to the end user. Such improvements in quality are in addition to the standards established in the 
administrative provisions that apply to the supply of electricity. In other words, smart grid investment should allow utilities to exceed the traditional measures of power quality. In view of society's growing dependence on an uninterrupted supply of high-quality electricity that is suitable for use by many sectors (e.g., information technology and communications), continuous improvement in quality of supply is needed for economic growth.

\subsubsection{Energy Efficiency}

The LTE defines energy efficiency as all actions that lead to an economically viable reduction of the amount of energy required to meet the energy needs that society demands, thus ensuring a level of quality equal to or greater than that delivered before the actions were taken. Lawrence Berkley National Laboratory (Rybka et. al 2015) uses an equivalent, shorter definition of energy efficiency: "using less energy to provide the same service."

Energy efficiency offers many benefits to Mexico. It is usually the least-cost new "supply" resource, leading to the adage that the least-expensive kilowatt-hour is the one that is not used. In addition to reducing total system cost, energy efficiency saves natural resources and has positive environmental effects.

Smart grid technologies can increase the efficiency of energy use in several ways, including energy efficiency at the customer level but also upstream in the transmission and distribution grid. In the upstream applications, smart grid technologies reduce losses and inefficiencies, reducing the supply requirements for the same set of services consumers use and thus fulfilling exactly the definition of energy efficiency.

\subsubsection{Electricity Losses}

Electricity losses in Mexico's national grid, mainly in the distribution network, are at values well above those recorded worldwide, and the losses represent a major problem affecting the economic viability of utilities that are "productive state companies." Implementing smart grid solutions to reduce these losses represents an important opportunity to significantly improve the efficiency and the economics of the SEN. The LIE requires that the operation of SEN be within efficient parameters, such that, among other efficiency parameters, electricity power losses must be reduced.

Figure 14 shows the trend of distribution losses (pérdidas) in the interior of Mexico from 2002 through 2015; Figure 15 shows the trend of electricity losses in the Valley of Mexico for the same period. The losses are shown in absolute units $(\mathrm{GWh})$ and in relative units (percent of energy delivered). 
LOSS OF POWER (Kilowatt-Hour [KWh]) 2002-2015 DISTRIBUTION IN INTERIOR OF MEXICO

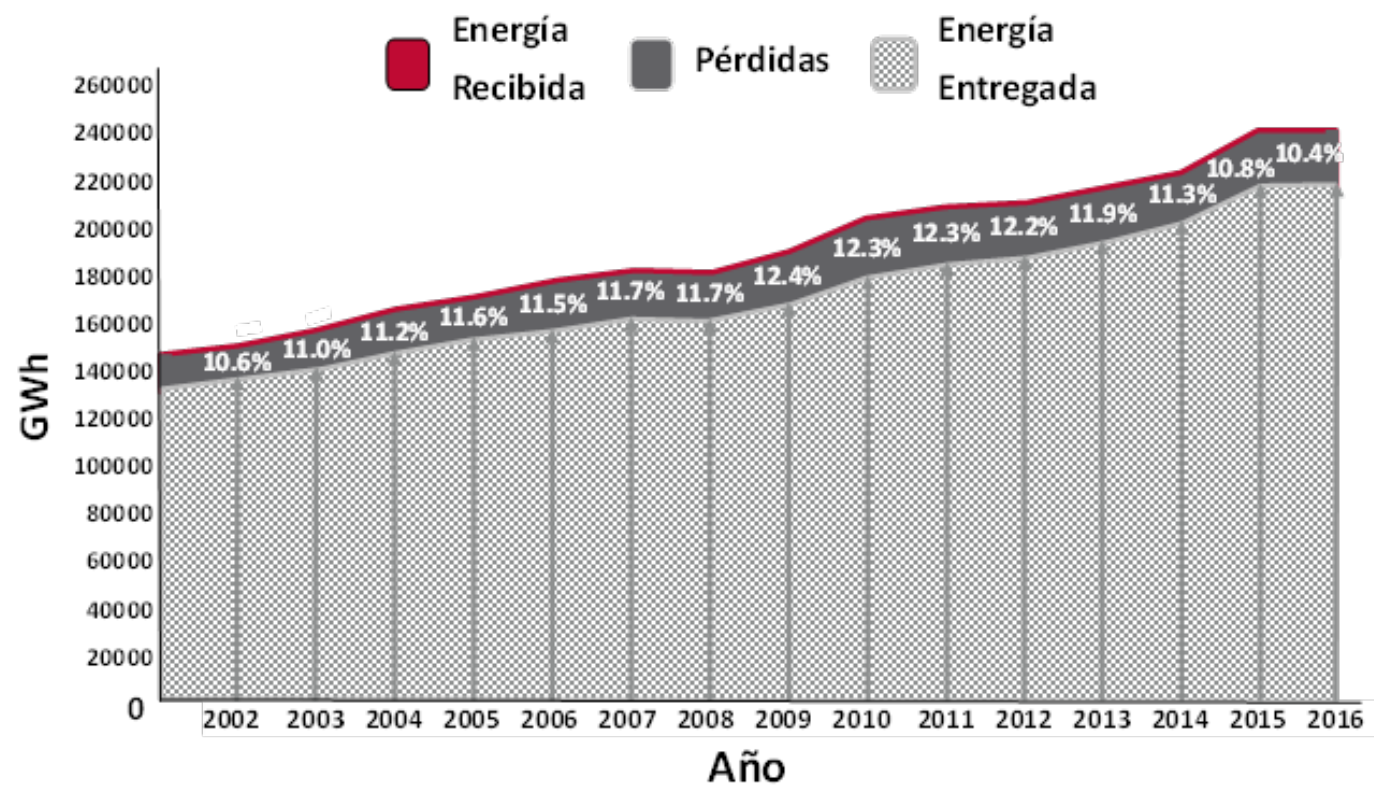

Figure 14. Trend of electricity losses (pérdidas) in the interior of Mexico, 2002-2015

(SENER 2016d, 16)

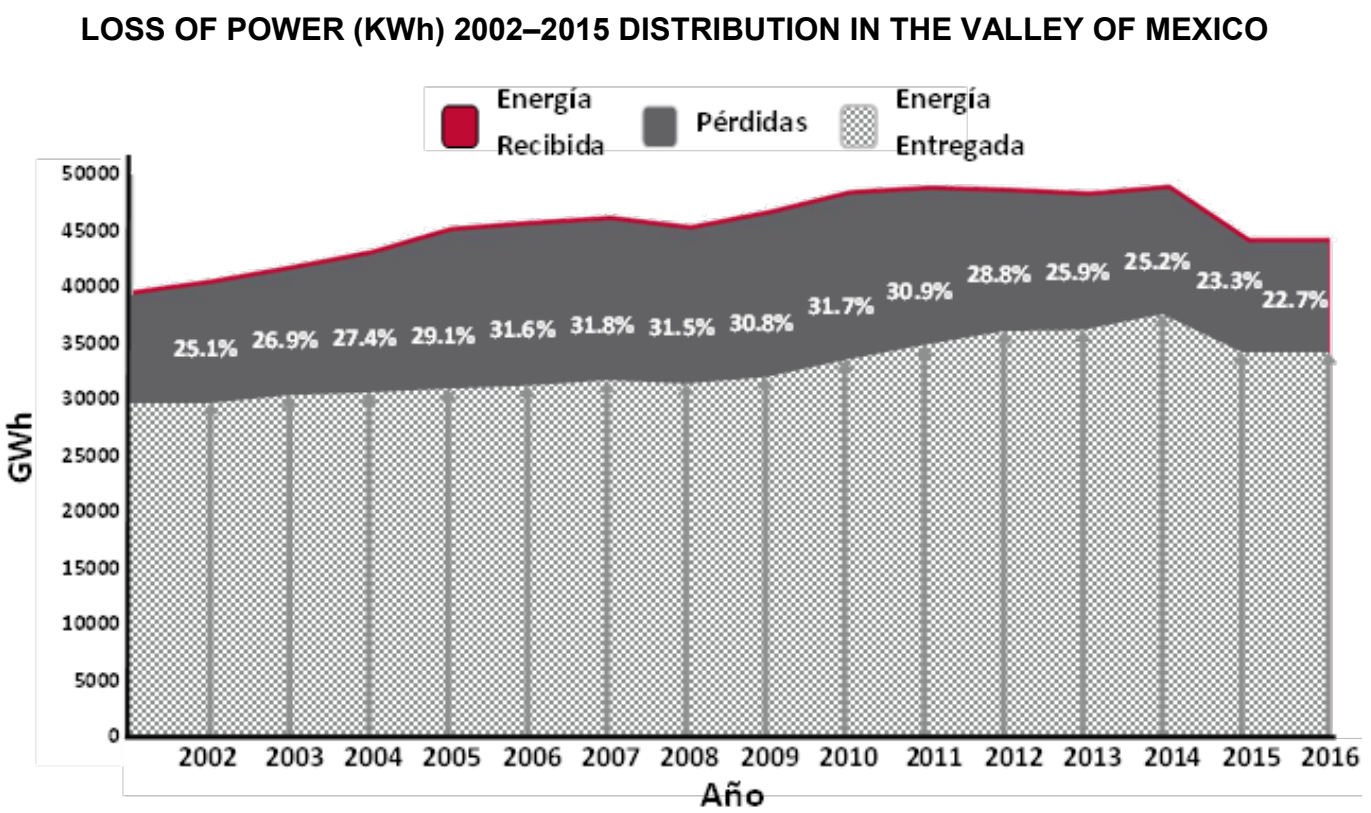

Figure 15. Trend of electricity losses (pérdidas) in the Valley of Mexico, 2002-2015

(SENER 2016d, 16)

These charts suggest progress in reducing the percentage of energy lost, particularly in the Valley of Mexico, which was served by Luz y Fuerza del Centro until 2010, when it was taken over by CFE. However, the losses are still well above industry standards. SENER has identified smart grid investments in meters as one of the leading tools for reducing these losses. 


\subsubsection{Efficient Operation of National Interconnected Electric Grid}

To increase operational efficiency, mainly in transmission and distribution, all parts of those systems must operate properly according to their design conditions. CFE must regularly upgrade and expand its infrastructure, incorporating new technologies, and removing inefficient equipment from service.

CFE must also incorporate asset management systems to extend the life of the equipment-based on analysis and monitoring of the operating conditions and the state of all its elements - to ensure optimal maintenance processes and to identify and implement modernization or replacement of assets.

Smart grid technologies essentially apply information and communications technologies to the power grid. In the same way that internet capabilities have improved the efficiency of other processes in society, information and communications technology capabilities can provide a similar service to the electric grid.

\subsubsection{Clean Energy}

Mexico has adopted strong goals for the acquisition of clean energy, including $35 \%$ of electricity generation by 2024. Meeting these goals will require open access to the national transmission network and general distribution networks on terms that are equitable to all forms of generation. The goals and obligations set out in the LTE regarding clean energy and reducing polluting emissions will require review of the planning process, and they will include all required modernization and expansion. This will be especially important in areas with high potential for clean energy that can be developed or modernized efficiently and at market conditions. All this must be accomplished in a way that ensures the stability of the electric network. Furthermore, in terms of economic sustainability, new technologies must be used in the operation of the national transmission network and general distribution networks to allow greater penetration of clean energies and efficient management of the variability of the same, according to international best practices, strengthening the stability and security of the network, all within conditions of economic viability.

Smart Grid can assist Mexico in meeting its clean energy goals. Properly designed and executed, smart grid investment can address multiple objectives, such as modernization and expansion of the transmission grid, thus helping integrate larger amounts of renewable energy and improving the stability and security of the grid.

\subsubsection{Customer Involvement in System Management}

One of the most significant long-term effects of smart grid technology will be to enable the grid's dealings with customers to be two-way instead of the traditional one-way communication from utility to customer. Two-way communication allows more-effective system management through, for example, more-efficient matching of load and supply.

One application of customer involvement will be options for demand response (DR). In determining and structuring electricity tariffs, it will be important to consider the controllable demand mode and promote more efficient use of energy by the customer by incentivizing them 
to manage their consumption within a framework of dynamic tariffs. Customer involvement will need to be implemented gradually, with consideration given to the impact this may have on rates.

\subsubsection{Additional Service Offerings}

Smart Grid will spawn new services and open the power market to new players at the customer level. This will increase the usefulness of the utilities' existing investments and increase value of the SEN for customers.

In planning the SEN, it is necessary to involve consumers, including large and small companies through their chambers and associations, and to consider their business plans and expectations of additional services in the energy field, which should be in accordance with the policies and regulations issued by the authority.

\subsection{How Smart Grid Measures Can Serve Mexico's Energy Goals}

Before considering various individual smart grid measures, it is helpful to consider, at a high level, the systematic approach to implementing a smart grid that will be necessary for success.

While well-known and established in industries such as aerospace, the application of a systems approach to policy is infrequently (or incompletely) considered in the power sector. Its applications in science and engineering rely on detailed models, but the notion of looking at a problem as a whole and in context is fundamental to the systems approach. The process involves three high-level steps that are similar in any decision evaluation methodology (e.g., Kepner and Tregoe 1976):

1. Objectives
A. Investigate the objectives of the desired change
B. Determine ways to measure the effectiveness of alternatives to achieve change
C. Define criteria for applying the measures (e.g., scoring and weighting) to select alternatives

2. Alternatives
A. Discover alternatives within the whole and in context, involving the breadth of stakeholders involved in the desired change
B. Analyze alternatives for feasibility, risk, and cost

3. Decision
A. Compare alternatives in terms of the established criteria
B. Minimize risk by exploring expected outcomes, both positive and negative, to identify contingencies and preventive actions
C. Consider testing through evaluation-periods, pilots, or demonstrations.

Ideally, Smart Grid deployment projects should be selected and supported in proportion to how they contribute to national policy goals. It is helpful to illustrate this process by examining the development of Smart Grid in international settings. A sampling of that rich experience is contained in the next section. 


\subsection{Survey of International Experience with Smart Grid Technologies}

A compendium of case studies discussing important Smart Grid deployments in the transmission and distribution system can be found in the report, ISGAN: Spotlight on Smart and Strong Power $T \& D$ Infrastructure 2.0 (Normark 2016), which includes the following country examples:

- Austria: maximizing the distributed energy resources (DER) hosting capacity of lowand medium-voltage networks

- Belgium: increasing hosting capacity by intelligent control of PV inverters

- Canada: energy storage and DR for improved supply reliability

- China: Multi-terminal system demonstrates that true networks can be built with HVDC.

- Denmark: more-efficient energy system by combining electricity and heat

- Germany: High-temperature superconducting transmission and distribution cables enable increased capacity in congested urban area.

- Ireland: An HVDC interconnector enables integration of wind power and improves electricity market.

- Italy: Wide-area measurement enhances the power system; the case study also explores the impact of the enforcement of a time-of-use tariff on residential customers in Italy.

- South Africa: Eskom establishes a grid situational awareness proof-of-concept.

- Sweden: An optimal combination of transmission technologies solves transmission congestion.

- United States: Wide-area measurement systems are used to avoid large-scale outages.

Additional relevant country experiences are discussed in the following sections.

\subsubsection{China}

\section{Demand Side Management}

Sixty GW of China's total capacity operate only 50 hours per year. This $60 \mathrm{GW}$ of capacity represents 5\% of demand and an expensive operational cost to the State Grid Corporation of China (State Grid). This peak is thus an opportunity for demand side management (DSM).

The State Grid, in collaboration with the National Energy Administration (NEA) of China, the U.S. Trade and Development Agency, and the U.S. Department of Energy (DOE) selected DSM as China's first smart grid pilot project. The pilot, which monitored and managed electricity use in two commercial buildings using an automated demand response grid-to-building control system, reduced loads by $15 \%$.

Following the pilot, in 2015, Chinese partners including Shanghai Electric Power, NARI Group, and the State Grid enlisted 33 commercial and public buildings and 31 industrial customers with a combined $100 \mathrm{MW}$ of load-shedding capacity to participate in further testing.

\subsubsection{France}

\section{Smart Substation}

The Smart Substation project, commissioned in 2016, is operating two fully digital smart substations in the northern France. It showed the feasibility of a global process bus, 
implementing the IEC-61850 standard, and it demonstrated the concept of a wide-area automation solution. The project was supported by the French government and was developed through a consortium led by RTE France, the French transmission system operator (TSO). Members of the consortium are the European Regional Development Fund (ERDF), Alstom Grid, Alcatel Lucent, Schneider Electric, and the start-up Neelogy.

\subsubsection{India}

\section{Unified Real-Time Dynamic State}

Power Grid Corporation of India Limited assembled the world's largest grid wide-area monitoring system (WAMS), with over 1,100 PMUs installed at more than 350 substations, and 34 phasor measurement unit (PMU) data systems in operation. To meet the communication requirements associated with synchrophasors, a fiber optic network is either available or under implementation to connect all PMU and PDC (phasor data concentrator) locations.

\section{Energy Accounting}

Maharashtra State Electricity Distribution implemented data and information technology (IT) applications for energy accounting, auditing, and consumer service centers for 95 towns in India. GIS-based indexing and asset mapping were included in the upgrade. By integrating GIS-based information and IT-based solutions, Maharashtra can effectively measure the aggregate technical and commercial losses and increase the reliability and quality of electric supply.

\subsubsection{Italy}

\section{Wide-Area Measurement System Platform}

Oscillatory stability is a concern, especially for the risk of undamped inter-area oscillations throughout large interconnected systems. The Italian system participates in the oscillatory modes of the continental European system, and it may experience internal oscillations, typically between north and south because of its longitudinal structure.

At Terna, the Italian TSO, algorithms were developed to evaluate the oscillatory stability determined from the WAMS. The WAMS developed in Italy consists of a set of PMUs, a dedicated data network, and computer systems for data processing and management, including monitoring applications and intelligent display at the National Control Center of Terna in Rome.

\subsubsection{United States}

In the United States, Smart Grid is regarded as an important tool to reach the country's energy goals. One of the most significant impacts of Smart Grid will be to enable DR.

In March 2011, the Federal Energy Regulatory Commission (FERC) issued Order 745, titled Demand Response Compensation in Organized Wholesale Energy Markets. It required institutions that administrator regional energy markets in the United States-known as regional transmission organizations (RTOs) and independent system operators (ISOs) - to compensate "demand response resources . . . at the market price for energy" as an alternative to generation of additional electricity "when dispatch of that demand response resource is cost-effective" (FERC 2011). 
Because smart grid technologies are essential to the success of DR, especially within the classes of small commercial and residential customers, DR has become a major driver of smart grid investment in the United States.

\subsubsection{European Union}

Much like the SENER's smart grid drivers, European Union (EU) energy policies are driven by three main objectives:

- Sustainable energy consumption

- Operation of a competitive environment that ensures affordable prices

- Secure energy supplies.

In an attempt to assess the progress of EU member nations' efforts to accomplish these three policy objectives, the Joint Research Centre Institute for Energy stratified them. By establishing the follow categorization, the research center provides a model roadmap for linking drivers to initiatives:

- Sustainability

- Reduction of carbon dioxide emissions

- System losses

- Transportation

- Integration of DER

- Competitiveness

○ Increased market participation

- Through aggregation of DG, storage, DR

- Improved market transparency

○ Interregional markets (harmonized)

- Security and quality of supply

- Safe integration of large-scale renewable energy sources

- Cyber security and data protection

- Operational improvement. 


\section{Mapping Smart Grid Measures to Key Drivers in Mexico}

Table 11 - on the following pages - presents options for implementing smart grid measures that address each of the eight drivers identified by SENER. In some cases, the table highlights the categories of smart grid activities; in other cases, specific measures are identified.

The table is not intended to be comprehensive but rather to be a guide to some of the specific smart grid measures that match with the drivers. The contents of the table are discussed in depth in the Section 6. 
Table 11. Mapping Smart Grid Measures to Drivers

\begin{tabular}{|c|c|c|}
\hline \multicolumn{3}{|c|}{ Driver 1: Quality, Reliability, Continuity, Safety, and Sustainability } \\
\hline Where in Grid & Smart Grid Measures & Comments \\
\hline Generation/Supply & $\begin{array}{l}\text { Install PMUs at large generator terminals and utility } \\
\text { renewable sites for monitoring and active response } \\
\text { during grid event and for generator model validation } \\
\text { Install lidar or other instrumentation for better } \\
\text { forecasting }\end{array}$ & $\begin{array}{l}\text { In Sections } 6.1 .1 \text { and 6.1.2, see: } \\
\text { - PJM case study for generator PMUs } \\
\text { - ERCOT case study for wind site PMUs } \\
\text { - Case study for generator control of Colombia XM, the } \\
\text { Colombian electric utility (Leon and Gomez 2011). }\end{array}$ \\
\hline Transmission & $\begin{array}{l}\text { Develop PMU data for post-mortem outage analysis } \\
\text { Acquire software and IT for real-time use of PMU data } \\
\text { Deploy FACTS devices for transmission control } \\
\text { Install "smart wire" technology, and wide-area } \\
\text { monitoring, protection, and control systems } \\
\text { (WAMPACS) }\end{array}$ & $\begin{array}{l}\text { See the Bonneville Power Administration case study } \\
\text { addressing oscillatory stability (Section 6.1.26.1). }\end{array}$ \\
\hline Distribution & $\begin{array}{l}\text { Implement FLISR and integrate into business systems } \\
\text { (e.g., outage management and asset management) } \\
\text { Install sensors on all secondary transformers to } \\
\text { enhance outage management and preventative } \\
\text { maintenance }\end{array}$ & $\begin{array}{l}\text { See Section } 6.1 .3 \text { for additional smart grid applications that } \\
\text { increase quality and reliability of service. }\end{array}$ \\
\hline Customer Premises & $\begin{array}{l}\text { Implement interruptible load, critical peak pricing, or } \\
\text { other tariffs that let load reductions contribute to } \\
\text { providing capacity on peak days; alternatively, utility or } \\
\text { third-party aggregators could enroll customers and } \\
\text { subsequently bid into the wholesale market }\end{array}$ & \\
\hline Other/Combined & Implement cybersecurity measures & \\
\hline
\end{tabular}




\begin{tabular}{|c|c|c|}
\hline \multicolumn{3}{|c|}{ Driver 2: Quality of Supply } \\
\hline Where in Grid & Smart Grid Measures & Comments \\
\hline Generation/Supply & Use DR for voltage and frequency support & Smart inverters enable this application. \\
\hline Transmission & $\begin{array}{l}\text { Install power quality measurement units or integrate } \\
\text { comparable functionality into revenue metering for } \\
\text { large (e.g., industrial) customers served at } \\
\text { transmission-class voltages to inform service quality } \\
\text { and system compatibility (i.e., flicker, harmonics), fast } \\
\text { fault clearing, and other devices. }\end{array}$ & $\begin{array}{l}\text { An important application here is traveling wave fault } \\
\text { location and clearing. }\end{array}$ \\
\hline Distribution & $\begin{array}{l}\text { Employ Volt/VAR (volt-ampere reactive) optimization } \\
\text { (VVO), DER voltage control schemes } \\
\text { Reduce nontechnical losses and implement FLISR } \\
\text { technology to shorten the time and affected customers } \\
\text { during an outage }\end{array}$ & \\
\hline Meter & Use AMI for superior power quality measurements & \\
\hline Other/Combined & Use smart inverters in solar applications & \\
\hline
\end{tabular}




\begin{tabular}{|c|c|c|}
\hline \multicolumn{3}{|c|}{ Driver 3: Energy Efficiency } \\
\hline Where in Grid & Smart Grid Measures & Comments \\
\hline Generation/Supply & Optimize generator dispatch with merit order dispatch & $\begin{array}{l}\text { Merit order dispatch is enabled by Smart Grid } \\
\text { communication system upgrades. }\end{array}$ \\
\hline Transmission & $\begin{array}{l}\text { Consider "smart wire" technologies to optimize } \\
\text { transmission system, thus avoiding overloaded lines } \\
\text { reducing losses, and improving efficiency }\end{array}$ & \\
\hline Distribution & $\begin{array}{l}\text { Implement voltage optimization, smart power factor } \\
\text { correction schemes, and conservation voltage } \\
\text { reduction schemes }\end{array}$ & $\begin{array}{l}\text { Significant energy savings-enabled by AMI meters and } \\
\text { enhance communications-are possible here. }\end{array}$ \\
\hline Meter & $\begin{array}{l}\text { For AMI customers, provide information portal to } \\
\text { educate customers about their usage } \\
\text { Provide customers the ability to control their bills, } \\
\text { deliver messages about energy efficiency, } \\
\text { communicate incentive offers, and other functions }\end{array}$ & $\begin{array}{l}\text { Promoting energy efficiency will accompany the use } \\
\text { of DR. }\end{array}$ \\
\hline Customer Premises & $\begin{array}{l}\text { Implement power factor correction } \\
\text { Use metering data to inform energy audits and } \\
\text { subsequent energy efficiency incentive offers }\end{array}$ & \\
\hline
\end{tabular}




\begin{tabular}{|c|c|c|}
\hline \multicolumn{3}{|c|}{ Driver 4: Electricity Losses } \\
\hline Where in Grid & Smart Grid Measures & Comments \\
\hline Transmission & $\begin{array}{l}\text { Implement dynamic line ratings technology to measure } \\
\text { thermal and/or physical line tension (or sag) to optimize } \\
\text { line flows }\end{array}$ & This can be addressed using PMU's. \\
\hline Distribution & $\begin{array}{l}\text { Implement VVO } \\
\text { Employ DR to reduce peak loads, when resistance } \\
\text { losses are highest in transformers and in conductors } \\
\text { Use AMI data to inform preventative maintenance at } \\
\text { secondary transformers, thus increasing their efficiency } \\
\text { and reducing losses }\end{array}$ & $\begin{array}{l}\text { An emerging application is using PMUs in the } \\
\text { distribution grid. }\end{array}$ \\
\hline Meter & $\begin{array}{l}\text { Install tamper-proof AMI devices where theft is high to } \\
\text { reduce nontechnical losses } \\
\text { Employ AMI to measure feeder losses accurately, } \\
\text { identifying maintenance needs } \\
\text { Improve meter accuracy with AMI }\end{array}$ & \\
\hline Customer Premises & $\begin{array}{l}\text { Employ rate structures that incentivize peak load } \\
\text { reductions and lead to lower technical losses }\end{array}$ & $\begin{array}{l}\text { The highest gains will be with customers with the } \\
\text { highest usage. }\end{array}$ \\
\hline Other/Combined & $\begin{array}{l}\text { Use distributed energy resource management systems } \\
\text { (DERMS) to provide control and feedback to DG } \\
\text { systems and help control local voltage levels }\end{array}$ & \\
\hline
\end{tabular}




\begin{tabular}{|c|c|c|}
\hline \multicolumn{3}{|c|}{ Driver 5: Efficient Operation of National Electric Grid } \\
\hline Where in Grid & Smart Grid Measures & Comments \\
\hline Transmission & $\begin{array}{l}\text { Implement near-term or real-time forecasts of solar and } \\
\text { wind power generation and use in dispatch decisions } \\
\text { Increase the efficiency of power flow, considering } \\
\text { system losses while accounting for generation dispatch } \\
\text { (e.g., using wide-area measurements) } \\
\text { Provide substation automation, centralized protection, } \\
\text { intelligent switch technologies, and dynamic line } \\
\text { ratings for more efficient and more reliable operation } \\
\text { of the grid }\end{array}$ & $\begin{array}{l}\text { See Section } 6.5 .2 \text { for additional smart grid applications } \\
\text { that increase efficiency of operations. Also see Driver } 1 \text {, } \\
\text { above in this table. }\end{array}$ \\
\hline Distribution & $\begin{array}{l}\text { Implement voltage conservation } \\
\text { Utilize dynamic line ratings } \\
\text { Upgrade to automated substations }\end{array}$ & \\
\hline Customer Premises & $\begin{array}{l}\text { Implement dynamic pricing (e.g., time-of-use, peak load } \\
\text { pricing, and real time pricing) for AMI-served customers }\end{array}$ & $\begin{array}{l}\text { Consider starting with the largest users in the residential } \\
\text { class for AMI installation. }\end{array}$ \\
\hline
\end{tabular}




\begin{tabular}{|c|c|c|}
\hline \multicolumn{3}{|c|}{ Driver 6: Clean Energy } \\
\hline Where in Grid & Smart Grid Measures & Comments \\
\hline Generation/Supply & $\begin{array}{l}\text { Improve forecasting for renewable resources to enable } \\
\text { smooth integration of large amounts of variable } \\
\text { resources } \\
\text { Implement long-term planning that captures geospatial } \\
\text { diversity and temporal variability of renewable } \\
\text { resources, along with realistic cost trajectories and } \\
\text { operational interactions with other generators, } \\
\text { transmission, storage, and DR }\end{array}$ & \\
\hline Transmission & $\begin{array}{l}\text { Evaluate and co-optimize potential transmission } \\
\text { projects that consider potential renewable energy } \\
\text { deployments }\end{array}$ & \\
\hline Distribution & $\begin{array}{l}\text { Implement energy storage and load controls for } \\
\text { enabling greater renewable penetration } \\
\text { Enable DG at residences } \\
\text { Deploy combined heat and power generation for large } \\
\text { commercial customers to reduce fossil fuel generation }\end{array}$ & \\
\hline Customer Premises & $\begin{array}{l}\text { Investigate to what extent DR and energy efficiency } \\
\text { could contribute to (1) firm capacity and (2) reduced } \\
\text { curtailment assuming high solar and wind penetration }\end{array}$ & \\
\hline Other/Combined & $\begin{array}{l}\text { Use smart inverters to optimize the use of distributed } \\
\text { solar generation }\end{array}$ & \\
\hline
\end{tabular}




\begin{tabular}{|l|l|l|}
\hline \multicolumn{2}{|c|}{ Driver 7: Customer Involvement in System Management } \\
\hline Where in Grid & Smart Grid Measures & Comments \\
\hline Generation/Supply & $\begin{array}{l}\text { Enable customers to choose an energy supply } \\
\text { company through market design }\end{array}$ & High cost-effectiveness is possible if this measure is \\
\hline Meter & $\begin{array}{l}\text { Install AMl meters on all large commercial and large- } \\
\text { user residential customer premises }\end{array}$ & $\begin{array}{l}\text { arge users in residential class. } \\
\text { Customer Premises }\end{array}$ \\
\hline $\begin{array}{l}\text { Promote DR aggregation by third parties. } \\
\text { Couple any real-time pricing with enabling automation } \\
\text { that can schedule appliances and/or adjust set-points } \\
\text { based on prices and customer preferences }\end{array}$ & $\begin{array}{l}\text { Evaluate any proposed time-of-use rates against the } \\
\text { expectation of how net load curves may evolve over time. }\end{array}$ \\
\hline Other/Combined & $\begin{array}{l}\text { Create a customer portal tied into AMl for customer } \\
\text { education and awareness of usage } \\
\text { Provide incentive schemes to improve load shape }\end{array}$ & \\
\hline
\end{tabular}




\begin{tabular}{|c|c|c|}
\hline \multicolumn{3}{|c|}{ Driver 8: Additional Service Offerings } \\
\hline Where in Grid & Smart Grid Measures & Comments \\
\hline Meter & $\begin{array}{l}\text { Mandate AMI for large customers and for commercial } \\
\text { and high-usage residential customers } \\
\text { Mandate dynamic pricing (time-of-use or real-time) } \\
\text { Enable meters to provide local access to metering data } \\
\text { (i.e., allow users to obtain real-time consumption data } \\
\text { using a web portal via mobile devices) }\end{array}$ & \\
\hline Customer Premises & $\begin{array}{l}\text { For AMI, offer web-based information portal accessible } \\
\text { by mobile devices that provides feedback on real-time } \\
\text { and historical energy use. }\end{array}$ & $\begin{array}{l}\text { Such a feature could also be used to let customers } \\
\text { preview other, more responsive tariffs or to learn how their } \\
\text { energy use and service levels might change under a } \\
\text { particular DR program. }\end{array}$ \\
\hline Other/Combined & Utilize microgrids with renewable energy supply & $\begin{array}{l}\text { This measure represents a means of helping extend grid } \\
\text { services to the remaining } 2 \% \text { of the population without } \\
\text { access (e.g., PV Magazine 2016). }\end{array}$ \\
\hline
\end{tabular}




\section{Smart Grid Measures for Mexico}

We now visit each of the drivers for Smart Grid in Mexico and discuss smart grid measures that would serve that driver. The discussion elaborates on the measures identified in the previous section; each subsection is mapped to a driver, and each driver subsection is subdivided into the various points of application in the grid.

\subsection{Driver 1: Quality, Reliability, Continuity, Safety, and Sustainability}

\subsubsection{Generation/Supply}

Smart grid technologies can improve many existing generation practices and enable grid operators to improve reliability with greater insight into the variability of renewable generation.

Installing PMUs at large generator terminals and at large renewable generation sites can (1) enable improved system monitoring and active response during grid events and (2) improve modeling of generators. Installation of lidar or other smart grid instrumentation will lead to greater accuracy in forecasting wind and solar performance, increasing reliability and often reducing costs because the operator will have advanced information about changes in variable generation.

\subsubsection{Transmission}

\section{PMU-Based Wide-Area Monitoring, Protection, and Control Systems (WAMPACS)}

One of the earliest and most successful smart grid measures for transmission is the use of PMUs, which can capture conditions on the transmission grid at an instantaneous moment across the grid. CENACE has installed PMUs on its system, and it is helpful to review here the applications of PMUs and other smart grid applications for transmission.

PMU-based WAMS have been the focus of smart grid investments for the transmission systems in the United States and across the world in the past few years. In addition to providing transmission situational awareness, the WAMS are being increasingly deployed for system operations - including monitoring of large generators and renewable sites - and for model validation and disturbance recording.

Though most newer digital protection relays and other digital recorders have embedded PMU functionality, a modern communication architecture consisting of PDCs, higher bandwidth communication channels, and central phasor processing capabilities is required for effectively using these systems. Though commercially available, WAMS-based real-time applications, including real-time path rating and inter-area oscillation detection and control, are limited; development of other applications is of immense interest in the power systems research community. Other offline applications include large disturbance and outage analysis, digital disturbance recording, generator model validation, network equivalents, and study of disturbance propagation in large systems (NASPI n.d.).

We now turn to a review of some successes with WAMPACS and related technologies around the world. 


\section{United States}

PMUs are being widely deployed for wide-area monitoring (WAM) of the bulk power system across all three interconnections in North America: the Eastern Interconnection, the Electric Reliability Council of Texas (ERCOT), and the Western Electricity Coordinating Council (WECC, which includes a part of CFE in Mexico). Regional entities such as PJM, ${ }^{8}$ ISO-NE ${ }^{9}$ (Ghiocel et al. 2014), ERCOT (Chen et al. 2012), and WECC (Kincic et al.) in the United States are using high-resolution PMU data to validate planning models of wind farms, FACTS devices, generators, fault-induced delayed voltage recovery (FIDVR) response (Bravo and Chassin 2016), and HVDC systems, ensuring better accuracy for system planning and operational contingency analysis.

The Bonneville Power Administration (BPA), a large utility located in the U.S. Pacific Northwest, has 134 PMUs located at 230-kV and 500-kV substations. These PMUs collect synchrophasor data for 445 voltage and current signals. The WAMS is used for operations such as real-time situational awareness and alarms, wide-area remedial action scheme (RAS), power plant model validation, and post-event analysis (Faris 2016; Huang et al. 2013). Other large utilities such as Dominion Virginia Power (Jones, Pal, and Thorp 2015), Tennessee Valley Authority (Zhang et al. 2010), and Entergy (Werho et al. 2016) have deployed significant WAMS systems for phasor-based state estimation, wide-area system separation, islanding, and restoration. California ISO and ERCOT use PMUs for real-time monitoring of PV and wind generation sites.

\section{China}

With an installed capacity of about $1,056 \mathrm{GW}$, WAMS plays a major role in grid operations in China. WAMS was operational at the China National Electric Power Dispatching and Communication Center in 2002. The functionality of the system was subsequently extended to include dynamic model parameter validation, low-frequency oscillation analysis, power system state estimation improvement, and wide-area protection against cascading trips. Two types of PMUs are widely deployed: substation PMUs and generator PMUs. Currently, WAMS is deployed in every regional and provincial power grid, covering all 500-kV substations, some critical 220-kV substations, and all generators rated above 100 MW (Bi 2013; Sun 2016).

\section{India}

India has an installed capacity of about $237 \mathrm{GW}$, with renewable sources constituting about $30 \mathrm{GW}$ of that total. Synchrophasor technology has been identified as a key technology for grid operations, especially with a growing share of renewables. A total of 62 PMUs have been deployed. A fully fledged WAMS — called the Unified Real-time Dynamic State Measurement Scheme-is under implementation. This system is envisaged to consist of over 1,700 PMUs, 32 PDCs, and 11,000 kilometer $(\mathrm{km})$ of optical fiber communication links. WAMS has been

\footnotetext{
${ }^{8}$ PJM Interconnection LLC is a regional transmission organization (RTO) serving a large portion of the eastern United States. Its name derives from Pennsylvania-(New) Jersey-Maryland interconnection.

${ }^{9}$ ISO New England (ISO-NE) is the independent not-for-profit company authorized by the Federal Energy Regulatory Commission in 1997 to operate the regional power system, implement wholesale markets, and manage the regional power system planning process for the region spanning Connecticut, Rhode Island, Massachusetts, Vermont, New Hampshire, and most of Maine.
} 
used to provide real-time situational awareness, angle-based line monitoring, calibration of "special protection schemes," oscillation monitoring, and system operation during natural calamities. In addition, the PMUs are used as islanding detection tools and for dynamic model validation and state estimation (Mukopadhyay 2014).

\section{Europe}

A series of blackouts in the European grid in 2003 led to the adoption of PMU-based WAMS for improved situational awareness. WAMS was also selected as the tool for addressing technical challenges in large interconnections when multiple Union for the Co-ordination of Transmission of Electricity synchronous zones were integrated and the Turkish power grid was subsequently added. Each European TSO has 3-30 PMUs installed that are connected to its individual data concentrator. In addition, PMU data from strategic locations are exchanged between the TSOs. The applications include voltage phase angle difference monitoring, real-time line thermal monitoring, voltage stability monitoring, and online monitoring of inter-area oscillations (Sattinger 2011; ENTSO-E 2015).

\section{South America}

The main driving force for the adoption of Brazilian Interconnected Power System was the vast geographical spread of the country's power grid and long-distance power transfers among its five interconnected regions (Moraes, Volskis, and $\mathrm{Hu}$ 2008). The MedFasee Project for deploying WAMS across Brazil was developed in three phases, at the end of which several PMUs were installed at low voltages and were interconnected using MedFasee PDCs, supplemented by OpenPDC as the front-end PDC. The WAMS applications include monitoring of electromechanical oscillations, validation of system controls, evaluation of special protection schemes, system-wide model validation, and post-event analysis (Decker et al. 2011).

The Colombian utility, XM, which manages the National Energy Transmission System, has deployed PMUs at major generating stations and strategic locations. The SIRENA ${ }^{10}$ WAMS project was launched after a total system blackout in April 2007. Specifically, PMU measurements were used to identify and improve the damping of the $0.06-\mathrm{Hz}$ forced oscillations that had previously caused load shedding of up to 1,100 MW. Other WAMS applications include risk assessment of loaded transmission corridors, post-event analysis, model validation, and oscillatory stability monitoring and control (Leon and Gomez 2011). Novel technology concepts such as "angle-controlled power plants" and automatic generation control are also being pursued (Sierra, Mendez, and Arenas 2014).

\section{Accurate Fault Location Using Traveling Waves}

Accurate fault location on transmission lines enables quicker service restoration of the faulted line. With extra-high voltage lines, faulted components are indistinguishable from non-faulted ones by visual inspection alone, hence the need for accurate fault location. Even if visual inspection alone were sufficient, with transmission towers 500 meters apart, visual inspection along a stretch would be time-consuming, causing unnecessary delays in service restoration. While other advanced technologies such as wavelet transformation are under development,

\footnotetext{
${ }^{10}$ SIRENA is the Spanish acronym for the Colombian National Defense System against Large-Scale Events.
} 
traveling wave fault location technologies are commercially available and provide a more accurate fault location than the current impedance-based methods (Fischer et al. 2012).

Such equipment leverages the accurate GPS signals and processing capabilities that are already available in transmission relays, making it easy to incorporate these systems. With improvement in communication and computational capabilities of modern digital relays, these systems can reliably estimate fault location within an error of 60 meters, greatly improving crew dispatch efficiency and service restoration. Such systems are being widely deployed in critical transmission lines and along rights-of-way with difficult terrain (Schweitzer et al. 2014).

\section{Flexible AC Transmission Systems (FACTS)}

FACTS refers to a wide range of power electronics-based controllers that can increase the flexibility and controllability of power systems. In the United States, FACTS has been identified as critical to the Smart Grid for enhancing controllability, stability, and power transfer capacities (NETL 2007). Common technical objectives for these systems include providing dynamic reactive power support, improving the transmission corridor capacities that are stabilityconstrained, improving system stability through control of real and reactive power flows, and mitigating subsynchronous resonance problems.

Examples of FACTS include unified power flow controllers (UPFCs), thyristor-controlled series compensators (TCSC), and static synchronous compensators (STATCOM). Initially proposed for the bulk power grid, these technologies are now being proposed for distribution systems for a range of objectives, including power quality improvement, integration of renewables, and voltage support (Song and Johns 1999). Smart inverters can perform STATCOM-like functions through their ability to control the reactive power output. A coordinated Volt-Var control scheme is needed to achieve effective voltage control.

\section{San Diego, California, United States}

A study conducted by California Energy Commission (CEC 1999) identified UPFC as the most suitable FACTS technology for the power-congested San Diego area and the associated benefits in terms of improved import capability. The identified UPFC configuration would enable San Diego Gas \& Electric (SDG\&E) to increase import capacity by $300 \mathrm{MW}$, from $2,450 \mathrm{MW}$ to $2,750 \mathrm{MW}$, with a payback period of 13 years.

\section{PingGuo, China}

A TCSC was installed in the China Southern Power Grid network at PingGuo. Such an installation could increase the capacity of the west-to-east transmission corridors by $242 \mathrm{MW}$. The TCSC system was designed for a total capacity of 800 megavolt ampere reactive (MVAR), providing a serial compensation of $40 \%$ (35\% fixed and 5\% controllable). In addition to improving the power transfer capabilities, the TCSC station is also used for improving the damping of lower frequency oscillations (Yue and Bailu 2005).

\section{Santiago, Chile}

Transelec, the main TSO in Chile, has installed a FACTS system comprising a STATCOM and a static VAR compensator. The STATCOM was installed at the Cerro Navia 220-kV substation and is rated at -65 to +140 MVAR. And, the static VAR compensator at the Polpaico 229-kV 
substation is rated at -65 to +100 MVAR. The objective of these systems is to provide stability to the $220-\mathrm{kV}$ grid during steady-state and contingency conditions by providing fast reactive power response for system contingencies and by regulating the voltage. In addition, these systems increased the power transfer capability by $200 \mathrm{MW}$ (from 1,400 MW to 1,600 MW) through the 300-km 500-kV corridor (ABB 2012).

\subsubsection{Distribution}

The design and operation of electricity distribution systems throughout the world have seen significant changes over the past few decades. The changes have mainly focused on improving safety, reliability, and cost-effectiveness while increasing deployment of DG resources. Each electric distribution utility has a different service territory, and their voltage and frequency metrics differ from place to place, even within the same country or the same utility. In Mexico, for example, each distribution system differs from place to place and time to time, with respect to voltage levels, types of customers, overhead versus underground designs, types of system protection devices used, methods used to monitor system status, and operational options for switching. However, new smart grid technologies can benefit all utilities.

Because of operational constraints and financial limits for adopting and deploying these potential smart grid measures, utilities must make prudent choices. Because cost is a limiting factor for every utility in the world, no matter the governance structure, we focus primarily on non-cost criteria in selecting new devices and systems for distribution system upgrades in Mexico.

There are many smart grid measures that Mexico can deploy to help improve safety, reliability, power quality, and sustainability, including those shown in Table 12.

Table 12. Smart Grid Measures and Expected Impacts

\begin{tabular}{|l|l|}
\hline Smart Grid Measure & Expected Area of Improvement \\
\hline $\begin{array}{l}\text { Electronic recloser controls } \\
\text { with SCADA }\end{array}$ & $\begin{array}{l}\text { This measure is expected to reduce the overall duration of outages. } \\
\text { Smart controls may improve safety for personnel working on lines using } \\
\text { remote "one-shot" controls. }\end{array}$ \\
\hline $\begin{array}{l}\text { Power-operated switches } \\
\text { with local or remote control }\end{array}$ & $\begin{array}{l}\text { These systems may reduce the overall duration of outages or reduce } \\
\text { the number of customers impacted by the outage. }\end{array}$ \\
\hline $\begin{array}{l}\text { Fault indicators, with or } \\
\text { without remote monitor } \\
\text { (CIRED 1998) }\end{array}$ & $\begin{array}{l}\text { Fault indicators help operations personnel restore outages and locate } \\
\text { the source of the problem. }\end{array}$ \\
\hline $\begin{array}{l}\text { FLISR systems (DOE } \\
\text { 2014a) }\end{array}$ & $\begin{array}{l}\text { These fault sensing and restoration systems can greatly reduce } \\
\text { duration and frequency of outages. }\end{array}$ \\
\hline $\begin{array}{l}\text { Electronic programmable } \\
\text { fuses }\end{array}$ & $\begin{array}{l}\text { These devices can greatly enhance fuse and circuit breaker } \\
\text { coordination, resulting in shorter outages and fewer impacted } \\
\text { customers. }\end{array}$ \\
\hline $\begin{array}{l}\text { Electronic relays for } \\
\text { breakers, secondary } \\
\text { networks, electronic } \\
\text { reclosers, and other } \\
\text { devices }\end{array}$ & $\begin{array}{l}\text { These controls help the operator and engineer program the behavior of } \\
\text { devices, resulting in safer and more reliable systems. }\end{array}$ \\
\hline
\end{tabular}




\begin{tabular}{|c|c|}
\hline Smart Grid Measure & Expected Area of Improvement \\
\hline $\begin{array}{l}\text { Power line carrier (PLC) } \\
\text { communication systems }\end{array}$ & $\begin{array}{l}\text { These communication systems can be very helpful in the monitoring } \\
\text { and control of smart grid devices and can help increase DER integration } \\
\text { and control. }\end{array}$ \\
\hline $\begin{array}{l}\text { SCADA systems (Thomas, } \\
\text { and McDonald 2015, 131) }\end{array}$ & $\begin{array}{l}\text { SCADA helps operators better visualize their systems and offers } \\
\text { superior control of distribution system devices at the substation and } \\
\text { beyond. Improvements in reliability, as well as in system operations, are } \\
\text { common. }\end{array}$ \\
\hline Intelligent capacitor controls & $\begin{array}{l}\text { Advanced controls help keep voltage levels and VAR flow levels at } \\
\text { appropriate settings, improving power quality, VVO, and DER } \\
\text { integration. }\end{array}$ \\
\hline $\begin{array}{l}\text { Voltage regulator controls } \\
\text { with bidirectional capability } \\
\text { and co-gen modes }\end{array}$ & $\begin{array}{l}\text { Advanced controls for voltage regulators allow improved voltage control } \\
\text { and integration of DER. }\end{array}$ \\
\hline $\begin{array}{l}\text { Smart power measurement } \\
\text { devices-current } \\
\text { transformers (CT) and } \\
\text { potential transformers (PT) }\end{array}$ & $\begin{array}{l}\text { Improved power quantity measurement allows greater visibility onto the } \\
\text { distribution system by operators, and it can improve reliability, power } \\
\text { quality, and levels of DER integration. }\end{array}$ \\
\hline ADMS & $\begin{array}{l}\text { Advanced distribution management systems, in whole, promise } \\
\text { significant improvements in system operations, losses, power quality, } \\
\text { and improved reliability. }\end{array}$ \\
\hline DERMS & $\begin{array}{l}\text { Distributed energy resources management systems promise greater } \\
\text { control and increased levels of DER integration, and they also afford } \\
\text { greater control of power quality. }\end{array}$ \\
\hline AMI & $\begin{array}{l}\text { Advanced metering infrastructure improves system operations by } \\
\text { reducing meter reads, increasing billing accuracy, enabling theft } \\
\text { detection, enabling load control, and providing information that helps } \\
\text { forecast future usage. AMI improves customer service by improving } \\
\text { billing accuracy, providing faster service restoration, and enabling } \\
\text { flexible billing and time-based rate options that can save the customer } \\
\text { money and support load control for the utility (EPRI 2007). }\end{array}$ \\
\hline $\begin{array}{l}\text { Advanced controls for load } \\
\text { tap changers (LTC) }\end{array}$ & $\begin{array}{l}\text { LTCs control the voltage levels on a substation, and they are very } \\
\text { common for many utilities. Advanced controls allow greater voltage } \\
\text { control and better power quality, but also can improve DER integration. }\end{array}$ \\
\hline
\end{tabular}

a See Kothandaraman, lyer, and Subramanian (2002) for more information.

b See examples of these at "Products: Reverse Lookup," Schweitzer Engineering Laboratories, https://selinc.com/products/?configurable.yes.

These smart grid technologies are examples of systems being deployed by utilities, and the criteria that help determine which systems are deployed represent a starting place for decisionmaking. But, often the most impactful approach is for one utility to meet with a similar utility and share experiences. Most utility personnel are very interested in what their counterparts are doing at similar utilities, and they are often willing to share experiences to gain new perspectives. 


\section{Customer Premises}

Users of electricity routinely impact power system reliability and sustainability by dictating rates of load growth, adopting energy efficiency measures, choosing the retail tariff they would like to be billed under, and participating in other DR programs. ${ }^{11}$

Energy efficiency and other mechanisms for tempering load growth contribute to system reliability and sustainability by reducing the need to build new generators. With less load growth, higher planning reserve margins can be achieved with less investment on the utility side and likely with less investment overall, assuming almost all energy efficiency investments have positive returns. Emissions should also generally be reduced, assuming some of the saved electricity would have been generated using fossil fuels. As power systems become more and more decarbonized, the sustainability benefits of energy efficiency may become less clear, in the sense that its ultimate impact on the overall system will be more entangled with flexibility and other time-dependent considerations. However, in the main, less electricity consumed means fewer natural resources exploited.

Demand response - both traditional implementations that rely on interruptible load or time-ofuse tariffs and more recent or emerging versions that rely on some combination of customer aggregation, direct load control, real-time pricing, and sophisticated energy management systems - can improve system reliability by serving as a peak net load resource. This service can take several forms in both its procurement and deployment, but it essentially amounts to counting DR as firm capacity (or a reduced peak load forecast) in planning processes or capacity auctions and then actually deploying that DR in times of high wholesale prices or emergency/contingency.

For example, in the 150-GW PJM system, there are 12,866 unique MW of DR capacity (PJM. 2016a; McAnany 2016). Some of that capacity participates primarily in energy and ancillary service markets, but most of it $(11,635 \mathrm{MW})$ participates in what PJM calls their "load management" programs, which are called on during reliability events. In some years, that capability is not called on at all. In many years, it is called on a few times (five times or fewer per resource). And, in exceptional circumstances, it is relied on heavily to provide basic reliability, but still, fewer than ten times per resource per year.

For example, during an extended period of cold weather in January 2014-when a polar vortex occurred - there were six load management events, with calls for from $140 \mathrm{MW}$ to 3,042 MW, which helped meet a higher-than-usual load while the generation fleet was crippled by coldweather operational issues (PJM 2016b). ${ }^{12}$ Also, while PJM is exceptional in the degree to which it has integrated demand-side resources into its economic energy and ancillary service operations, capacity payments are still the biggest source of DR revenue, comprising 98\% of DR market revenue in 2015, and about $90 \%$ of revenue even in 2014 when DR saw significant levels of dispatch (McAnany 2016). Overall, in the regions of the United States served by ISOs and

\footnotetext{
${ }^{11}$ Also, at the premises level, unsafe or illegal practices may negatively impact system quality, reliability, continuity, and safety.

12 More than 40 GW of PJM's 180 GW were unavailable (PJM 2015).
} 
RTOs, the Federal Energy Regulatory Commission (FERC 2015) reports that about 6\% of peak demand is available to serve as a capacity resource.

Some forms of DR do not simply reduce load but rather shift load from one period to another. At low renewable penetrations, this type of DR tends to increase emissions by shifting generation from gas generators to coal. However, as more zero-marginal cost renewable resources are integrated, DR-based arbitrage shifts loads to times of surplus renewable generation, thereby reducing curtailment and emissions. Hummon et al. (2013) demonstrate DR increasing the dispatch of coal generators, decreasing dispatch of natural gas generators, and leaving wind and solar dispatch unchanged for one particular test case. Denholm et al. (2013) explicitly show an increasing emission to decreasing emissions crossover point from the addition of a storage resource to a test system simulated at various wind and solar penetrations.

Thus, the operation of DR resources can improve reliability and continuity in times of peak net load or contingencies. The sustainability impacts of energy shifting DR depends on system composition, and of course, grid operation rules. Under a basic least-cost framework without a price on carbon, DR will typically increase emissions from low renewable systems and will decrease them when more wind and solar generation is present. A nuanced sense of timing with regard to the simultaneous deployment of DR and renewables, or rules formulated to dampen the negative emissions impacts of quicker DR deployment timelines, may be in order, depending on the relative importance of system efficiency and sustainability.

\subsection{Driver 2: Quality of Supply}

Power quality is often measured by a utility as maintaining voltage levels within normal operating boundaries (often a nominal level of $+/-5 \%$ ), maintaining frequency of the system, minimizing outages, and controlling undesirable harmonic currents that can cause serious damage to customer equipment and the utility system. Organizations such as IEEE ${ }^{13}$ and the IEC $^{14}$ have working groups that have developed and maintain standards that support power quality metrics and operations.

Quality of supply, or simply power quality, is a critical metric for any utility and its customers, because poor power quality can result in higher energy consumption, overheating of equipment, an increased number of outages, and often damage to both utility and customer equipment. Damage to any equipment can then cause disruptions in goods, services, quality of life, and safety if power disruptions are extensive. Therefore, those making any Smart Grid deployments should consider the impact to the utility and utility customer.

Ultimately, all smart grid measures will have direct or indirect impacts on power quality. All utility organizations in Mexico need to agree to and adopt suitable power quality standards and the operators must strive to maintain.

\footnotetext{
${ }^{13}$ See, for example, "IEEE Power Quality Standards," Power Standards Lab, http://www.powerstandards.com/IEEE.php.

${ }^{14}$ See, for example, "IEC Power Quality Standards," Power Standards Lab, http://www.powerstandards.com/IEC.php.
} 
A variety of smart grid measures can improve power quality. In some cases, they are completely new technologies; in other cases, the measures are simply intelligent upgrades to existing technologies. Table 13 highlights a subset of the previously discussed transmission and distribution smart grid measures that can be employed to improve power quality.

Table 13. Smart Grid Distribution Measures Affecting Power Quality

\begin{tabular}{|l|l|}
\hline Smart Grid Measure & Expected Area of Improvement \\
\hline Intelligent capacitor controls & $\begin{array}{l}\text { Advanced controls help keep voltage levels and VAR flow levels at } \\
\text { appropriate settings, improving power quality, VVO, and DER } \\
\text { integration. }\end{array}$ \\
\hline $\begin{array}{l}\text { Voltage regulators controls with } \\
\text { bidirectional capability and co- } \\
\text { gen modes }\end{array}$ & $\begin{array}{l}\text { Advanced controls for voltage regulators allow improved voltage } \\
\text { control, integration of DER. }\end{array}$ \\
\hline $\begin{array}{l}\text { Smart power measurement } \\
\text { devices: current transformers } \\
\text { and potential transformers }\end{array}$ & $\begin{array}{l}\text { Improved power quantity measurement allows greater visibility onto } \\
\text { the distribution system by operators. And, it can improve reliability } \\
\text { and power quality, and can increase levels of DER integration }\end{array}$ \\
\hline ADMS & $\begin{array}{l}\text { ADMS systems, in whole, promise significant improvements in } \\
\text { system operations, losses, power quality, and improved reliability. }\end{array}$ \\
\hline DERMS & $\begin{array}{l}\text { DERMS systems promise greater control and increased levels of } \\
\text { DER integration, and they also afford greater control of power } \\
\text { quality. }\end{array}$ \\
\hline AMI & $\begin{array}{l}\text { AMI supports system monitoring that can quickly detect voltage } \\
\text { issues and power quality problems. }\end{array}$ \\
\hline Advanced controls for LTCs & $\begin{array}{l}\text { LTCs control the voltage levels on a substation, and they are very } \\
\text { common for many utilities. Advanced controls allow greater voltage } \\
\text { control and better power quality, but they can also improve DER } \\
\text { integration. }\end{array}$ \\
\hline
\end{tabular}

\subsection{Driver 3: Energy Efficiency}

As reflected under Driver 3 in Table 11, energy efficiency can be enhanced by Smart Grid at either the retail or wholesale level, that is, at the customer level or upstream from the customer. The wholesale electric system will save energy by becoming more efficient at the generator, transmission, or distribution level. Those efficiencies are characterized in other parts of this report. For that reason, this section addresses energy efficiency at the customer level.

The meter is essential to customers' improved energy efficiency. The growth of customer efficiency programs, time-sensitive customer rate structures, and DR programs will depend on having frequent and accurate data from an advanced meter.

\subsubsection{The Meter}

If a utility uses the metering platform to support communication with grid technology, a utility must consider whether the metering system can handle grid communication as well as meter reading. 
In addition, a metering system should support industry standard protocols, such as the InterControl Center Communications Protocol ${ }^{15}$ or the Distributed Network Protocol. ${ }^{16}$ If a metering system supports existing standards, a utility can more easily integrate the metering communication platform with existing systems such as distribution automation or SCADA systems. Supporting industry standards allows a utility to integrate hardware from various vendors and/or integrate multiple systems. A metering vendor that requires use of its own grid hardware — rather supporting industry standards — represents a warning sign.

Utility metering systems are communication platforms. A technology evaluation for smart meters should start with utility use cases and then map those use cases to system requirements. The system architecture for a smart meter system is critical because metering system design, its level of capability, and how the metering system is implemented will all determine how useful it is to the utility.

Typical use cases for a utility include the following:

- Metering: Typical AMI systems transmit meter reads from every five minutes to every hour.

- Distribution Automation: Several metering systems can support grid devices on their communication platforms, so utilities can deploy technologies such as line sensors and capacitor bank controllers on their metering communication platform.

- Home Energy Management Systems: Metering systems often have home energy management capability by which the utility can manage devices in residences through the metering communication platform.

- DER Integration: As DERs become more prevalent, the need to communicate with components such as PV inverters, storage inverters, and electric vehicles becomes necessary. A utility may use the metering communication platform to communicate with DERs and renewable energy generating facilities (e.g., California Rule $21^{17}$ ), in which case that capability becomes a criterion for meter selection. A utility may not need to communicate with renewable generation components directly; however, the ability to measure and sense bidirectional power is needed in many new meter deployments.

- System Maintenance: Many metering systems have upgradeable firmware and software, so metering systems should be able to provide over-the-air upgrades to meters, access points, grid-level components, and connected devices behind the meter.

Establishing well-defined requirements is critical when selecting a smart meter system. The necessary system capabilities are determined by examining use cases and determining the system functions needed to implement those use cases.

\footnotetext{
15 The Inter-Control Center Communications Protocol or ICCP is an international standard for data exchange over wide-area networks between utility control centers, utilities, power pools, regional control centers, and non-utility generators.

16 The Distributed Network Protocol or DNP3 is a set of communications protocols used between components in process automation systems. Its main use is in utilities such as electric and water companies.

${ }^{17}$ See "Rule 21 Interconnection," California Public Utilities Commission, http://www.cpuc.ca.gov/Rule21/.
} 
If certain functionality is not needed in the short term but may be needed later, it is important that the systems being considered can either implement those features now or implement them in the future via over-the-air upgrades.

Finally, any functionality advertised by a metering or communication system vendor should be available for demonstration with actual hardware, and it should be ready to implement in the field in the short term.

\subsubsection{Metering System Technology and Standards}

\section{Communications}

AMI metering systems in the United States typically use the unlicensed spectrum at 900 megahertz (MHz). Some older systems use $450 \mathrm{MHz}$ or $2.4 \mathrm{GHz}$ radios, but these are not as commonly used. Raw data throughput in these metering systems ranges from 100 kilobits per second (Kbps) to 1 gigabit per second (GBps). The bandwidth capability will reflect the age of the system or the sophistication of the system design. The higher the throughput, the more capable the system is. Better throughput allows the implementation of multiple features, with multiple technologies, without causing degradation in system performance or reliability.

\section{Security}

The meter is considered the firewall into the utility, and metering systems implement security by using industry standards, such as IPv4 (Internet Protocol Version 4) and IPv6 (Internet Protocol Version 6), as well as AES, the Advanced Encryption Standard. Metering systems that use their own technology to communicate with the metering end point instead of an industry standard such as IPv4 or v6 may introduce vulnerabilities that are unknown until they are tested.

Metering systems are more secure when they use industry-accepted methods of encryption, such as AES. Any utility should hire an independent third-party security firm to conduct objective penetration testing to verify that metering system's security implementation is successful and secure.

\section{System Maintenance}

Over-the-air upgrades are critical to any metering system, so a request for proposal should include a demonstration of system upgrades, metering firmware upgrades, meter program upgrades, and home energy management system or inverter upgrades if required. When any metering system is demonstrated, a utility should require the vendor to refer larger clients that have conducted such upgrades. As part of the request for proposal, a utility considering a metering implementation should contact these large metering clients and walk through the upgrade process with them. It is very valuable to learn from the experience of those who have implemented — and have upgraded—large-scale metering systems.

\section{Web Access and Data Warehouse}

Finally, meters that execute readouts every five minutes or every hour produce a great deal of data. Different communities have different requirements for data retention, but regardless, metering data becomes very large very quickly. So, a utility considering a metering deployment should also plan on implementing a data warehouse. 
Another factor of smart meter implementation is customer access via a website or mobile application. This type of implementation should be supported through a data warehouse and not through a transactional billing system. These considerations should be included up front in the metering system design and should be planned on throughout the implementation.

\subsubsection{Demand Response}

DR is emerging as a critical component for system operators, as it allows greater flexibility regarding when and where loads consume power on the grid while allowing consumers the option to use power when costs are lower. Though DR programs are often designed and deployed by third parties rather than utilities, they often utilize communications, control systems, and technologies that are outside the utility system. Most DR is aimed at load relief at the system level rather than the distribution level, but that may change as utility operators find new methods of using the more granular approach that may yield load relief at the feeder level. Studies from Sweden, in which DR/DSM solutions are based on temperature control systems from Swedish company Ngenic, concluded economic savings are mainly to be found in energy conservation and in cost savings from shifting demand to lower-cost periods in time (Persson et al. 2012).

The system operator can leverage the installation of smart meters and the detailed information these devices provide through DR programs such as demand bidding and market participation for capacity and ancillary services. Access to a web-based provision of energy prices via the internet - such as via OASIS, Organization for the Advancement of Structured Information Standards - is necessary to effectively and efficiently allow consumer participation.

Demand bidding allows consumers to bid on specific load reductions in the electricity wholesale market. A bid is accepted if it is lower than the market price. When a bid is accepted, the customer must curtail his or her load by the amount specified in the bid or face penalties. Capacity market programs are offered to customers who can commit to providing prescheduled load reductions when system contingencies arise. Participants usually receive a day-ahead notice of events and are penalized if they do not respond to calls for load reduction. Ancillary services market programs allow customers to bid on load curtailment in the spot market as operating reserve. $^{18}$

However, because the system operator does not have physical control of the customer's load response, information on the actual performance of DR resources during system emergencies or in response to high prices is crucial to assessing the long-term viability of DR resources. For these resources to be treated comparably to traditional generation assets, system operators must be confident that nontraditional resources perform in consistently and predictably. Measurement and verification, enabled by AMI, offers all market participants, and especially system operators, the opportunity to tangibly recognize the value of DR.

\footnotetext{
${ }^{18}$ U.S. Department of Energy, "Benefits of Demand Response in Electricity Markets and Recommendations for Achieving Them," Report to the United States Congress, February 2006. https://eta.lbl.gov/publications/benefitsdemand-response-electricity.
} 
DR may reduce unwanted loading of electrical networks. In fact, it provides system flexibility that may be used to optimize use of network assets and to balance loading of generation units. In a particular moment, there may be multiple purposes for which DR could be used.

Smart grid systems can provide utility operators and consumers with situational awareness during times of grid stress or limited energy availability (e.g., during a large power plant outage). Thus, any devices that can monitor system conditions, such as AMI or ADMS, can help inform utility operators of potential or real problems with feeders or substations, or even system-wide problems. That information can be conveyed to DR system operators so that loads can be shed appropriately.

Communications systems that support Smart Grid deployment, such as PLC technology, as well as the communication capabilities of some AMI systems, may be leveraged to help control devices for DR on a distribution feeder.

There are several international networks in the DR and DSM areas. The International Energy Agency (IEA) has a "technical collaboration programme" named IEA DSM in which several organizations and countries are represented. The International Smart Grid Action Network (ISGAN) ${ }^{19}$ is another technical collaboration programme with international participation. Furthermore, in industrial collaborations such as the Global Smart Grid Federation, national smart grid alliances are represented.

For the Mexican market, it is likely that U.S. DR and DSM companies will be most active. A collection of service providers in the Nordic countries can be found in THEMA Consulting Group $(2014,47)$. A list of DR services and some DR service providers are found in Table 14.

Table 14. Demand Response Costs in Selected Nordic Countries.

\begin{tabular}{|l|l|l|c|c|}
\hline Country & Service Provider & Product & $\begin{array}{l}\text { Installment } \\
\text { Cost (euros) }\end{array}$ & $\begin{array}{l}\text { Fixed Monthly } \\
\text { Cost (euros) }\end{array}$ \\
\hline Finland & Helsingin Energia & $\begin{array}{l}\text { Termo home } \\
\text { automation }\end{array}$ & 600 & 6.00 \\
\hline Finland & Fortum & Fortum Fiksu & 124 & 15.00 \\
& & & 8.95 \\
\hline Norway & Lyse Energi & Smart Heating & Control & 4.75 \\
\hline Norway & Lyse Energi & Smart Light & 1,000 & 3.50 \\
\hline Sweden & Ngenic & Ngenic Tune & 550 & 0.00 \\
& & & 333 & 5.50 \\
\hline
\end{tabular}

(Nordic Council 2014)

\footnotetext{
${ }^{19}$ For more information about ISGAN, see http://www.iea-isgan.org/.
} 


\subsection{Driver 4: Electricity Losses}

As noted previously, Mexico's electricity losses from both technical and nontechnical causes are significantly larger than those of the industry on average. The losses affect both the cost of electricity to the system ${ }^{20}$ and the equity of prices charged to customers who pay their electric bills. ${ }^{21}$ Smart grid measures can contribute to lowering the level of electrical losses in various ways, including those described in this section.

\subsubsection{Nontechnical Losses}

AMI systems have alarms that indicate when a meter has been disconnected or tampered with, alerting the utility to a potential power theft attempt.

With electromechanical meters, power can be stolen by unplugging the meter and turning it upside down. However, newer meters will operate efficiently and not malfunction if turned upside down, so this method of theft is circumvented with the advent of AMI.

Metering systems now contain logic to evaluate meter readings to analyze whether the usage is typical for that user or is somehow unusual. If a metering system does not have this logic, a meter data management system usually will. The objective of this type of system is to alert the utility when a meter reading is unusual. This will occur when power usage drops dramatically or increases in an out-of-the-ordinary manner. Such data logic, analytics, and usage evaluation can help identify theft.

Since 2011, BC Hydro ${ }^{22}$ has installed 1.93 million smart meters, replacing more than $99 \%$ of its customers' meters. One of the drivers for the project was to detect and reduce energy theft (nontechnical losses). They projected a 75\% reduction in electricity theft by the end of fiscal 2016 , and they are now approaching theft reductions of more than $80 \%$. Nontechnical energy losses have been significantly reduced from $850 \mathrm{GW}$ per year to nearly $175 \mathrm{GW}$ per year (BC Power Hydro Smart 2016).

According to Forbes (Kelly-Detwiler 2016), the new network of smart meters allowed BC Hydro to turn these losses into a mathematical problem. Elizabeth Fletcher, BC Hydro's Deputy Director of Smart Metering and Infrastructure Programs, said that with the new data, BC Hydro can "analyze energy going into a part of grid, and compare it with what is being consumed, plus technical losses, and determine where in fact there is energy that is missing... We can isolate sections of grid." BC Hydro created an application to analyze the massive amounts of data, including some two million measurements per day, with an integrated geospatial interface to pinpoint energy theft.

\footnotetext{
${ }^{20}$ Technical losses consist of energy lost to the system, which raise the cost of electricity for all.

${ }^{21}$ Nontechnical losses consist primarily of electricity theft and non-payment of bills.

22 The BC Hydro and Power Authority is a Canadian electric utility in British Columbia generally known simply as BC Hydro.
} 


\subsubsection{Technical Losses}

\section{Transmission}

With increased congestion on transmission line corridors and the increased costs and regulations associated with laying new transmission lines, generator dispatch and power transfer are not optimal. This leads to a high cost of generation and transmission of electricity and to high losses. The maximum carrying capacity of a transmission line is defined as the thermal limit. The transmission lines are typically limited by voltage and small signal stability considerations.

On top of these constraints, system planners and operators impose operating margins that are often very conservative, thereby further limiting the line capacity. However, the use of DLR technologies can increase the efficient use of an existing transmission network and mitigate transmission congestion (DOE 2014b). These technologies enable operation of the lines closer to their "true stability" limits rather than imposing conservative margins. These technologies also include dynamic security assessment whereby the security of the grid operation is evaluated on a real-time basis. This reduces the need for conservative margins on power system operation, including reserves and line capacities. The effect is to reduce the overall cost of operation and extract maximum value from the assets without adversely impacting grid security. Additional information on this topic is provided in Section 6.5.2.

\section{Distribution}

The distribution system should be operated with safety, reliability, power quality, and costeffectiveness in mind. Grid operators focus on restoring power after an unplanned outage, but during normal operations, they focus on maintaining power quality and voltage levels. Several of the smart grid measures previously noted will support efficient grid operations, and some may help reduce losses on the system.

AMI systems have been very useful for utilities that employ comparative methods to measure technical losses on a feeder or substation. If the total energy consumed on a circuit is compared to the total energy supplied at the substation feeder head, the loss can be accurately calculated and compared with similar feeders. If the difference is significant, there may be reason to suspect nontechnical theft of power on the system rather than technical losses only associated with line losses or heating of equipment. Once theft is identified, AMI can help pinpoint where the theft is occurring.

Voltage level control is a primary component of helping reduce system losses; thus, VVO is a potentially powerful tool that could be used to reduce losses. VVO methods, enabled by smart grid technologies, leverage voltage regulators, LTCs, capacitor banks, and measurement devices to reduce overall losses and reduce customer consumption levels. One utility estimated that with some field verification, a $1 \%$ reduction in nominal voltage resulted in a $1 \%$ reduction of system losses (NEMA n.d.). Smart grid devices that may help VVO methods include:

- Improved LTC controls with remote measurement feedback systems

- Voltage regulator controls with SCADA or other communications

- Capacitor controls that maintain VAR supply and balance voltage levels simultaneously 
- AMI systems that allow system operators to monitor service voltage levels and help control voltage regulation systems

- ADMS, which can utility a host of equipment and monitoring devices and offer holistic feeder control for optimized VVO

- DERMS systems that provide control and feedback to DG systems and assist in controlling local voltage levels.

\subsection{Driver 5: Efficient Operation of National Electric Grid}

\subsubsection{Bulk Power Level}

Bulk power operations are most economically efficient when load and variable generation forecasts are accurate, demand elasticity is captured with demand (demand-side) or DR (supplyside) bids, and generators bid their true marginal costs and flexibility. Smart grid elements such as additional and higher-fidelity sensors, fast communications, better algorithms, and improved software interfaces play into this by improving forecasts and enabling demand-side aggregation.

Variable generation forecast improvements, especially on the order of hours to days out, involve pairing weather forecasts with particular wind and solar plant characteristics represented by some combination of physical plant modeling, statistical modeling (e.g., regression, exponential smoothing, and time series modeling) or machine learning techniques (e.g., neural networks and support vector machines). The appropriate forecasting methods vary somewhat by technology. For example, while simple persistence forecasts are remarkably accurate for wind on short timescales (one minute to a few hours out), to be applicable to solar plants, the persistence heuristic must be applied to the fraction of clear sky output rather than the absolute output to account for the obvious diurnal and seasonal patterns (Soman 2010; Ibanez et al. 2012).

Furthermore, for solar plants, cloud motion forecasts derived from satellite imagery provide significant forecast improvements in the two- to five-hour-ahead timeframe. This is in comparison not only to fraction of clear sky output persistence forecasts but also to using numerical weather prediction data, which only becomes the most accurate forecasting method for solar for forecasts that are at least six hours out (Pelland et al. 2013).

This is like the period in which weather forecasts become important components of wind forecasts. Wind differs from solar, however, in that there is no equivalent measurable feature like cloud cover that can significantly improve forecasts one to six hours out. Typically, machine learning or statistical methods are used to improve wind persistence forecasts in those timeframes (Soman et al. 2010).

A whole different set of problems and questions arise with distributed solar. In particular, how should distributed solar be folded into load forecasts? Will explicit visibility enabled by smart grid communications eventually be needed? Will curtailment be necessary? Without adding additional communications, either existing load forecasting methods can, over time, adapt to the PV being added to the system. Or, distributed solar profiles can be proactively forecast, assuming the institutions in charge of PV interconnections maintains a locational database of installed systems. 
California $^{23}$ and Hawaii ${ }^{24}$ have both started down the path of the latter approach, recently adding behind-the-meter solar forecasting to their energy management systems. In addition to making use of data on PV installations, the forecasting methods are also calibrated with (partial) measurements of both actual PV production and net load. Comparing net load at particular substations on clear and cloudy days can be especially helpful. However, there do not appear to be any studies describing the extra value being realized by explicitly modeling distributed PV versus having load forecasting methods simply adapt to net load over time (Hoff 2014; Nakafuji, Hong, and Enayati 2014).

At penetrations of distributed PV that are even higher than those California and Hawaii are experiencing, additional communications with at least some systems may be needed, but when and where such capabilities might be needed is purely speculative for now. One-way communications (from the distributed PV systems back to the system operator) would provide explicit visibility into real-time production and real-time on-off status. Upgrading to two-way communication would further enable the system operator to send signals instructing distributed systems to modulate or curtail operations. Smart inverter control settings are likely sufficient to handle system stability needs in the medium term, but centrally issued curtailment orders may be desirable in the longer term.

Some aspects of demand-side elasticity, such as investments in energy efficiency, the effects of different tariff structures (e.g., time-of-use or demand charges), and the capacity value of a collection of interruptible load tariffs can be reflected in demand bids without smart-grid enabled aggregation methods. However, other methods aimed at tapping demand elasticity and flexibility require more large-scale, automatically coordinated communication. On the simple end, critical peak pricing can be implemented by the utility simply sending out mass e-mail and phone (voice or text) notifications. That has been shown to be sufficient to obtain significant responses in several trials (NV Energy 2015).

However, deeper response is generally possible with electronic signals flowing directly to energy displays at a minimum, and also to control-enabled devices such as programmable communicating thermostats or smart appliances (Faruqui, Hledik, and Palmer 2012).

Furthermore, such operator-to-controller signals are necessary for more sophisticated DR programs based on real-time pricing or direct load control; however, the methods for sending those signals can vary.

Real-time prices can be broadcast by the utility either directly to smart-meters or by using internet protocols. Direct load controllers can set the state of equipment directly based on a centrally issued signal. Alternatively, DR aggregators may send their own signals via internet protocol, and those signals may feed into the objective function of a site-wide energy management system, or they may simply adjust one particular appliance (e.g., a programmable communicating thermostat). In these cases, the demand-side dispatch signals reflect what the

\footnotetext{
23 "Integration of Behind-the-Meter PV Fleet Forecasts into Utility Grid System Operations ,” DOE, http://energy.gov/eere/sunshot/integration-behind-meter-pv-fleet-forecasts-utility-grid-system-operations.

24 "Distributed Resource Energy Analysis and Management System (DREAMS) Development for Real-time Grid Operations," DOE, http://energy.gov/eere/sunshot/distributed-resource-energy-analysis-and-management-systemdreams-development-real-time.
} 
demand-side aggregator (e.g., utility or third party) needs to do to fulfill their operational obligations, as determined by the wholesale market or other coordinating mechanism.

\section{Information Systems}

The sophistication of electronic information systems is one of the most important factors for the functioning of effective, efficient, and competitive markets. Information systems can mitigate market barriers by enabling real-time management of energy flows and transactions.

In the United States, OASIS (Open Access Same-time Information Systems) provides information on capacities, prices, transactions, and other variables. This information is essential to facilitate a properly functioning marketplace.

Information systems for electricity can support alternatives to traditional generation, including independent third-party marketers of DG and storage, as well as consumer participation (e.g., DR). Using electronic information, these entities can package capacity and energy services and build flexible arrangements between the distributed suppliers and the system operator to compete with traditional generation.

Markets cannot function properly unless information is accessible. Energy policy may have a role to play in this regard. Regulators, as market facilitators, can target information asymmetries.

\section{Nodal Representation}

Parson et al. (2015) suggest the dispersed nature of the Mexican system may justify nodal representation of the system for transmission and market analysis. In the United States, locational marginal prices are used to evaluate the marginal cost of supplying load at individual locations. Identifying and valuing system constraints may lead to improvements grid efficiency and increased market participation by nontraditional participants. Additionally, by including regionalism - versus single-node transmission-modeling - in resource planning, markets may better incorporate locational differences in fuel price and load growth, as well as resource capability (e.g., geothermal, solar, and wind).

\subsubsection{Transmission Measures}

As we have seen, the efficiency of Mexico's national electric grid can be positively influenced by applying information technologies to the power supply function. Similarly, improvements in the operation of the transmission system can offer large gains in overall system efficiency, providing operators with more options for plant dispatch, load balancing, and loss reduction.

\section{Dynamic Line Rating (DLR) Technologies}

Transmission lines are rated for their load-carrying capacity, which is limited based on the characteristics of the conductor and associated equipment. It can also vary depending ambient temperatures, solar radiation, and wind speed and direction (Aivaliotis 2010). Where traditional static line ratings provide conservative operational limits of overhead transmission-circuits, dynamic line rating (DLR) technologies provide real-time capacity information and measurements of the condition of the conductor, which improves the efficient and safe operation of transmission. 
New York Power Authority (NYPA) and Oncor Electric Delivery Company LLC of Texas (DOE 2014c) each accomplished work through the DOE Smart Grid Investment Grant program to implement technologies collectively referred to as DLR. Comparing DLR to static line ratings "is a bit like comparing a high-tech video to a black-and-white photograph," wrote NYPA in a case study (DOE 2015). Between NYPA and Oncor, four different technical approaches to DLR were demonstrated and evaluated. Both companies confirmed the presence of real-time capacity above the static rating in most instances - with up to 25\% additional usable capacity at NYPA — which was made available for system operations.

\section{Substation Automation}

Substation automation is a broad category of devices and processes that contribute to moreefficient and reliable operation of the bulk power system. Power electronics and control systems coupled with sophisticated algorithms have made significant strides in the area of substation operation. Removing the human element and its capacity for error has resulted in operational improvements and contributed positively to continuity of supply metrics. Furthermore, a decrease in the hours spent working in the field in high-voltage situations has increased safety metrics. However, equipment is generally upgraded and vintage substation elements are generally replaced in stages, and it is difficult to directly attribute performance changes.

Steps for implementing these automation efficiencies include data collection, supervisory analysis, and control. The first step requires instrumentation for each stage of power flow in a substation. The data collected are transmitted to a centralized control center, which makes decisions using algorithms and programming logic. Next, a control command is issued to substation equipment to optimize the power flow. This may be coordinated with any substations on the system, which are also automated for ensuring all elements are performing efficiently and reliably.

\section{Centralized Substation Protection}

Modern protection technologies at the substation level play an important role in maintaining the reliability of power system operations. Each power system component in a substation requires protection against abnormal currents, abnormal voltages, internal faults, external faults, and other unexpected circumstances. In traditional systems, each of these functions is performed by a separate relay. Programmable digital relays are increasingly replacing traditional electromechanical versions; a digital relay can replace several electromechanical relays. Digital relays also provide for the added ease of updating the relay settings and accurately defining the operational characteristics.

The next level of protection digitalization is "centralized protection" architecture, where the idea is to provide a data bus for all field measurements in the substation. Thus, all these measurements are available to all digital relays in the substation. In traditional systems, a current or voltage reading outside a specified range may cause a relay to trip. With centralized systems, an aberrant data read could be checked against other measurements for veracity, thereby improving the reliability of relay operations.

When measurements are unavailable, derived measurements from existing measurements can be used, providing redundancy to these systems. Such a scheme reduces the impact of undetected failures that have enabled blackouts to propagate in the past. Other benefits include improved 
relay asset management, enhanced power equipment management, including condition-based maintenance, and improved cybersecurity from reduced access points (Das 2015).

\section{Intelligent Switch Technologies}

Intelligent switches are smart grid technologies for the distribution system. They enable rerouting of power to minimize the number and duration of customers impacted by outage. Such automated outage detection and management technologies overcome the problems of time delays and crew management associated with manual outage management procedures. Pacific Gas \& Electric (PG\&E), a large utility serving Northern California, installed these switches in $20 \%$ of their circuits through its Targeted Circuit Program. The circuits selected were those most vulnerable to outages. These measures enabled PG\&E to record the lowest outage indices in company's history in $2013 .{ }^{25}$ The upgrades have put the utility in a better position to face future challenges, such as increased penetration of renewables and integration of electric vehicles.

\subsubsection{Distribution Measures}

Significant work has been accomplished in the United States through the DOE Smart Grid Investment Grant program. Such efforts advance the auxiliary systems and communications networks that are essential to the transmission and grid considerations discussed in this section, where two examples illustrate this point.

First, Detroit-based DTE Energy (DTE) significantly increased the scope of its smart grid technology deployment, installing 725,000 smart meters and distribution automation (DA) devices at 11 substations and on 55 circuits (ABB Wireless 2017). Deploying the new devices and systems was not without challenges. DTE underestimated the volume of data generated by the new technologies and its impact on IT needs. DTE partially addressed this challenge by adding IT system capacity. In addition, DTE worked with its vendors to improve the speed and performance of their products by deploying a new bus architecture - the systems that transfer data between different IT components - using the Common Information Model. "This was a cost-efficient solution for us. At some point in time, increasing system capacity by simply adding more hardware becomes cost-prohibitive," explained Tony Melton, DTE's IT Portfolio Manager.

In the second example, the Georgia System Operations Corporation modernized bulk power management and control center operations for 38 electric membership corporations in Georgia. The goals for the project were to improve economics of power transactions, deploy infrastructure to more effectively communicate grid reliability and security information, and defend against cybersecurity threats. The project added a dual-path fiber optic network for enhanced communications, developed new models and data management tools for outage management and cybersecurity, and implemented a new integrated transmission network model for enhanced state estimation and dispatcher training.

25 “PG\&E's Smart Grid Delivers Customer Benefits and Improved Reliability," PG\&E News Releases, October 1, 2014 , https://www.pge.com/en/about/newsroom/newsdetails/index.page?title=20141001_pges_smart_grid_delivers custo mer_benefits and improved_reliability 


\subsubsection{Customer Measures including DR}

Here, the IEC Vocabulary definition of DR is applied: "action resulting from management of the electricity demand in response to supply conditions." It should be noted that IEC defines the related term DSM as, "process that is intended to influence the quantity or patterns of use of electric energy consumed by end-use customers."(IEC 2018). Although the definitions to a large extent conceptually overlap, DR may be seen as focusing on load shifting in time, whereas DSM is that plus demand reduction/energy conservation.

Navigant Research (2017) has ranked top DR service providers for residential customers (Figure 16). It should also be noted that many new companies, including those from the digital communications sector are continuously entering the area.

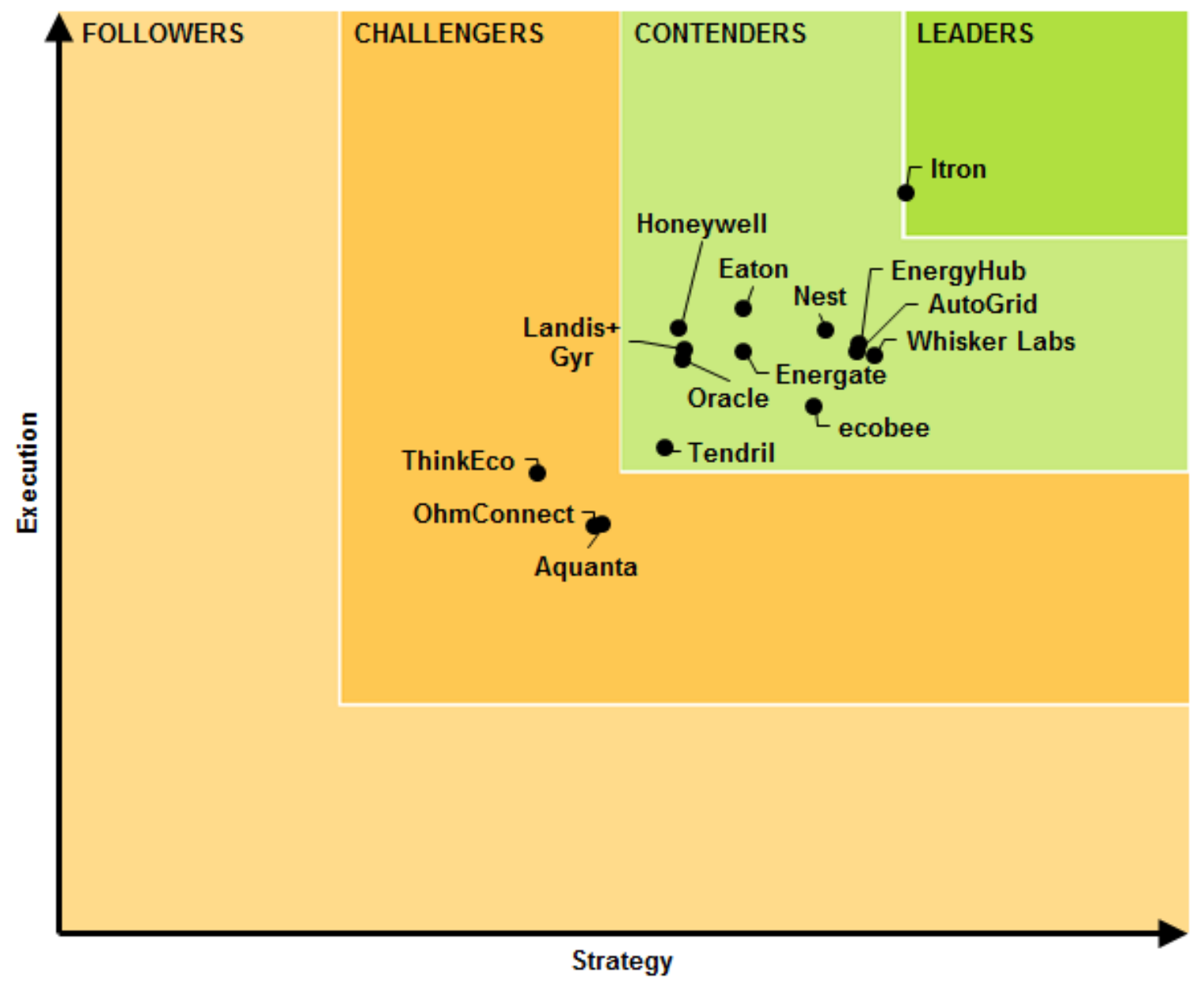

Figure 16. Navigant ranking of residential demand response providers

(Navigant Research 2017) 


\subsection{Driver 6: Clean Energy}

\subsubsection{Renewable Energy Integration}

Renewable energy integration efforts are necessary when renewables reach high penetration levels. Renewable power has variable characteristics and, in some cases, lacks inertia, so a utility distribution management system must manage renewables differently.

Smart Grid can facilitate the integration of renewables in several ways. First, renewable energy integration requires integration of functionality like that specified in Phase 2 of California's Rule 21. This ruling specifies standards for inverter communications, which can enable management functions such as curtailment, emergency shut off, and frequency ride through. Such communications can be direct, with hardware such as inverters. And, some communications can occur through system management using aggregators, such as PV management companies. If a utility wishes to communicate directly with residential or commercial renewable components, this capability should be evaluated in the metering request for proposal. The technology to reach the inverters can vary from cellular, to $\mathrm{Wi}-\mathrm{Fi}$, to $900 \mathrm{MHz}$ (as a meter), or $2.4 \mathrm{GHz}$, like a home energy management system. If a utility manages renewables through companies functioning as aggregators, the utility will specify requirements at the business-to-business level. Aggregators typically use their own cellular or Wi-Fi communication infrastructure, so a utility can use that infrastructure and specify distribution requirements, as well as the required latency and reliability level.

Second, DERMS are another smart grid measure that can help in the monitoring and control of renewable energy systems and can help maximize the amounts of the renewable energy tied to the grid. DERMS are systems that are mostly in the nascent phase. They are akin to the ADMS systems being considered by many utilities. But, there are several smart grid systems that can help improve the levels of integration of clean renewable DG systems. Starting at the substation, smart controls for LTCs and for substation breakers help maintain optimum voltage and protection on a circuit, which are two of the most important metrics when considering DER. Improved microprocessor-based controls with communications and intelligence can greatly improve the conditions on a circuit and thus improve DER hosting capacity.

Third, voltage regulators are used on many distribution circuits, especially where there are longer and more rural circuits. When replacing older controls with smart grid technology, intelligent voltage regulator controls will enable bidirectional flow of energy, allow voltage control in two directions, and can increase the operational flexibility of the system and support DERs.

Fourth, smart grid capacitor controls are critical in helping support voltage and reactive power flow (VAR). With the advent of smart inverters, the use of reactive power absorption methods to increase hosting capacity is becoming very common for utilities with larger amounts of DER tied to distribution systems. Ensuring the capacitors are turned on when needed — and turned off when not needed - is an important consideration for distribution system operators and engineers.

NREL has done significant work on the integration of high penetration of renewables, including wind. Here are some important excerpts from Ela (2013), which discusses the challenges and approaches that can work to permit significant renewable energy integration" 
...through the use of inertial response, primary frequency response, and automatic generation control (also called secondary frequency response), wind power can aid in balancing the generation and load on the system. These active power (i.e., real power) control services have the potential to assist the electric power system in terms of disturbances and during normal conditions while also potentially providing economic value to consumers and variable renewable generation owners.

Wind turbines can provide an inertial response similar to that of conventional generators by using energy stored in the rotating blades or capturing more energy from converters...The controls on the power electronics-based converters sense the frequency drop and then determine the appropriate increase in power output. Although wind plants are not widely required to provide inertial response, some plants in Quebec do so. Unlike wind turbines, solar energy systems do not have rotating masses, so they require auxiliary energy to provide a similar response.

When equipped with governor-like controls, wind generating plants can contribute to grid frequency through torque or pitch control. Solar plants can provide this entirely through electronic controls. Wind and solar plants respond best to grid frequency increases, which require a drop in power generation. They can provide primary frequency response to frequency drops, which require a power increase, only when they are operating below maximum output levels. Such curtailment of energy could have a significant economic impact on a wind or solar plant. Although primary frequency response from wind and solar plants is not widely required, some wind plants in Texas do provide frequency response because of recent requirements in the Electric Reliability Council of Texas.

Wind generators can respond to automatic generation control signals to provide regulation service, although they do not typically do so today. In the same way that wind turbines can provide frequency response, their blades can be pitched to rapidly increase or decrease output. However, to be able to increase output, they must be scheduled below maximum power output. To date, the primary growth in solar energy penetration has been on the distribution grid. As solar energy penetration increases on the transmission grid, the ability of solar plants to provide regulation could become more important.

Active power controls are not widely used today by wind and solar generators because economic barriers - including upfront equipment costs, lost opportunity costs, and potential to increase loading impacts on the turbine components discourage their use. Renewable generation operators are not able to justify such costs unless they are compensated for providing these services or are required to do so. In addition, wind and solar generators must operate below full generation output to provide certain balancing services. This has economic consequences. The cost for renewables to provide support services is the lost opportunity cost of generating energy that could be sold into market. Renewable generators have higher opportunity costs than conventional generators that save on fuel costs by not providing power. Thus, wind and solar generators require greater compensation to provide grid support services because otherwise they could provide power to the system from a free fuel supply - the wind or sun. 


\subsubsection{The Role of Storage}

New challenges are created by the increase in renewable energy penetration in the electricity system, which are driven by:

- Increased variable generation of electricity, mainly from renewable energy sources

- Increased electrification of the energy system (e.g., electrification of the transport sector).

The many opportunities to solve these challenges include:

- More flexibility in production

- More flexibility through the use of DSM

- Increased transmission capacity over broader geographic areas allowing sharing of resources

- Energy storage.

Energy storage is a key area of focus whenever Smart Grids are discussed. The main reason electricity storage has become relevant to Smart Grids is the recent dramatic cost reductions in battery storage, which have been driven largely by the electrification of the transport sector.

\section{Leading Storage Technologies}

Beyond traditional large-scale storage technologies such as pumped hydro, we believe that new storage technologies (e.g., lithium-ion batteries and super-capacitors) will become essential, as these technologies are best suited for short-term storage. In addition, there is rapidly increasing interest in local storage combined with PV solar to support trends toward selfconsumption. But, local energy storage could also be used to provide several other services such as peak load reduction, energy arbitrage, and ancillary services to the system. For local storage, lithium-ion batteries will be the natural choice, as the cost performance, which is driven by the development of electric vehicles, is rapidly increasing. A very significant development is that several automotive companies (Tesla, Mercedes, and Nissan) have started offering local storage solutions. These new entrants in the market come from extremely competitive environments, and this will likely drive down the cost for home storage and increase the market uptake.

Super-capacitors will have a role to play where the combination of high power requirements and many cycles are needed. Typical applications could be frequency regulation and short-term storage supporting fast chargers for buses and cars. High-power batteries or super-capacitors can be combined with traditional frequency regulation sources such as hydro to provide initial fast response.

\section{Main Requirements and Challenges}

In the short term, the main focus must be on bringing down the cost of storage and developing new business models that support deployment of the product. But beyond that, there is a need to increase the awareness of how storage can solve challenges in the power system. This awareness must be improved for utility planners and operators who have not operated in an environment in which storage can be cost-effective and can address many problems in the power system. Furthermore, regulators' awareness of this new product must be improved—regulation sometimes presents a challenge by not allowing distribution companies to own storage. 


\section{The Storage Market}

The market uptake for storage is very local. For example, in Germany, local storage is a wellestablished business driven by both incentive schemes and high awareness among customers. The main application is increased self-consumption when storage is paired with PV installations. Other examples of good market uptake are Italy and the UK, where centralized storage is used for ancillary services. For example, National Grid UK has just concluded a bidding round for commercial installation of battery storage for frequency regulation. The total capacity for the project is $200 \mathrm{MW}$, and the pricing appears very competitive with other solutions. The conditions for applying storage are as good in many markets as they are in Germany, Italy, and UK, so we should expect that when the lessons learned from these early adopter countries are disseminated, we will see a rapid market uptake in other countries.

The market for battery storage is growing rapidly. To properly understand the market, it is important to understand that battery storage can be located in many parts of the electric system and also offer so many different services. This is illustrated in Figure 17.

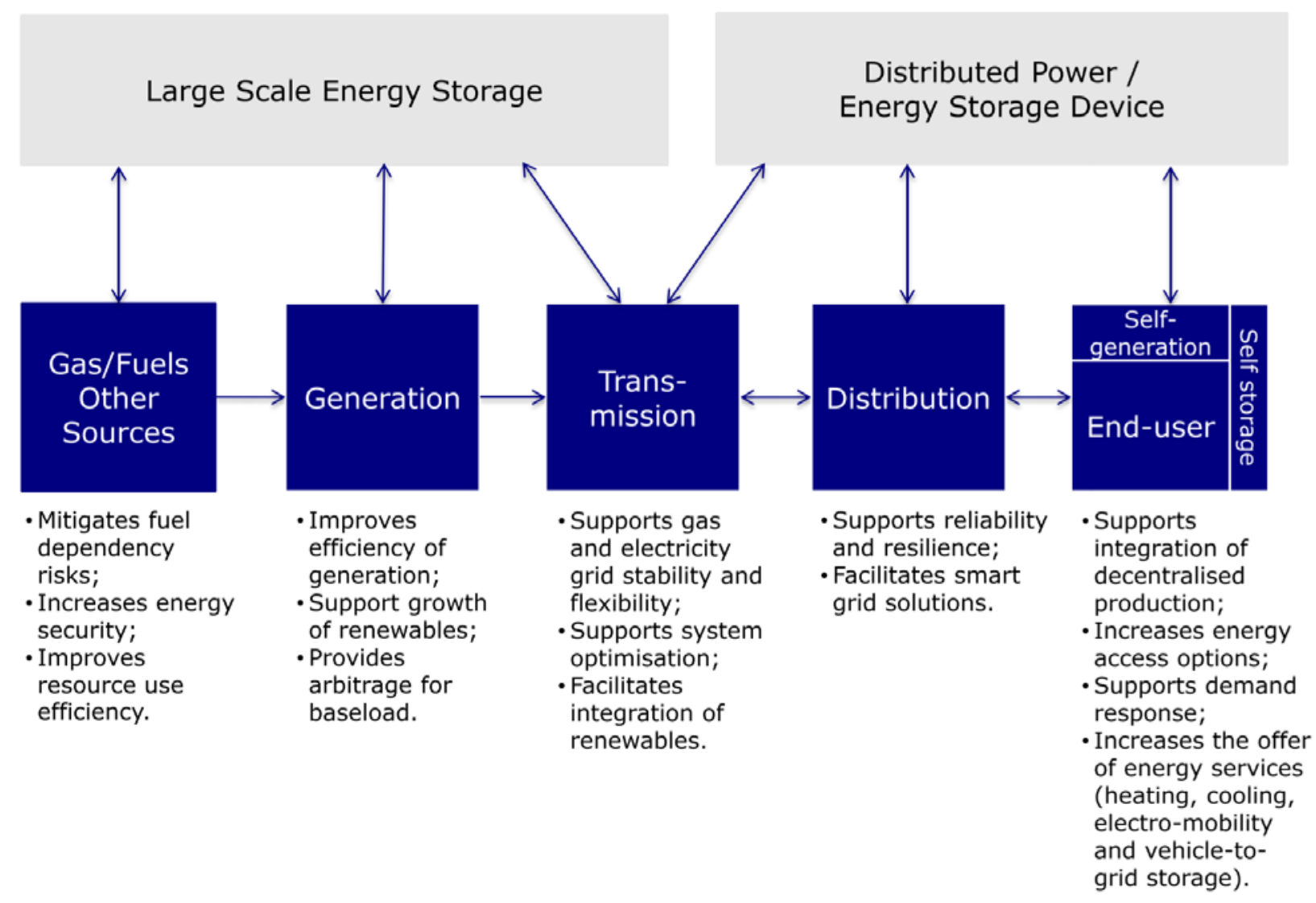

Figure 17. Variety of electrical storage services

(European Parliament 2015) 


\section{Cost of Battery Storage}

It is interesting to dig deeper into the cost for stationary energy storage. The recent price level for stationary batteries is significantly higher than it is for automotive (mobile) storage. Figure 18 is a good illustration of battery cost trends. It suggests that in 2015 the price per $\mathrm{kWh}$ was about three times higher for stationary storage than it was for automotive storage. The batteries for stationary storage generally have a less demanding application in terms of environment and load cycle, and the large price difference can only by explained by limited competition and a small market today. However, it should also be pointed out that the stationary Tesla Wallpack already offers a battery price of USD 350/kWh for a battery system, and competition for this application is heating up.

One reasonable conclusion is that the costs for home storage will drop dramatically, and this will also drive the market for home storage to grow beyond current expectations. Even so, the profitability will continue to be greater in the home storage market for the cell producers for the foreseeable future.

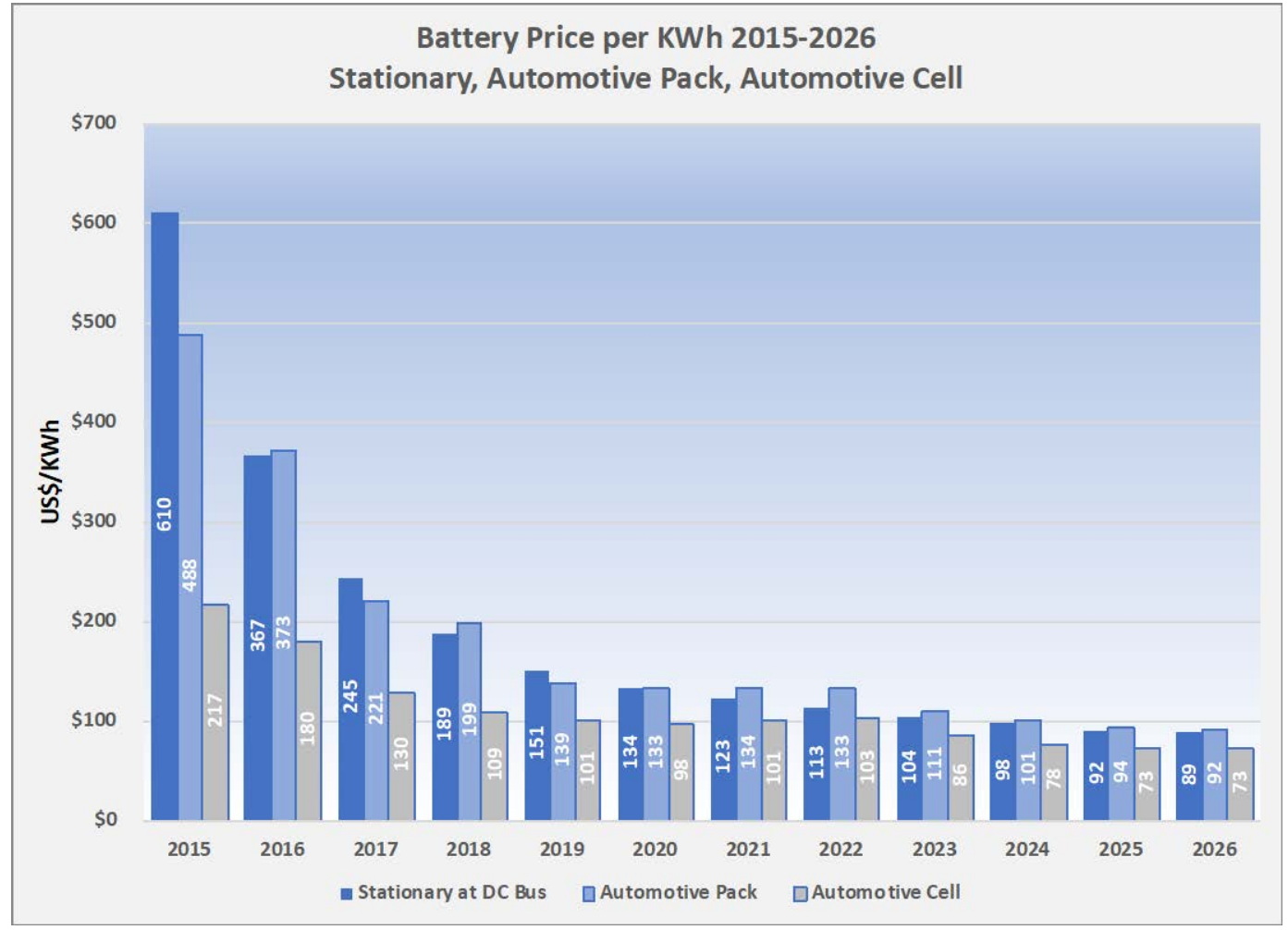

Figure 18. Costs of electrical storage

The figure is by the authors, with data provided by Cairn ERA Advisors in 2018. 


\section{Potential Market for Battery-Supported Frequency Regulation}

Frequency regulation is an important market that could develop quickly where the value is high. National Grid UK has recently purchased 200 MW of stationary batteries to support frequency regulation. ${ }^{26}$ In the United States, PJM has also bought several $100 \mathrm{MW}$ of batteries to support frequency regulation (Haywood Queen 2016). An example is included in Figure 19.

\section{Supply Curve for most beneficial option per site by service type}

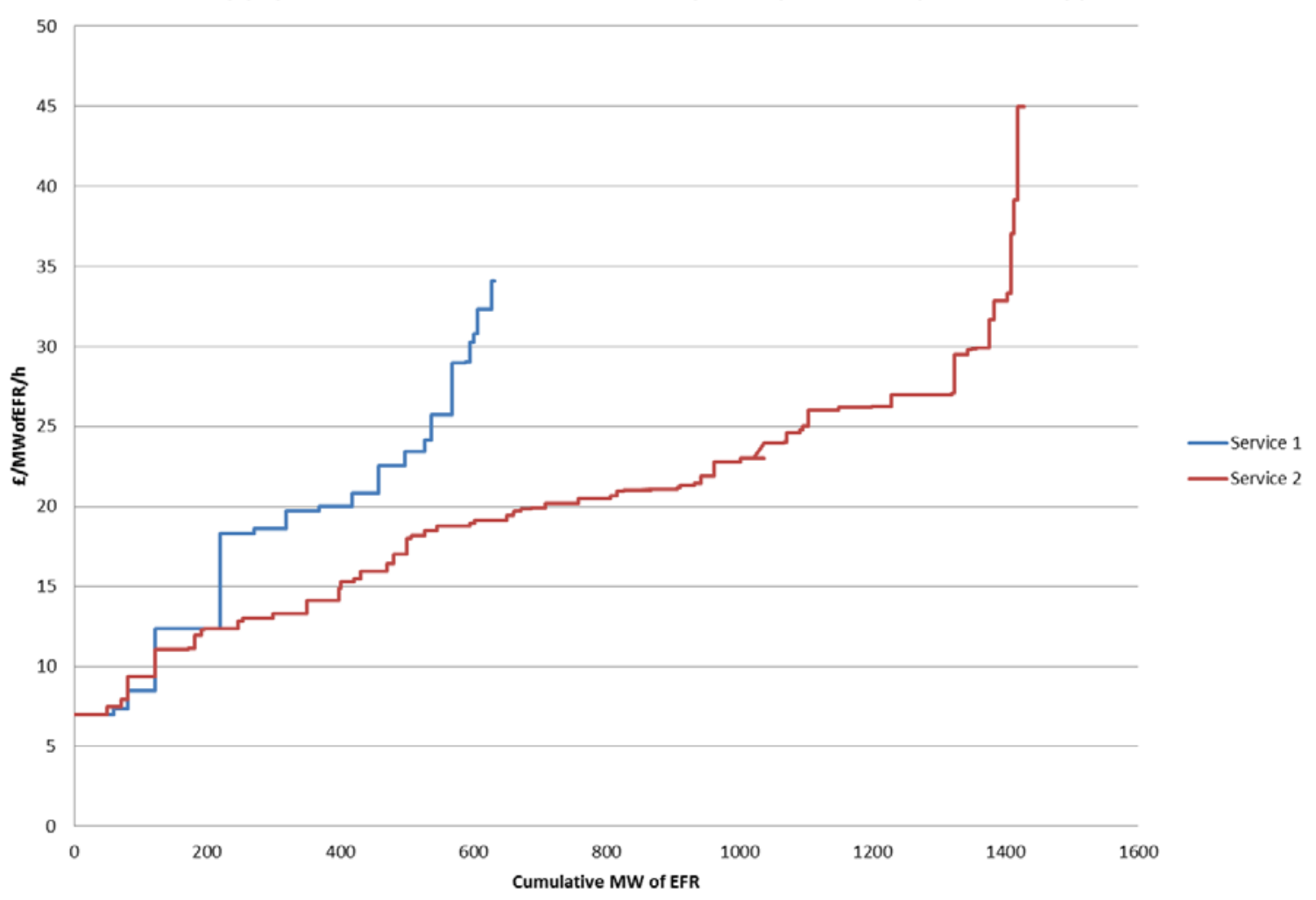

Figure 19. Supply curve for battery-provided regulation service

(National Grid 2016)

$E F R=$ enhanced frequency response

\section{Conclusions on Storage}

As mentioned, there are many ways to solve the new challenges in the electricity system; clearly, there will not be one "winning solution" and many of the mentioned solutions will be applied. But, equally clearly, energy storage in general — and battery storage in particular — will play a major complementary role to smart grid technologies and will help enable a modernized grid. This is driven by many factors, including:

26 "Enhanced Frequency Response," National Grid UK, https://www.nationalgrid.com/uk/electricity/balancing-services/frequency-response-services/enhancedfrequency-response-efr 
- As a result of large improvements in price/performance for batteries in the automotive sector, battery prices have dropped by $80 \%$ in the last decade. Today, complete battery packages are below USD 150/kWh, and prices are expected to fall to below USD $100 / \mathrm{kWh}$ in the next 5-10 years.

- Battery solutions can be deployed more quickly than many competing solutions, such as building additional grids.

- Battery solutions are highly scalable; that is, batteries can be economically deployed from utility-scale installations down to the individual household level.

IT solutions are becoming very inexpensive. This allows aggregation of services, including battery storage services, from many distributed systems, which makes it possible to bundle many services into what appears to the purchaser to be service from a single supplier (e.g., Isono et al 2014).

\subsection{Driver 7: Customer Involvement in System Management}

\subsubsection{Demand Response}

In September 2016, IEA released comprehensive reports on flexible consumers and prosumers, as well as DSM, which are summarized in Table 15. 
Table 15. Report from IEA Task 17: Integration of DSM, Energy Efficiency, Distributed Generation and Renewable Energy Sources

\begin{tabular}{|c|c|c|c|}
\hline $\begin{array}{l}\text { IEA Subtask: } \\
\text { Title }\end{array}$ & Summary & Notes & $\begin{array}{l}\text { Report } \\
\text { Reference }\end{array}$ \\
\hline $\begin{array}{l}\text { Subtask 10: Roles } \\
\text { and Potentials of } \\
\text { Flexible } \\
\text { Consumers and } \\
\text { Prosumers }\end{array}$ & $\begin{array}{l}\text { Overview of roles, } \\
\text { technology } \\
\text { characteristics and } \\
\text { potentials }\end{array}$ & $\begin{array}{l}\text { This report discusses DR-based } \\
\text { drivers of flexibility. Cost structure is } \\
\text { one driver, and the relation of fixed } \\
\text { and dynamic pricing is of importance } \\
\text { for customer incentives. Other } \\
\text { potential drivers from a customer } \\
\text { perspective include carbon } \\
\text { conservation. The report presents } \\
\text { experiences from European countries } \\
\text { and summarizes how U.S. legislative } \\
\text { directives are supporting DR. Roles of } \\
\text { actors in the power system are } \\
\text { presented. The system benefits in } \\
\text { terms of reduced network loading, } \\
\text { balancing, and services for the TSO in } \\
\text { periods of alert operation. Finally, } \\
\text { energy storage in boilers and batteries } \\
\text { are assessed. }\end{array}$ & Stifter et al. 2016a \\
\hline $\begin{array}{l}\text { Subtask 11: } \\
\text { Valuation Analysis } \\
\text { of Residential } \\
\text { Demand Side } \\
\text { Flexibility }\end{array}$ & $\begin{array}{l}\text { Analysis of } \\
\text { business cases } \\
\text { and existing } \\
\text { valuation } \\
\text { frameworks }\end{array}$ & $\begin{array}{l}\text { This report presents several methods } \\
\text { for measuring valuation of flexibility. } \\
\text { It also summaries some sample } \\
\text { valuations of selected smart grid } \\
\text { projects. }\end{array}$ & Esterl et al. 2016 \\
\hline $\begin{array}{l}\text { Subtask 12: Best } \\
\text { Practices and } \\
\text { Lessons Learned }\end{array}$ & $\begin{array}{l}\text { Collection of } \\
\text { demonstration } \\
\text { projects and } \\
\text { country specific } \\
\text { background } \\
\text { information }\end{array}$ & $\begin{array}{l}\text { This report is comprehensive } \\
\text { documentation of demonstration } \\
\text { projects from around the world. }\end{array}$ & Stifter et al. $2016 \mathrm{~b}$ \\
\hline $\begin{array}{l}\text { Subtask 13: } \\
\text { Conclusion and } \\
\text { Recommendations }\end{array}$ & $\begin{array}{l}\text { Reflects the } \\
\text { summary of Task } \\
17 \text { with } \\
\text { conclusions and } \\
\text { recommendations }\end{array}$ & $\begin{array}{l}\text { This report presents conclusions and } \\
\text { recommendations based on findings } \\
\text { in the other reports. Benefits and } \\
\text { potential of flexibility at each level of } \\
\text { the power system are discussed (i.e., } \\
\text { on macro, meso, micro and nano } \\
\text { levels). Finally, the report discusses } \\
\text { how to make valuations of electricity } \\
\text { and energy flexibility. }\end{array}$ & Stifter et al. $2016 \mathrm{c}$ \\
\hline
\end{tabular}

Clearly, market design is essential for the success of DR. Thus, policymakers and the regulator have a key role in creating the right conditions. Preferably, grid tariffs should be designed so the true cost drivers are part of the design. Also, the instant wholesale market price should be reflected in the price for the users. 
It is important that customers have access to their real-time energy data so that they can receive and act on real-time price signals to incentivize decisions that support load management across the system.

\subsubsection{Time-of-Use Rates}

Dynamic pricing for residential electricity use will bring significant advantages to utilities and their customers; the customer response elicited by time-of-use rates will lower overall system cost to the benefit of all consumers. Properly implemented, time-of-use rates are more equitable and will induce customers to use electricity more efficiently. There is no serious debate about these statements.

But utilities and their regulators have notably not moved toward dynamic pricing for residential customers in the United States. The reasons for the lack of movement include concerns about the cost of new metering infrastructure needed to support dynamic pricing and fears of consumer resistance. But, the pressures to move to dynamic pricing are mounting and the foregone benefits are adding up. There are several ways in which regulators might introduce time-sensitive rates in a way that will be acceptable to consumers.

Time-of-use rates have always enjoyed theoretical support. But now, there are several new, practical reasons that utilities and their regulators should move toward them.

- Electrification of Transportation. Demand for electric vehicles will grow steadily over the next two decades. A mechanism is needed to induce or require customers to charge vehicles during off-peak times. Today's time-insensitive residential prices will lead to higher system costs if customers plug in their vehicles after work, adding to the lateafternoon summertime peak load on generation and distribution systems. In the other direction, nighttime energy loads from electric vehicles will be desirable by utilities with significant wind generation.

- Residential Distributed Generation. Residential adoption of DG, especially small-scale solar systems, appears to be accelerating as the cost of systems fall and residential financing options grow. Unless electricity is priced on a time-sensitive basis, the correct value of such DG to the utility system is obscured. Net metering at time-sensitive rates will increase payments to solar systems, permitting utilities to charge compensatory rates to solar customers for distribution service.

- Deployment of Smart Meters and the Associated Market Opportunities. The deployment of smart meters and the arrival of those operating between utilities and their customers will require rational retail pricing of electricity. Time-of-use rates are essential to the new energy markets that will develop because of grid modernization.

- Market for Residential Energy Efficiency and DR Technologies. Usage-sensitive pricing will stimulate the use of home energy management tools. Energy efficiency and residential DR will be boosted by the use of dynamic pricing, which will also be required by vehicle-to-grid transactions.

There may be non-price approaches to each of these challenges, involving separate metering of vehicles, solar panels, and smart appliances. But only dynamic pricing addresses all four considerations simultaneously and consistently. 


\subsection{Driver 8: Additional Service Offerings}

Most of the smart grid applications "upstream" from the customer are relatively well characterized and are being implemented by utilities around the world. Less well understood are new services that Smart Grid will produce for consumers. These new products and services will arrive based on the creativity of smart grid vendors and the evolving appetites of consumers. There are several necessary conditions to enable the growth of those services.

\subsection{Need for an AMI platform}

AMI systems can integrate with home energy management systems, and systems exist to do so in different ways with different technologies and standards. The mix of technologies and standards that is best for any utility is determined by the programs that a utility wants to implement.

In the United States, home energy management systems typically use ZigBee 2.4-GHz radios running Smart Energy Profile 1.x or IEEE 2030.5. Another communication standard used is WiFi, which supports the Open ADR (automated DR) standard. If a utility implements an industry communication standard, customers can purchase compliant devices on their own, without utility involvement. This scenario will work as long as the market supports these standards by producing and selling the compliant devices.

If a utility requires a particular functionality, a metering vendor should be required to show how the functionality currently works and with which supporting devices.

\subsection{Enabling of Smart Grid Vendors to Find a Market}

Consumers will soon be introduced to smart grid applications (apps) provided by third-party vendors. These may entail hardware (e.g., thermostats or motion sensors) but might also be software (e.g., applications to analyze customer usage data). For many customers, the apps will provide a level of control that allows them to affect the time and quantity of consumption without having AMI metering capability.

Allowing third parties to sell such services directly to customers reduces the need for distribution utility investment and thus limits the commitment of ratepayer funds to supporting deployment. Distribution utility DR programs or tariffs can be paired with deployment of the third-party apps to establish a compensation stream for customers that reflects the contribution of participating customers on mitigating system loads. A more favorable system load shape benefits all customers, and thus appropriate compensation from all customers to those who choose to invest and participate in these tariffs is justified.

In the longer term, as third-party aggregators emerge, the apps can be marketed by aggregators as part of an overall retail customer service package. The aggregator recovers the value created by the app by beneficially participating in the wholesale market, the participating customer benefits from having a preferred tariff offered by a competitive provider, and all customers benefit by having low-cost demand side resources bid into wholesale markets.

Government policy should enable and encourage new third-party providers to enter the market in Mexico. 


\subsection{Need for Customer Education}

The success of the modern electric grid will depend in part on the active participation of consumers, or of agents on their behalf, such as aggregators or third-party smart grid providers. Specifically, accomplishing Mexico's energy goals may require a consumer base that is more informed about its energy use. Consumer education can also be used to help achieve less lofty goals, such reducing nontechnical losses caused by theft of electricity.

Channels through which SENER, CRE, CFE, and CENACE might act to build customer knowledge about energy use including:

- CFE-promoted use of customer engagement services such as Opower or Tendril; peer comparison of usage is interesting to customers and familiarizes them with their own electric profile.

- A public information campaign focused on a well-defined message (e.g., a campaign to brand the theft of electricity as socially unacceptable and harmful to others)

- A customer web portal at which customers can, for example, see their bills, pay their bills, estimate the benefits of solar, and learn energy efficiency techniques

- A speakers' bureau of representatives of SENER, CRE, CFE, and CENACE who would available to present at community meetings

- Use of bill inserts or other customer contact opportunities (point of sale for pre-paid services)

- Greater use of social media to engage customers; agencies should engage an expert to ramp up their presence on all social media platforms and convey energy-related messages in a way that is appealing to younger people. 


\section{Analysis of Costs and Benefits for Smart Grid Investment}

\subsection{Cost and Benefits of Smart Grid Investments}

A policymaker will want to examine the cost-effectiveness of smart grid investments. The traditional method for assessing this is called a cost-benefit analysis. This section explores what is known about the benefits and costs of smart grid investment.

First, we distinguish between two levels of analysis: (1) the cost-benefit analysis of Smart Grid as a high-level strategy and (2) the application of cost-benefit analysis to individual smart grid projects consisting of small sets of smart grid measures.

\subsubsection{Cost-Benefit Analysis of Smart Grid as a High-Level Strategy}

One of the more important recent studies of Smart Grid's net benefits was conducted by the Joint Research Centre of the European Union. Their cost-benefit analysis (Giordano et al. 2011) estimated the costs and benefits of extending a small pilot project to all of Rome, Italy. The project was limited to the distribution system operated by Azienda Comunale Elettricità e Acque, the electricity distribution system operator for Rome. The smart grid improvements studied were intended to serve three purposes:

1. Improve system quality and continuity of Rome's energy network through automation systems for fault detection and isolation on the medium-voltage energy network

2. Improve the distribution network observability through monitoring and remote control of the low-voltage energy flows

3. Assess the positive impact of automation with the new grid management criteria.

In other words, the Rome study examined only a fraction of the smart grid activities considered in this report for Mexico.

The results of the cost-benefit analysis for Rome showed that, over an 18-year period, the net present value of the benefits from the project is estimated to be $€ 39.1$ million. This equates to an internal rate of return of $16.67 \%$ (Giordano et al. 2011).

In another 2011 study, the Electric Power Research Institute (EPRI) produced a technical report titled Estimating the Costs and Benefits of the Smart Grid (EPRI 2011). In brief, EPRI updated an earlier report with this report, and they applied a revised, more advanced model of the Smart Grid to the U.S. power system. The EPRI report (EPRI 2011) estimates that the vision of a full Smart Grid will require an investment of USD 17 billion to USD 24 billion per year over the next 20 years. But, this large investment is dwarfed by the benefits calculated by EPRI. The bottom line of the report is that the benefit-cost ratio, which is estimated to be $2.8-6.0$, is multiples of the investment required. Table 16 summarizes EPRI's estimate of the costs and benefits of this major investment. 
Table 16. EPRI-Estimated Cost and Benefits of the Smart Grid

\begin{tabular}{|l|l|}
\hline & 20-Year Total \\
\hline Net investment required & USD 338 billion-USD 476 billion \\
\hline Net benefit & USD 1,294 billion-USD 2,028 billion \\
\hline Benefit-cost ratio & $2.8-6.0$ \\
\hline
\end{tabular}

(EPRI 2011)

The benefits are distributed among nine categories, as shown in Table 17.

Table 17. EPRI-Estimated Distribution of Smart Grid Benefits

\begin{tabular}{|l|c|c|}
\hline \multirow{2}{*}{ Attribute } & \multicolumn{2}{|c|}{$\begin{array}{c}\text { Net Present Worth (2010) } \\
\text { (billions of dollars) }\end{array}$} \\
\cline { 2 - 3 } & Low & High \\
\hline Productivity & 1 & 1 \\
\hline Safety & 13 & 13 \\
\hline Environment & 102 & 390 \\
\hline Capacity & 299 & 393 \\
\hline Cost & 330 & 475 \\
\hline Quality & 42 & 86 \\
\hline Quality of Life & 74 & 74 \\
\hline Security & 152 & 152 \\
\hline Reliability & 281 & 444 \\
\hline Total & $\mathbf{1 , 2 9 4}$ & $\mathbf{2 , 2 0 8}$ \\
\hline
\end{tabular}

(EPRI 2011)

In a third example, ESTA published Smart Grid Regulatory Framework for Mexico (ESTA 2014) on behalf of CRE under a project funded by the U.S. Trade and Development Agency. For the report, ESTA was tasked with estimating the benefits to Mexico of the twin programs of Smart Grid and the expansion of renewable energy. Text Box 1 describes some of the key benefits of investing in smart grid technologies. 


\section{Text Box 1. Cost Effectiveness of Smart Grid Investment}

\section{(from ESTA 2014)}

The evaluation of the smart grid and renewable energy programs in Mexico suggest that significant value can be created.

In developing a dedicated renewable energy program, we see large potential benefits stemming from reductions in fuel cost expenditures. Beyond that, we also see significant benefits coming from deferral of distribution network requirements and reductions in requirements for synchronized reserves and frequency regulation.

On the smart grid initiative, the largest benefits stem from the opportunities associated with automation distribution operations. The single largest source of value stems from automating the meter reading process, moving from a manual read to an automated process with a digital architecture. Other significant benefits also are derived from developing feeder gateway temperature monitoring and voltage monitoring programs, with additional value coming from fault detection and phase and load balancing. The projected benefits for the transmission network are far smaller; nevertheless, there are viable opportunities in developing line temperature sensing capabilities and by deploying synchrophasors.

The total value proposition for both the smart grid program and the renewable energy initiative exceeds MXN 50 thousand million pesos relative to a "do nothing" strategy. Based on the high value proposition of these programs, we recommend further operational efforts to commence.

\subsubsection{Cost Benefit Analysis at the Measure or Program Level}

The criteria that should be considered when choosing smart grid measures include:

- Overall expectation on investment (cost-benefit analysis results)

- Impact on tariff rates (significant rate increases may not allow some technology deployment, while minimal rate impacts may be much more acceptable)

- Safety of utility line workers, meter readers, and the public as a result of the deployment of the technology

- Improvement in operational approaches for the distribution system dispatch and operations teams 
- Voltage of distribution systems in service territory (i.e., how many different distribution voltage levels need to be served and how many versions of a smart grid technology need to be stocked)

- Number of customers in service territory, city, region (technologies may have greater appeal with larger segments of customers, and vice versa)

- Number of customers per mile on distribution system (having fewer customers per mile may favor some technologies over others)

- Expected lifetime of the technology (most utility equipment is expected to be in service for 30 years or more, but systems that are expected to fail sooner or be obsolete before this interval should be given greater scrutiny)

- Track record of the company selling the smart grid technology and their experience in supporting the utility in the past (Do other utilities have experience with the smart grid company that they are willing to share that might support the project?)

- Impact on load serving capability of the distribution feeder or the overall distribution system (Can the smart grid measures improve this capability, and will that delay other investments?)

- Impact (possible improvement) on the operational effectiveness of the substation and transmission system

- Will the system extend the life expectancy of devices such as the substation transformer, LTCs, and circuit breakers?

- Expectations regarding improving the system (or Customer) Average Interruption Frequency Index (SAIFI/CAIFI) and the System (or Customer) Average Interruption Duration Index (SAIDI/CAIDI) reliability metrics by reducing duration or frequency of outages, or the number of customers impacted by an outage

- Other smart grid systems (and costs) needed to make the smart grid system practical.

CFE and CENACE should evaluate the cost and benefits of Smart Grid. Some elements might be analyzed quantitatively (e.g., the investment costs and the revenue streams), while some criteria might be assessed qualitatively (e.g., the possible health benefits of increased renewable energy penetration enabled by smart grid practices and technologies).

ISGAN Annex 3 (Ajou University 2014) focuses on cost-benefit analysis and Toolkits and has various resources that may be of use for Mexico in their assessments.

\subsection{What Should be Considered Costs and Benefits}

EPRI (2010) identifies 23 specific benefits of smart grid deployment that should be considered in a cost-benefit analysis:

1. Optimized generator operation

2. Deferred generation capacity investments

3. Reduced ancillary service cost

4. Reduced congestion cost

5. Deferred transmission capacity investments

6. Deferred distribution capacity investments 
7. Reduced equipment failures

8. Reduced distribution equipment maintenance cost

9. Reduced distribution operations cost

10. Reduced meter reading cost

11. Reduced electricity theft

12. Reduced electricity losses

13. Electricity cost savings

14. Reduced electricity cost

15. Reduced sustained outages

16. Reduced major outages

17. Reduced restoration cost

18. Reduced momentary outages

19. Reduced sags and swells

20. Reduced carbon dioxide emissions

21. Reduced emission of sulfur oxides, nitrogen oxides, and particulate matter that is micrometers or less in diameter

22. Reduced oil use by electric vehicles (not monetized)

23. Reduced widescale blackouts.

This appears to be a comprehensive list of the benefits that can be expected "upstream" from the customer meter and mostly "inside the utility's fence." Missing from this list are larger societal benefits that are not captured in the price of electricity. These include such benefits as increased national security and reduced defense costs as energy independence is increased. Also missing from the list are some of the consumer benefits of Smart Grid, including better customer service, energy knowledge and empowerment, smart customer devices, and improved comfort and indoor air quality. Additional benefits such as these may be difficult to measure. Regarding energy efficiency measures, the Rocky Mountain Institute notes that, "Though hard to quantify and monetize, these real benefits are often worth far more than the saved energy" (RMI 2016). 


\section{Obstacles to Implementation of Smart Grid Programs and Investment in Them}

\subsection{International Experience and the Valuation of Flexibility}

Institutionalizing market and regulatory models to enable valuation of flexibility is one of the key challenges being faced in many markets. A recent joint workshop organized by the IEA and ISGAN focused on this topic. According to IEA's and ISGAN's (2016) concept note for the workshop, flexibility is the ability of a power system to maintain reliability and continuous service in the face of rapid and large swings in supply or demand. Future energy systems will require much greater amounts of flexibility, which will necessitate a broad platform of smart grid and information and communications technologies spanning all areas of the electricity system:

- Flexible System Operation that Extracts Flexibility from Existing Systems: This includes decisions made closer to real time and, more frequently, improved use of wind and solar forecasting and better collaboration with neighboring networks. Without sufficient flexibility, system operators may need to frequently curtail wind and solar generation or shed loads causing limited or extended blackouts

- Flexible Generation: This includes power plants that can ramp up and down quickly and efficiently and run at low output levels

- Flexible Transmission and Distribution: This includes ensuring networks can access a broad range of balancing resources - including sharing between neighboring power systems - with smart network technologies that better optimize transmission and distribution usage

- Flexible Demand-Side Resources: The incorporation of Smart Grids can enable customers to value their flexibility by responding to market signals or schemes, including direct load control

- Storage Solutions: These might also deliver increased flexibility, either as an integrated part of demand side flexibility or as stand-alone resources connected directly to the network.

Key takeaways from the workshop that may be relevant to Mexico include the following:

- Many players are already in the flexibility market, but clear rules are needed (e.g., regulatory reform and appropriate market incentives). But, another view is that the market will regulate itself and hardly needs any specific rules.

- Favorable legislation and other circumstances (e.g., susceptibility to natural disasters) can drive the market, as is the case in California.

- Economically feasible applications already exist without financial support, but many are hindered by legislative barriers.

- A coordinated process would be required so that distribution and transmission system operators, technology providers, and regulators create an appropriate market framework.

- Ancillary services should be procured by — rather than developed by — utilities, and they will be offered if the need is clearly defined.

- The most important question is, where does flexibility give the most value? 
- Technology providers and regulators need to reach out to technology providers to get feedback and comments on potential regulations.

- In Austria, regulators worked with the TSO to change rules of load frequency control, and they now allow smaller storage entities to contribute to the market via pooling. This helped reduce costs by $30 \%$ in 2015 and was expected to reduce costs by $40 \%$ in 2016 .

- The EU is developing new legislation on market design that includes flexibility.

- Operational strategies for having a 20\%-30\% share of wind power have been developed. Transmission grid build-out and the management of variability and uncertainty is a significant challenge, but flexible operational methods have been recognized as a key enabler. In Europe, increased wind generation has mostly been enabled by robust grids. Portugal is managing close to a $100 \%$ wind share, Norway is building transmission lines to manage North Sea wind, and Ireland is reducing curtailed wind at close to a $40 \%$ share.

- The key message is, "let the market work." Price signals are the basis for investments in flexible capacity. The market should work without distortions; barriers need to be removed and certain types of flexibility should not be promoted at the expense of other flexibility types. Specific regulations are not needed; market rules are only needed to ensure the market price is corrected during scarcity driven interventions.

- Both resilience and cybersecurity are ongoing challenges for which there is no simple solution. One possible solution is the agile fractal grid, under which all segments of the grid operate with the same information and control model. Another possible solution is restoration, whereby small islanded sections of the grid are formed to provide black-start capabilities.

- Thermally activated buildings (via heat pumps) represent a cost-efficient storage possibility for wind power. The large thermal mass of concrete building structures is used as a buffer or heat sink for changing cooling or heating loads. Almost no additional construction measures other than installed water pipes in the ceiling are needed, and operation is simply controlled. The customer benefits from lower power prices (low-load hours), and the load can be shifted to when the wind energy is available. Currently, 150 thermally activated buildings are being constructed in Vienna, Austria.

\subsection{Cybersecurity Concerns}

\subsubsection{Confidentiality, Integrity, and Availability}

One widely applicable model for guiding cybersecurity policies is the so-called CIA triad of Confidentiality, Integrity, and Availability. Confidentiality manages and limits access to information. Integrity provides assurance that information is accurate. Availability delivers the information reliably.

Confidentiality - protecting personal privacy and proprietary information - is the least critical objective for power system reliability. Yet, it is becoming more important in smart grid systems involving interactions with customers, such as DR and AMI networks. From the perspective of power system reliability, availability and integrity are the most important security objectives in the Smart Grid. A disruption of access to or use of information may undermine the physical delivery of power. Consequently, a primary security goal of smart grid operations is availability. The unauthorized modification or destruction of information can cause errors in power 
management. As smart grid systems become more interdependent, integrity becomes increasingly important to security.

Malicious attacks fall into three types based on the CIA triad:

- Attacks targeting confidentiality that are intended to acquire unauthorized information from network resources in the Smart Grid

- Attacks targeting integrity that are aimed at deliberately and illegally modifying or disrupting data exchange in the Smart Grid

- Attacks targeting availability, also called denial-of-service (DoS) attacks, or attempts to delay, block, or corrupt the communication in the Smart Grid.

\section{Confidentiality Attacks: Disclosure of Customer Information}

Attackers targeting confidentiality have no intent to modify information transmitted over power networks but instead seek access to communication channels or data stores at the enterprise. Unlike attacks on availability and integrity, such attacks have negligible effects on the functionality of the Smart Grid. Yet, the social and reputational impacts can be significant, as has been demonstrated by data breaches across various sectors.

\section{Integrity Attacks: False Data Injection}

Attacks targeting data integrity attempt to modify data in order to corrupt critical information exchange in the Smart Grid. The target can be either customer information or power system measurements.

\section{Availability Attacks: Denial of Service}

Note that compared with the internet, the Smart Grid features a delay-constrained network because of time-critical parameters for delivery of information or control messages for the power systems (e.g., IEC 61850 messages). In the Smart Grid, a DoS attacker does not need to completely shut down network access using extreme means (e.g., all-time jamming) but instead may launch weaker versions of attacks to intentionally delay the transmission of a message to violate its timing requirement. A delay can be catastrophic for power infrastructures. For instance, an attacker can cause severe damage to power equipment if the attack successfully delays the transmission of a protection message in the case of trip protection in substations (Metke 2010). Therefore, the goals of DoS attacks on the Smart Grid include not only disrupting resource access but also violating the timing requirements of critical message exchange.

\subsubsection{Guidelines for Smart Grid Cybersecurity}

In addition to these high-level objectives, the National Institute for Standards and Technology (NIST) recommends specific cyber- and physical-security requirements for the Smart Grid. Their three-volume report, Guidelines for Smart Grid Cyber Security (NIST 2014), presents an analytical framework that organizations can use to develop effective cybersecurity strategies tailored to their particular combination of risks and vulnerabilities. 
For our purposes, the NIST security requirements (NIST 2014) can be summarized as follows:

- Attack Detection and Resilience Operations: The Smart Grid features a more open communication network over larger areas than legacy power systems. Accordingly, it is almost impossible to ensure every part or node in the Smart Grid is invulnerable to network attacks. Therefore, the communications network needs to consistently perform profiling, testing, and comparison to monitor network traffic status (e.g., to detect and identify abnormal incidents that are due to attacks). Moreover, the network must also have the self-healing ability to continue network operations during attacks. Because of the critical importance of power infrastructures, resilience operation in communications networks is essential to sustaining network availability in the Smart Grid.

- Identification, Authentication, and Access Control: The smart grid network infrastructure incorporates millions of electronic devices and users. Identification and authentication are the essential processes of verifying the identity of a device or user as a prerequisite for granting access to resources in the smart grid information system. The focus of access control is to ensure resources are accessed by only appropriate and correctly identified personnel. Strict access control must be enforced to prevent unauthorized users from accessing sensitive information and controlling critical infrastructure. To meet these requirements, every node in the Smart Grid must have at least basic cryptographic functions, such as symmetric and asymmetric cryptographic primitives, to perform data encryption and authentication.

- Secure and Efficient Communications Protocols: Unlike in conventional networks, message delivery in the Smart Grid requires both time-criticality and security, in particular in distribution and transmission systems. However, the two objectives usually contradict each other. As networks (or subnetworks) in the Smart Grid cannot always use secure, physically protected, and high-bandwidth communications channels, optimal tradeoffs are required to balance communication efficiency and information security in the design of communications protocols and architectures for the Smart Grid.

\subsubsection{Architectural Considerations}

NREL's cyber-physical security practice recommends a systemic view of cybersecurity. Such a view may be considered a "profile" of different security technologies and procedures, woven together to meet the security requirements of a particular implementation of policy, procedural, and communications standards designed to provide specific services.

It is helpful, from a systemic view, to recognize that smart grid communication standards are designed to meet many different requirements at many different "layers." Two commonly used reference models are used to describe these layers: the International Organization for Standardization (ISO)/Open Systems Interconnection (OSI) ${ }^{27}$ 7-layer reference model and the GridWise Architecture Council (GWAC) stack. ${ }^{28}$ With respect to the objectives of various smart grid standards, some standards address the use of wireless media, fiber optic cables, or power

\footnotetext{
${ }^{27}$ See "ISO 7498-1:1994, Information Technology: Open Systems Interconnection: Basic Reference Model: The Basic Model," https://www.iso.org/standard/20269.html.

28 The GWAC Stack is available at "GridWise Architecture Council," http:/www.gridwiseac.org, in the GridWise Interoperability Context-Setting Framework.
} 
line carrier. Others address the "transport" layers for getting messages from one location to another. Still others cover the "application" layers, the semantic structures of the information as it is transmitted between software applications.

Cybersecurity is a crosscutting issue, and it should be reflected in requirements at all levels. When taking a systems approach, the problem must be considered in its entirety and in context. Thoroughly investigating the security objectives of the reference models (OSI or GWAC) represents the first step toward smart grid security. Cybersecurity should address all layers, endto-end, from the source of the data to the ultimate destination of the data. Yet, smart grid communications standards do not address the importance of specific data or how it might be used in systems. Understanding context is important to the systemic approach; requirements should reflect the implementation environment rather than simply the standard itself.

\subsubsection{Regulatory Framework}

Practical experience has shown that investments in security are often linked to regulatory requirements. Return on investment in security is often difficult to establish. The complexity and lack of clarity with the risks involved can further complicate executive board approval. Yet, a host of regulatory mandates have motivated various security implementations, including multifactor authentication, application security testing, as well as many other implementations. Examples are not limited to the North American Electric Reliability Corporation's (NERC) critical infrastructure protection requirements, but they include the Sarbanes-Oxley Act of 2002 and the Payment Card Industry Data Security Standards, both in the United States, as well as international financial mandates by various central banks, including the Reserve Bank of India and the Monetary Authority of Singapore (Kumar, Pandey, and Punia 2014).

\subsection{Consumer Receptivity}

Development of the Smart Grid will both motivate and enable improvements in the precision and sophistication of rate structures faced by consumers. Within the residential sector, smart meters will allow CFE to record demand and energy use in real time, in contrast to the situation where a meter reader records only energy use and then only monthly. Given the variance in system costs within a day and across the seasons, the Smart Grid will permit CFE to offer (or require) the use of a tariff with time-differentiated rates. Charging prices that reflect varying costs over time will present consumers with the true costs of the energy at the time it is used.

The $20 \%$ of residential consumers with the highest electricity use (the "top 20\%") will, in aggregate, consume a disproportionate fraction of electricity used by the entire residential consumer class. The distribution of residential consumers by usage is skewed, and we predict the top $20 \%$ of consumers will use at least $40 \%$ of the total kilowatt-hours in the residential class. Time-sensitive rates will be most relevant to the largest users of electricity in the residential class, as these are generally (but not exclusively) the consumers with the largest houses and the financial means to employ energy conservation and load-shifting techniques. For that reason, CFE is likely to find that the combination of AMI devices and "smart prices" targeted to this group of larger users will be highly cost-effective from the system perspective. 
Although the Smart Grid will enable the use of very sophisticated tariff structures, we suggest the initial dynamic pricing tariffs should be relatively simple and easy for the consumer to understand. For example, a tariff with fixed peak, shoulder, and off-peak prices during fixed time periods would be a reasonable first step for a dynamic pricing tariff. Over time and after public understanding and acceptance of time-of-use rates have been achieved, more sophisticated rate structures could be considered.

The "top 20\%" approach will be an effective way to lay the foundation on dynamic pricing. Some research suggests most consumers prefer time-of-use rates after they have experience with them. Following the introduction of the rates for the largest consumers, awareness and acceptance of a dynamic pricing structure is likely to spread, and voluntary subscription by smaller consumers will likely increase. 


\section{Summary}

Mexico, following its energy reform, is working and proactively planning for a system-level transformation with clean energies. This power system transformation occurring in Mexico includes clear national drivers or priorities for the implementation of smart grid-Redes Eléctricas Inteligentes - technologies. According to SENER, smart grids in Mexico must improve the operation of the National Electric System by increasing its efficiency, resilience, flexibility, quality, reliability, continuity, safety, and sustainability, and they must also serve to integrate large and distributed renewable energies and storage devices into the network.

To date, under the leadership of SENER and following clear responsibilities delineated in Mexico's energy reform, Mexico has performed analysis of the status of smart grid technologies with costs and benefits associated and is formulating a pathway for implementing the deployment of the next generation of smart grid technologies and the appropriate policies and regulations necessary to meet its objectives. Under the new planning criteria for the National Electric System in Mexico, SENER must work closely with CENACE, CFE Transmission, and the distribution and retail utilities to incorporate smart grid technologies. As the system operator, CENACE must present various investment options to SENER.

This report was written for SENER to comply with new law requirements. It links different available technologies to the individual drivers or priorities for Mexico's transformation, which will help SENER continue its smart grid implementation plan. This report will also serve as a guide to SENER in the assessment of future technology and grid investments included in the integrated resource plan (PRODESEN) and will aid to enact future policies and regulations. Finally, this report will help keep track of the progress made and direct appropriate actions when necessary. 


\section{References}

ABB Wireless. 2017. DTE Energy: Reliable Private Wireless Network for Smart Grid Applications. https://library.e.abb.com/public/a60283498be448c3b527d99395168c4d/dteenergy-reliable-private-wireless-network-smart-grid.pdf

- 2012. FACTS for Grid Voltage Stabilization and Increased Power Transmission Capability in Chile. Application Note 1JNS012661, 2012-08. ABB.

https://ibrary.e.abb.com/public/52c773fd577f026e48257a7d00285267/1JNS012661\%20LR.pdf.

Aivaliotis, Sandy K. 2010. Dynamic Line Ratings for Optimal and Reliable Power Flow. Presented at FERC Technical Conference, June 24, 2010.

Ajou University. 2014. ISGAN Project Annex 3: Benefit and Cost Analyses and Toolkits.

BC Power Hydro Smart. January 16, 2016. BC Hydro confirms benefits of smart metering program. https://www.bchydro.com/news/press_centre/news_releases/2016/smart-meter-factsheet.html. Accessed June 15, 2017.

Bi, T., The Dynamic Behavior of PMU and the Latest Developments in China. Presented at the Celebrating the Visions of Synchrophasor Pioneers, Washington D.C., May 8, 2013.

Bravo, R. J. and D. P. Chassin, "Fault Induced Delayed Voltage Recovery (FIDVR) Model Validation." 2016 IEEE/PES Transmission and Distribution Conference and Exposition (T\&D) 2016: 1-4.

CEC (California Energy Commission). 1999. Flexible AC Transmission Systems Benefits Study. California Energy Commission (CEC). P600-00-037.

CENACE (Centro Nacional de Control de Energía). "Subastas de Largo Plazo.” 2016a.

http://www.cenace.gob.mx/paginas/publicas/MercadoOperacion/SubastasLP.aspx.

_. 2016b. "Subastas de Largo Plazo."

http://www.cenace.gob.mx/paginas/publicas/MercadoOperacion/SubastasLP.aspx.

_. 2016c. "Subastas de Largo Plazo."

http://www.cenace.gob.mx/paginas/publicas/MercadoOperacion/SubastasLP.aspx.

Chen, Jian, Prakash Shrestha, Shun-Hsien Huang, N.D.R. Sarma, John Adams, Diran Obadina, and John Balance. 2012. "Use of Synchronized Phasor Measurements for Dynamic Stability Monitoring and Model Validation in ERCOT." 2012 IEEE Power and Energy Society General Meeting 2012: 1-7.

CIRED (Congrès International des Réseaux Electriques de Distribution). 1998. Fault Management in Electrical Distribution Systems: Final Report of the CIRED Working Group WG03 Fault Management. http://www.cired.net/publications/cired1999/papers/3/3 0.pdf. 
Comisión Federal de Electricidad (CFE) 2016. Soluciones para la Interoperabilidad de Sistemas para los Procesos de La Subdirección de Distribución, Alineados al Estándar Common Information Model para Datos y BPM para Procesos de Negocio (Proyecto: P-00115DIS).

Das, Ratan, Mital Kanabar, Mark Adamiak, Galina Antonova, Alexander Apostolov, Sukumar Brahma, Mohammad Dadashzadeh, et al. 2015. Centralized Substation Protection and Control, https://doi.org/10.13140/RG.2.1.2114.0568.

Decker, I. C., A. S. e Silva, M. N. Agostini, F. B. Prioste, B. T. Mayer, and D. Dotta. 2011. "Experience and Applications of Phasor Measurements to the Brazilian Interconnected Power System." European Transactions on Electrical Power 21(4): 1557-1573.

del Rio, P. and Unruh, G. 2007. Overcoming the Lock-Out of Renewable Energy Technologies in Spain: The Cases of Wind and Solar Electricity. Renewable and Sustainable Energy Reviews 11: $1498-1513$.

Denholm, Paul, Jennie Jorgenson, Marissa Hummon, David Palchak, Brendan Kirby, Ookie Ma, and Mark O'Malley. 2013. Impact of Wind and Solar on the Value of Energy Storage. Golden, CO: National Renewable Energy Laboratory. NREL/TP-6A20-60568. http://www.nrel.gov/docs/fy14osti/60568.pdf.

DOE (U.S. Department of Energy). 2006. Benefits of Demand Response in Electricity Markets and Recommendations for Achieving Them: A Report to the United States Congress Pursuant to Section 1252 of the Energy Policy Act of 2005. https://emp.lbl.gov/sites/all/files/report-lbnl1252d.pdf.

- 2014a. Fault Location, Isolation, and Service Restoration Technologies Reduce Outage Impact and Duration. December 2014. https://www.smartgrid.gov/files/B5 draft report-12-182014.pdf.

—. 2014b. Dynamic Line Rating Systems for Transmission Lines: Topical Report. https://www.smartgrid.gov/files/SGDP Transmission DLR Topical Report 04-2514_FINAL.pdf.

_.2014c. Oncor's Pioneering Transmission Dynamic Line Rating (DLR) Demonstration Lays Foundation for Follow-On Deployments.

https://www.smartgrid.gov/files/Oncor_DLR_Case_Study_05-20-14_FINAL.pdf.

Ela, Erik. 2013. Variable Renewable Generation Can Provide Balancing Control to the Electric Power System. Golden, CO: National Renewable Energy Laboratory. NREL/FS-5500-57820. http://www.nrel.gov/docs/fy13osti/57820.pdf.

ENTSO-E (European Network of Transmission System Operators for Electricity). 2015. Wide Area Monitoring: Current Continental Europe TSOs Applications Overview. Brussels, Belgium: ENTSO-E. https://www.entsoe.eu/Documents/SOC\%20documents/ Regional Groups Continental Europe/CE WAM Applications V5.pdf. 
EPRI (Electric Power Research Institute). 2007. Advanced Metering Infrastructure (AMI). Palo Alto, CA: EPRI. 1014793. https://www.ferc.gov/CalendarFiles/20070423091846EPRI\%20-\%20Advanced\%20Metering.pdf.

2010. Methodological Approach for Estimating the Benefits and Costs of Smart Grid Demonstration Projects. Palo Alto, CA: EPRI. 1020342.

https://www.smartgrid.gov/files/Methodological_Approach_for_Estimating_Benefits_Costs_Sm art 201007.pdf.

-2011. Estimating the Costs and Benefits of the Smart Grid: A Preliminary Estimate of the Investment Requirements and the Resultant Benefits of a Fully Functioning Smart Grid. Palo Alto, CA: EPRI. 1022519. https://www.smartgrid.gov/files/Estimating_Costs_Benefits_Smart_Grid Preliminary_Estimate $\underline{\text { In_201103.pdf. }}$

ESTA (ESTA International). 2014. Smart Grid Regulatory Framework for Mexico. http://www.cre.gob.mx/documento/3979.pdf (English) and http://www.cre.gob.mx/documento/3978.pdf (Español).

Esterl, Tara, Stefanie Kaser, Matthias Stifter, René Kamphuis, Matthias Galus, Marijn Renting, Arnoud Rijneveld, Roman Targosz, Steve Widergren, Lars Nordstrom, Daniel Brodén, and Stephen Galsworthy. 2016. IEA DSM Task 17: Valuation Analysis of Residential Demand Side Flexibility Demand Flexibility in Households and Buildings. Matthias Stifter, and René

Kamphuis, eds. IEA DSM. http://www.ieadsm.org/wp/files/IEA-Task-17-Subtask-11-Valuationanalysis-2016-09-15.pdf.

European Parliament. 2015. Energy Storage: Which Market Designs and Regulatory Incentives Are Needed?

http://www.europarl.europa.eu/RegData/etudes/STUD/2015/563469/IPOL_STU(2015)563469 EN.pdf

Faris, T. 2016. BPA PMU Installations. Presented at the WECC Joint Synchronized Information Subcommittee (JSIS), Portland, OR, September 2016.

Faruqui, Ahmad, Ryan Hledik, and Jennifer Palmer. 2012. Time-Varying and Dynamic Rate Design. Regulatory Assistance Project. https:/www.raponline.org/wpcontent/uploads/2016/05/rap-faruquihledikpalmer-timevaryingdynamicratedesign-2012-jul23.pdf.

FERC. 2011. Demand Response Compensation in Organized Wholesale Energy Markets, 18 CFR Part $35 \S$. https://www.ferc.gov/EventCalendar/Files/20110315105757-RM10-17-000.pdf.

FERC (Federal Energy Regulatory Commission). 2015. Assessment of Demand Response and Advanced Metering: Staff Report. http://ferc.gov/legal/staff-reports/2015/demand-response.pdf.

Fischer, N., V. Skendzic, R. Moxley, and J. Needs. 2012. Protective Relay Traveling Wave Fault Location. Presented at the International Conference on Developments in Power System Protection, Birmingham, UK, April 23-26, 2012. 
Ghiocel, Scott G., Joe H. Chow, David B. Bertagnolli, Michael Razanousky, George Stefopoulos, Bruce Fardanesh, Deepak Maragal, Michael Swider, and Dejan J. Sobajic. 2014. "Phasor-Measurement-Based Voltage Stability Margin Calculation for a Power Transfer Interface with Multiple Injections and Transfer Paths." 2014 Power Systems Computation Conference 2014: 1-6.

Giordano, Vincenzo, Flavia Gangale, Gianluca Fulli, and Manuel Sánchez Jiménez. 2011. Smart Grid Projects in Europe: Lessons Learned and Current Developments. European Commission, Joint Research Centre, Institute for Energy. https://ses.jrc.ec.europa.eu/sites/ses.jrc.ec.europa.eu/files/publications/smart grid_projects_in_eu rope lessons learned and_current_developments.pdf.

Groarke, David. 2013b. "Who Are the Top Vendors in Smart Grid?” GTM Research. https://www.greentechmedia.com/articles/read/who-are-the-top-vendors-in-smart-grid.

GTM Research. 2013. “The Networked Grid 150: The End-to-End Smart Grid Vendor Ecosystem Report and Rankings 2013." GTM Research. https://www.greentechmedia.com/research/report/the-networked-grid-150-report-and-rankings$\underline{2013}$.

Haywood Queen, Karen. 2016. "PJM Leverages Federal Rule Changes to Lead Country in Energy Storage." Energy News Network. November 28, 2016.

http://southeastenergynews.com/2016/11/28/pjm-leverages-federal-rule-changes-to-leadcountry-in-energy-storage/.

Hoff, Tom. 2014. Experience in CA with Behind-the-Meter PV Forecasts. Presented at the UVIG Forecasting Workshop, February 26. https://www.cleanpower.com/wpcontent/uploads/Experience-in-CA-with-Behind-the-Meter-PV-Forecasts-UVIG-Forecasting2014.pdf.

Huang, Zhenyu, Pengwei Du, Dmitry Kosterev, and Steven Yang, 2013. “Generator Dynamic Model Validation and Parameter Calibration Using Phasor Measurements at the Point of Connection." IEEE Trans. Power Syst. 28(2): 1939-1949.

Hummon, Marissa, David Palchak, Paul Denholm, Jennie Jorgenson, Daniel J. Olsen, Sila Kiliccote, Nance Matson, Michael Sohn, Cody Rose, Junqiao Dudley, Sasank Goli, and Ookie Ma. 2013. Grid Integration of Aggregated Demand Response, Part 2: Modeling Demand Response in a Production Cost Model. Golden, CO: National Renewable Energy Laboratory. NREL/TP-6A20-58492. http://www.nrel.gov/docs/fy14osti/58492.pdf.

Ibanez, Eduardo, Gregory Brinkman, Marissa Hummon, and Debra Lew. 2012. "A Solar Reserve Methodology for Renewable Energy Integration Studies Based on Subhourly Variability Analysis: Preprint." Second International Workshop on Integration of Solar Power in Power Systems Proceedings, Lisbon, Portugal. NREL/CP-5500-56169. http://www.nrel.gov/docs/fy12osti/56169.pdf. 
IEA (International Energy Agency). 2014. The Power of Transformation: Wind, Sun and the Economics of Flexible Power Systems. International Energy Agency.

https://www.iea.org/publications/freepublications/publication/The power_of_Transformation.pdf.

IEA (International Energy Agency), and ISGAN and the International Energy Agency. 2016. IEA-ISGAN Workshop: Flexibility in Future Energy Systems. Workshop held October 11, 2016, Paris.

https://www.iea.org/media/workshops/2016/flexibilityinfutureenergysystems/ISGAN_11_Octob er_Workshop at_20.09.pdf.

IEC. "IEC 60050 - International Electrotechnical Vocabulary - Welcome.” Electropedia, 2018. http://www.electropedia.org/

ISGAN. 2016. Phase-Sensitive Enabling of Household Engagement in Smart Grids. International Smart Grid Action Network, Annex 7 - Smart Grid Transitions.

http://www.iea-isgan.org/wpcontent/uploads/2018/02/ISGAN_PolicyBrief_HouseholdEngagementInSmartGrids_2017.pdf

Isono, Eri, Yoshio Ebata, Taichi Isogai, and Hideki Hayashi. 2013. "Development of Battery Aggregation Technology for Smart Grid." Power Electronics Conference (IPEC-Hiroshima 2014 - ECCE-ASIA) 2014 International. 1868-1873.

http://ieeexplore.ieee.org/document/6652141/.

Jones, Kevin D., Anamitra Pal, and James S. Thorp. 2015. "Methodology for Performing Synchrophasor Data Conditioning and Validation.” IEEE Trans. Power Syst. 30(3): 1121-1130.

Kelly-Detwiler, Peter. 2016. "How a Big Utility Fought Back Against Marijuana Growers Stealing Electricity," Forbes. April 27, 2016. http:/www.forbes.com/sites/peterdetwiler/2016/04/27/bc-hydro-combatting-electricity-theftwith-big-data/\#60deb1731cbb.

Kepner, Charles Higgins, and Benjamin B. Tregoe. 1976. The Rational Manager; a Systematic Approach to Problem Solving and Decision Making: Problem Analysis for Decision Making, 2nd ed.

Kincic, S, B. Wangen, W. A. Mittelstadt, M. Fenimore, M. Cassiadoro, V. VanZandt, and L. Perez. 2012. "Impact of Massive Synchrophasor Deployment on Reliability Coordination and Reporting." 2012 IEEE Power and Energy Society General Meeting 2012: 1-8.

Kumar, V. Ananda, Krishan K. Pandey, and Devendra Kumar Punia (2014). “Cyber Security Threats in the Power Sector: Need for a Domain Specific Regulatory Framework in India." Energy Policy 65: 126-133.

Kothandaraman, C., Sundar K. Iyer, and Subramanian S. Iye. 2002. "Electrically Programmable Fuse (eFUSE) Using Electromigration in Silicides." IEEE Electron Device Letters 23(9): $523-525$. 
Leon, R., and J. Gomez, 2011. Secretaría de Energía-SENER Secretaría de Energía-SENER -SIRENA. Presented at the North American Synchrophasor Initiative (NASPI) Working Group Meeting, San Francisco, October 12, 2011.

Linvill, Carl, Ronald Binz, and Riccardo Bracho. 2016. First Steps in the Smart Grid

Framework: A Ricitos de Oro Pathway Toward Power System Reform in Mexico.

McAnany, James. 2016. 2015 Demand Response Operations Markets Activity Report. PJM Demand Side Response Operations. https://www.pjm.com/ /media/markets-ops/dsr/2015demand-response-activity-report.ashx.

Metke, Anthony R., and Randy L. Ekl. 2010. "Smart Grid Security Technology." Proceedings of Innovative Smart Grid Technologies Conference Europe.

Moraes, Rui M., Hector A. R. Volskis, and Yi Hu. 2008. "Deploying a Large-Scale PMU System for the Brazilian Interconnected Power System." Third International Conference on Electric Utility Deregulation and Restructuring and Power Technologies 2008: 143-149.

Mukopadhyay, Subrata. 2014. Indian Experience with Smart Grid Applications: Transmission Sector. Presented at the IEEE PES GM, 2014.

Nakafuji, Dora, Anthony Hong, and Babak Enayati. 2014. Minimum Day Time Load Calculation and Screening. Presented at the Distributed Generation Interconnection Collaborative (DGIC), April 30. http://www.nrel.gov/tech deployment/pdfs/2014-04-30 minimum-day-time-loadcalculation-and-screening.pdf.

NASPI (North American SynchroPhasor Initiative). n.d. Synchrophasor System Benefits Fact Sheet. https://www.naspi.org/sites/default/files/reference_documents/62.pdf

National Grid. 2016, August. Enhanced Frequency Response Market Information Report. https://www.nationalgrid.com/sites/default/files/documents/EFR\%20Market\%20Information\%20 Report $\% 20 \mathrm{v} 1 \% 20 \% 281 \% 29$ 1.pdf.

Navigant Research. 2017. "Residential DR Leader Board." https://www.navigantresearch.com/research/navigant-research-leaderboard-residential-demandresponse.

NEMA. n.d. Volt/VAR Optimization Improves Grid Efficiency. https://www.nema.org/Policy/Energy/Smartgrid/Documents/VoltVAR-OptimazationImproves\%20Grid-Efficiency.pdf.

NETL (National Energy Technology Laboratory). 2007. A Systems View of the Modern Grid: V. 2.0. Prepared for the U.S. Department of Energy Office of Electricity Delivery and Energy Reliability. https://www.smartgrid.gov/files/a systems_view_of the modern_grid.pdf

NIST (National Institute of Standards and Technology). 2014. Guidelines for Smart Grid Cyber Security: NISTIR 7628 Revision 1. Three vols. https://www.nist.gov/publications/guidelinessmart-grid-cybersecurity. 
Normark, B. et al. 2016. Spotlight on Smart and Strong Power T\&D Infrastructure. International Smart Grid Action Network (ISGAN), Power T\&D System. Accessed May 2018. http://www.iea-isgan.org/spotlight-on-smart-and-strong-power-td-infrastructure-2-0/.

NV Energy. 2015. Nevada Dynamic Pricing Trial Final Report: An Evaluation of NV Energy's Choose When You Use Program. NV Energy DOE Project DE-OE0000205. https://www.smartgrid.gov/files/NV_Energy_NDPT_Final_Report_20151026.pdf.

Pavlovic, Jeff. N.d. Power Reforms at 2 1/2 years: Goals, Design and Accomplishments. Presentation.

Pelland, Sophie, Jan Remund, Jan Kleissl, Takashi Oozeki, and Karel De Brabandere. 2013. Photovoltaic and Solar Forecasting: State of the Art. IEA PVPS, Task 14: 1-36.

Persson, Einar, Björn Berg, Fredrik Fernlund, and Olle Lindbom. 2012. Pilotstudie i Vallentuna: Reflektioner rörande Affärsmodeller för Förbrukarflexibilitet och Självlärande Prognosstyrning för Kundanpassad Effektreglering. https://energiforskmedia.blob.core.windows.net/media/18784/pilotstudie-i-vallentunaelforskrapport-2012-48.pdf.

PJM. 2015. “The Polar Vortex, One Year Later.” PJM Plugged In. January 7. http://pluggedin.pjm.com/2015/01/the-polar-vortex-one-year-later/. — . 2016a. "PJM Load Forecast Report.” PJM Resource Adequacy Planning Department.

_. 2016a. "Summary of PJM-Initiated Load Management Events." Spreadsheet. http://www.pjm.com/ /media/planning/res-adeq/load-forecast/alm-history.ashx.

_. 2016b. "Load Management Events Summary 1991-Present." Spreadsheet. http://www.pjm.com/ /media/library/reports-notices/load-forecast/2016-load-report.ashx.

PV Magazine. 2016. "México: Inauguran Micro Red Híbrida Aislada en Baja California." August 25. PV Magazine. https://www.pv-magazine-latam.com/2016/08/25/mxico-inauguranmicro-red-hbrida-aislada-en-baja-california/.

RMI (Rocky Mountain Institute). 2016. "Valuing Non-Energy Benefits." http://www.10xe.orwww.10xe.org/keysolutionsbuildings5.

Rybka, Gregory, Ian Hoffman, Charles Goldman, and Lisa Schwartz. 2015. "Flexible and Consistent Reporting for Energy Efficiency Programs: Introducing a New Tool for Reporting Spending and Savings for Programs Funded by Utility Customers,"

Sattinger, Walter. 2011. "Application of PMU Measurements in Europe TSO Approach and Experience.” PowerTech, 2011 IEEE Trondheim 2011: 1-4.

Schweitzer, Edmund O. III, Armando Guzmán, Mangapathirao V. Mynam, Veselin Skendzic, Bogdan Kasztenny, and Stephen Marx. 2014. "Locating Faults by the Traveling Waves they Launch.” 2014 67th Annual Conference Protective Relay Engineers 2014: 95-110. 
SENER (Secretaría de Energía). 2016a. Tabla de Offertas Ganadoras de la Primera Subasta de la $1^{a}$ subasta eléctrica de largo plazo.

http://www.gob.mx/cms/uploads/attachment/file/69972/Tabla_Subasta_FIN.pdf

- 2016b. Con Precios Altamente Competitivos se Anuncian los Resultados Preliminares de la $2^{a}$ Subasta Eléctrica de Largo Plazo. https://www.gob.mx/sener/prensa/con-preciosaltamente-competitivos-se-anuncian-los-resultados-preliminares-de-la-2-subasta-electrica-delargo-plazo?idiom=es.

—. 2016c. Sistema de Información Energética. http://sie.energia.gob.mx/

—. 2016d. Programa de Redes Eléctricas Inteligentes.

https://www.gob.mx/cms/uploads/attachment/file/90007/Programa_de_Redes_El_ctricas_Intelig entes 09 05_ 16.pdf

_. 2017a. Implementacion de la Reforma Energetica y su Perspectiva 2017.

http://implementaciondelareformaenergetica.com/la-reforma-energetica-y-su-perspectiva-en-el$\underline{2017 /}$

2018a. Programa de Desarrollo del Sistema Eléctrico Nacional (PRODESEN) 20182032. https://www.gob.mx/cms/uploads/attachment/file/331770/PRODESEN-2018-2032definitiva.pdf.

SENER en colaboacion con AIE (la Agencia Internacional de Energía. 2011. Indicadores de Efeciencia Energetica en Mexico: 5 Sectores, 5 Retos. http://www.gob.mx/cms/uploads/attachment/file/85305/Bibliograf_a 6.pdf.

Sierra, Juan Federico Villa, Gabriel Fernando Paez Mendez, and Jeider Augusto Perez Arenas. 2014. "Angle Controlled Power Plants for PMU Based AGC: A New AGC Technology, Based on the dV and dQ Controlled Nodes Concept and PMU Triggered Load Shedding." IEEE PES T D Conference and Exposition 2014: 1.

Soman, Saurabh S., Hamidreza Zareipour, Om Malik, and Paras Mandal. 2010. "A Review of Wind Power and Wind Speed Forecasting Methods with Different Time Horizons." IEEE North American Power Symposium 2010, 1-8. http://ieeexplore.ieee.org/xpls/abs all.jsp?arnumber=5619586.f.

Song, Yong-Hua, and Allan Johns, 1999. Flexible AC Transmission Systems (FACTS). IET: Institution of Engineering and Technology.

Stifter, Matthias, René Kamphuis, Matthias Galus, Marijn Renting, Arnoud Rijneveld, Roman Targosz, Steve Widergren, Lars Nordstrom, Daniel Brodén, Tara Esterl, Stephanie Kaser, Pekka Koponen, Stephen Galsworthy, Werner Friedl, and Suryanarayana Doolla. 2016a. IEA DSM Task 17: Roles and Potentials of Flexible Consumers and Prosumers: Demand Flexibility in Households and Buildings. Matthias Stifter, and René Kamphuis, eds. IEA DSM. http://www.ieadsm.org/wp/files/IEA-DSM-Task-17-Subtask-10-role-and-potentials-2016-0929.pdf. 
Stifter, Matthias, René Kamphuis, Matthias Galus, Marijn Renting, Arnoud Rijneveld, Roman Targosz, Steve Widergren, Lars Nordstrom, Daniel Brodén, Tara Esterl, Stephen Galsworthy, Pekka Koponen, and Suryanarayana Doolla. 2016b. IEA DSM Task 17: Pilot Studies and Best Practices: Demand Flexibility in Households and Buildings. Matthias Stifter, and René Kamphuis, eds. IEA DSM. http://www.ieadsm.org/wp/files/IEA-DSM-Task-17-Subtask-12Sharing-experiences-best-practices-2016-09-22.pdf.

Stifter, Matthias, René Kamphuis, Matthias Galus, Marijn Renting, Arnoud Rijneveld, Roman Targosz, Steve Widergren, Lars Nordstrom, Daniel Brodén, Tara Esterl, Stephanie Kaser, Stephen Galsworthy, and Suryanarayana Doolla. 2016c. IEA DSM Task 17: Conclusions and Recommendations: Demand Flexibility in Households and Buildings. Matthias Stifter, and René Kamphuis, eds. IEA DSM. http://www.ieadsm.org/wp/files/IEA-DSM-Task-17-Subtask-13conclusions-recommendations-2016-09-27.pdf.

Sun, Wentao, Xiaoyang He, Junci Tang, Feng Jiang, Di Jiang, Jian Zhang, Peng Liu, and Chaojun He. 2016. "Extended Application of Online Security and Stability Analysis System in Liaoning Power Grid." China International Conference on Electricity Distribution 2016: 1-5.

THEMA Consulting Group. 2014. Demand Response in the Nordic Electricity Market: Input to Strategy on Demand Flexibility. TemaNord 2014:533. Copenhagen: Nordic Council of Ministers.

Thomas, Mini S., and John Douglas McDonald. 2015. Power System SCADA and Smart Grids. Boca Raton, FL: CRC Press/Taylor and Francis.

Tjader, J., and S. Ackeby. 2016. The Role and Interaction of Microgrids and Centralized Grids in Developing Modern Power Systems: A Case Review. International Smart Grid Action Network, Annex 6: Power Transmission and Distribution.

Wellinghoff, Jon, and Morenoff David L. 2007. "Recognizing the Importance of Demand Response: The Second Half of the Wholesale Electric Market Equation.” Energy Law Journal 28(2):389-419.

Werho, Trevor, Vijay Vittal, Sharma Kolluri, and Sze Mei Wong, 2016. "A Potential Island Formation Identification Scheme Supported by PMU Measurements.” IEEE Trans. Power Syst. 31(1): 423-431.

Yue, Fan, and Qaun Bailu. 2005 "Electrical Design Aspects of Pingguo TCSC Project." IEEE/PES Transmission Distribution Conference Exposition: Asia and Pacific 2005: 1-6.

Zhang, G Guorui, S. Lee, Ritchie Carroll, Jian Zuo, Lisa Beard, and Yilu Liu, 2010. "Wide Area Power System Visualization Using Real-Time Synchrophasor Measurements." IEEE PES General Meeting 2010: 1-7.

Zinaman Owen et al. 2015. Power Systems of the Future: A 21st Century Power Partnership Thought Leadership Report. DOE/GO-102014-4492. https://www.nrel.gov/docs/fy15osti/62611.pdf 


\section{Bibliography}

Calisti, Roberto, Angelo L'Abbate, Gianluigi Migliavacca, Alessandro Zani, and Philip Overholt. 2016. Storage and Balancing as Key Elements for Future Network Planning and Electricity Markets Design. International Smart Grid Action Network, Annex 6, Power T\&D System.

DOE (U.S. Department of Energy). 2015. Control Center and Data Management Improvements Modernize Bulk Power Operations in Georgia. SmartGrid.gov. https://www.smartgrid.gov/files/Control-Center-Data-Management-Improvements-Georgia.pdf.

- 2015. Improving Efficiency with Dynamic Line Ratings: Successes from New York Power Authority's Smart Grid Demonstration Project. SmartGrid.gov. https://www.smartgrid.gov/files/NYPA_Improving-Efficiency-Dynamic-Line-Ratings.pdf.

- 2015. Michigan Utility Modernizes Electricity Delivery and Provides Improved Service to Customers. SmartGrid.gov. https://www.smartgrid.gov/files/DTE Energy Case Study.pdf.

Dumoulin-Smith, Adrien, and Geoffrey Wright. 2016. A Power Struggle: Demand Response and the Limits of FERC's Authority. Duke University Law School.

Edquist, Charles. 2002. "Part V Innovation Policy in the New Context, Chapter 12: Innovation Policy-A Systemic Approach." In The Globalizing Learning Economy. Oxford Scholarship ISBN-13: 9780199258178.

EIA (U.S. Energy Information Administration). 2011. Smart Grid Legislative and Regulatory Policies and Case Studies. Attachment C: Smart Grid Around the World: Selected Country Overviews. https://www.eia.gov/analysis/studies/electricity/pdf/smartggrid.pdf

- 2015. Guidebook for Cost/Benefit Analysis of Smart Grid Demonstration Projects: Revision 3. Palo Alto, CA: EPRI. 3002006694. https://www.smartgrid.gov/files/GuidebookCost-Benefit-Analysis-Smart-Grid-Demonstration-Projects.pdf.

"Estudio de Fundamentos para la Elaboración de Políticas Públicas Relacionadas con Redes Eléctricas Inteligentes en Mexico" (Study of Fundamentals for the Elaboration of Public Policies Related to Intelligent Electrical Networks in Mexico) Secretaría de Energía-Instituto de Investigaciones Eléctricas_2013

"Evaluación Ex - Post del proyecto de Equipo de Medición Inteligente de Distribución en la División valle de México Centro" (Ex-Post Evaluation of the Distribution Intelligent Measurement Project in the Division Valle de Mexico Centro), CFE - Instituto de Investigaciones Eléctricas_2014.

Hirst, Eric, and Brendan Kirby. 2001. Retail-Load Participation in Competitive Wholesale Electricity Markets. https://www.researchgate.net/publication/237409583 RetailLoad_Participation_in_Competitive_Wholesale_Electricity_Markets 
Parsons, B., J. Cochran, A. Watson, J. Katz, and R. Bracho. 2015. Renewable Electricity Grid Integration Roadmap for Mexico: Supplement to the IEA Expert Group Report on Recommended Practices for Wind Integration Studies. NREL/TP-7A40-63136. https://www.nrel.gov/docs/fy15osti/63136.pdf.

San Cristobal, J.R. 2011. "Multi-Criteria Decision-Making in the Selection of a Renewable Energy Project in Spain: The Vikor Method." Renewable Energy, 36: 498-502.

St. John, Jeff. 2015. "Can China Create a Demand Response Industry from Scratch?”. Green Tech Media (GTM). March 09, 2015. http://www.greentechmedia.com/articles/read/can-chinacreate-a-demand-response-industry-from-scratch.

Stern, Florian. 2015. Demand Response in China: The Market \& Strategic Positioning of Active Players. Azure International. http://www.azureinternational.com/images/stories/azure/publications/pdf/DEMAND-RESPONSE-INCHINA The-Market-Strategic-Positioning-of-Active-Players 2015 Azure-International FS.pdf.

"Visión, Políticas y Mapa de Ruta para la Red Eléctrica Inteligente de CFE" (Vision, Policies and Road Map for the CFE Intelligent Electrical Network); Comisión Federal de Electricidad_ 2012. 


\section{Appendix A. Summary of the ESTA International Report}

The content in this appendix is excerpted with permission from the executive summary of ESTA International's Smart Grid Regulatory Framework for Mexico report (ESTA 2014).

\section{Priority Recommendations}

In creating the Regulatory Roadmap, ESTA International provided 42 recommendations, addressing seven focus areas: (1) CRE and CFE, (2) third-party providers, (3) renewable resources, (4) end users, (5) smart grid costs and benefits, (6) customer privacy, and (7) legislative recommendations. Here, we present our top five recommendations.

Priority Recommendation 1: CRE should support the creation and execution of a multi-party planning process for Smart Grid planning and implementation.

Successful deployment of Smart Grid technologies and services will require the coordinated efforts of many parties, both inside and outside government. For this reason, our top recommendation is that Mexico establishes a government and industry-wide voluntary group to advise the government on the implementation of Smart Grid - The Smart Grid Task Force. The governance structure of a Smart Grid Task Force should follow and mimic the existing overall governance arrangements for the energy industry and the power sector.

Based in part on this recommendation in the draft version of this Report, a formal smart grid working group was established in Mexico in April 2014. This group was created to coordinate all efforts on Smart Grid in Mexico and to ensure an integrated planning process (encompassing policy, regulation and technology deployment) is considered to develop the Smart Grid. The charter members of the Task Force are SENER, CFE and CRE. We hope and expect that the Task Force will be expanded to include participation by industry vendors and research and academic resources.

Priority Recommendation 2: CRE should require CFE to make "no regrets" Smart Grid investments that emphasize detection of outages, poor power quality, distribution transformer conditions before failure, etc.

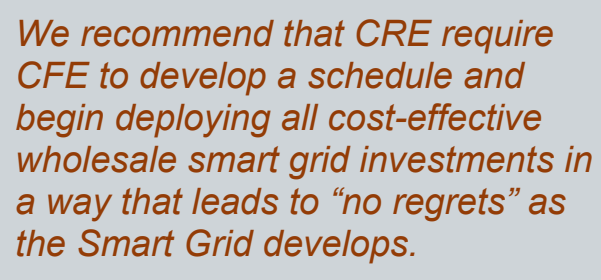

The Smart Grid investments that attract less media attention are those we have termed "wholesale" investments, made on the utility's side of the meter. These investments include installation of sensing devices to improve telemetry, giving the utility "visibility" into all operational aspects of the grid. 
Such investments can be made alone or in concert with Advanced Metering Infrastructure (AMI) devices. The principal benefits include Outage Detection, Voltage Management, Restoration, Power Quality Monitoring, Transformer Preventative Maintenance, Precision and time-stamped meter reading, Precision and time-stamped consumption information, and Real-time operational and locational information. Because these investments can be made in a way that will be consistent with a variety of future courses that the retail Smart Grid might take, we call them "no regrets" investments. Importantly, the Smart Grid Task Force will be well-suited to assist CFE and CRE to identify and prioritize such investments.

Priority Recommendation 3: In concert with other Mexican consumer rights agencies, CRE should develop a Consumer Bill of Smart Grid Rights detailing privacy, access to information, and consumer control over the use of consumer energy data.

Privacy concerns loom large in many countries that are developing the Smart Grid. It is very important to address this issue at the beginning of Smart Grid development, before the "genie is out of the bottle." A very good place to start is developing a Consumer Bill of Smart Grid Rights.

CRE has the power, working with SENER and CFE to issue the needed directives, and could be supported by IFAI and the Ministry of Economy. This action should be coupled with a code of conduct for Smart Grid vendors that details how permission, protection and use of customer data will be implemented by players in the Smart Grid.

Priority Recommendation 4: Define Competitive Renewable Energy Zones by technology (i.e., wind and solar) and make this information publicly available.

Development of a strong, competitive renewable energy industry in Mexico requires, among other things, the coordination of transmission build out and renewable development. Third party developers must know where transmission infrastructure will be built and on what schedule. Transmission owners must know where the wind and solar resources are and tailor their transmission planning to meet the need.

Competitive Renewable Energy Zones (CREZs) are a tool to proactively facilitate the development of renewable resources. In cooperation with CFE, such information should be developed and be available to resource developers, reflecting the priorities set by CRE for the type of technology and appropriate locations to expand such resources in the most economical way. Correctly implemented, CREZ will be a successful case of "build in and they will come."

Priority Recommendation 5: Budgetary steps should be taken to ensure CRE has adequate financial resources to obtain the expertise and skills required to address the complexity of Smart Grid initiatives.

CRE will have responsibility for regulatory aspects of electric power sector in Mexico that generates approximately USD 15 billion of revenue annually. The implementation of smart initiatives has the potential resulting in an investment of USD 1.0 billion to USD 4.0 billion in the next 13 years. The regulatory oversight of such a major undertaking and fast technological advances in Smart Grid requires adequate financial resource as well as experienced and skilled personnel to effectively perform their responsibilities. 
Simply put, a few million

dollars spent prudently at

a regulatory agency with

a mission to review and

guide Smart Grid

investments could avoid

costly mistakes in

deploying Smart Grid.

\section{Opportunities for Private Investment and Implementation Financing}

ESTA provided 36 recommendations concerning incentives for Renewable Energy, Distributed Generation, and Non-Utility companies. They include Regulatory Strategies 1) Regarding Market Segments; 2) To Encourage the Development and Integration of Small-scale Distributed Renewable Generation Projects; 3) To Encourage the Development and Integration and End-user Scale Projects; 4) To Encourage the Development and Integration of Non-Utility Small Scale Projects; 5) To Encourage the Development and Integration of Utility Scale Projects; 6) To Encourage the Development of Energy Management and Demand Response Activities by Third Parties; and 7) To Encourage the Development of Energy Management and Demand Response Activities for Consumers.

ESTA also assessed the potential role of financial institutions in providing debt and equity financing or loan guarantees for smart grid projects in Mexico. These financial institutions include the Inter-American Development Bank, the World Bank (including the International Bank for Reconstruction and Development for public sector projects and the International Finance Corporation for private sector projects), and the Export-Import Bank of the United States.

\section{Preliminary Environmental and Development Assessment}

ESTA conducted preliminary environmental and development assessment of Smart Grid deployment and increased use of renewable energy in the Mexican power portfolio as required by the U.S. Trade and Development Agency grant that funded the effort.

The analysis was carried out on two levels: 1) the micro-level of a single renewable energy project; and 2) at the macro-level of Mexican society. At the micro level, we consider the environmental concerns that may arise in the development of wind, solar and projects and outline preventative or reparative measures that can be taken to offset environmental concerns. At the macro societal level, we consider the link between Smart Grid and deeper penetration of renewable energy and assess how the growth in renewable energy will help Mexico meet its environmental goals. 
The value to society of

these resources,

manifested in their capacity

for stimulating economic

development and their

impact on the emissions of

greenhouse gas and other

pollutants, far overshadows

any environmental risks

and costs measured at the

local level.

\section{Economic Analysis and Implementation Plan}

One aspect of this study is to assess the financial impact in Mexico of implementing the Smart Grid and significantly increasing the amount of renewable energy used in the country. Bottom line, evaluation of the Smart Grid and renewable energy programs in Mexico suggests significant value can be created.

In developing a dedicated renewable energy program, we see large potential benefits stemming from reductions in fuel cost expenditures. Beyond that, we see significant benefits coming from deferral of distribution network requirements and reductions in requirements for synchronized reserves and frequency regulation.

The total value for the smart grid program and the renewable energy initiative together exceeds MXN 50 thousand million pesos relative to a "do nothing" strategy. Based on the high value proposition of these programs, we recommend further operational efforts to commence.

For the Smart Grid initiative, the largest benefits stem from the opportunities associated with automation of distribution operations. The single largest source of value stems from automating the meter reading process, moving from a manual read to an automated process with a digital architecture. We did not quantify the customer benefits of Smart Grid. From other countries, we know those benefits will also be large.

We close by reiterating that implementing the Smart Grid will bring substantial economic, social and environmental benefits to Mexico. The recently enacted Energy Reform and the Electric Industry Act has strengthened Mexico's ability to implement the Smart Grid by giving clear authority to the CRE. 


\section{Appendix B. Summary of Mexico's Smart Grid Program}

The content in this appendix is excerpted with permission from SENER's Programa de Redes Eléctricas Inteligentes report (SENER 2016d).

\section{Legal Framework}

The Energy Transition Law (LTE) indicates that a Smart Grid program must identify, evaluate, design, and establish the strategies, instruments, actions and projects related to electricity networks, which could include the following items in terms of the transmission and distribution networks:

- The use of digital information and control technologies to improve the reliability, stability, safety and efficiency;

- Dynamic optimization of the operation;

- Development and integration of distributed generation projects;

- Development and incorporation of controllable demand and the resources derived from Energy Efficiency

- Deployment of intelligent technologies for measurement and communication in Smart Grids

- Integration of smart equipment and appliances;

- Development of communication and interoperability standards for interconnected devices and equipment, including the infrastructure that services these networks;

- Information required by consumers and their options for the timely control of their resources;

- Development and integration of advanced energy storage technologies and other technologies useful for meeting peak demand;

- Identification and use of underutilized power generation capacity for the substitution of fossil fuels for electric power in transportation systems;

- Promotion of interconnection protocols to facilitate electricity providers' access to the electricity stored in electricity vehicles

- Identification and reduction of barriers for the adoption of Smart Grid technologies, and the research on the viability of moving towards a scheme of electricity prices in real time or time of use.

The Energy Transition Law (LTE) also establishes that every three years, the National Center for Energy Control (CENACE), with the support of the Energy Regulatory Commission (CRE), the Electricity Transporters, Distributors and Suppliers, must prepare and propose to SENER a Smart Grid Program. This Smart Grid Program which will aim to support the modernization of the National Transmission Network and the General Distribution Networks, to maintain a reliable and secure infrastructure that satisfies the electricity demand in an economically efficient and sustainable manner, and that facilitates the incorporation of new technologies that promote the reduction of costs of the electricity sector. In addition, the Smart Grid program will enable the provision of additional services through their networks, the generation from Clean Energies including the incorporation of Distributed Clean Generation, and the allowing of a greater interaction between the consumers' devices and the National Electricity System. 


\section{Smart Grid Drivers}

The National Smart Grid program published by SENER has initially identified the following eight drivers (numbered) to determine the development of Smart Grids in Mexico. It is intended that within the new planning criteria, the incorporation of Smart Grid technologies must meet the following criteria (bulleted):

- Improve the operation of the National Electric System, increasing its efficiency, flexibility, resilience, quality, reliability, continuity, safety and sustainability

- Promote the generation of electricity from clean energy sources, on a large scale

- Allow dynamic optimization of the operation of the National Electric System

- Support the management of the Wholesale Electricity Market

- Incorporate Distributed Generation, including that of renewable energy sources

- Increase the interaction of consumers with the system

- Influence planning and operations to improve the quality of the service provided to the final user

- Facilitate the provision of additional services and the integration of electric vehicles and storage resources.

1. Quality, Reliability, Continuity, Security and Sustainability: The Energy Regulatory Commission (CRE) will issue the necessary provisions in this matter so that the electricity service is carried out considering economic aspects and observing the correct operation and integrity of the various equipment and devices in the networks, using acceptable parameters on: voltage, availability and capacity of the networks, interruptions of the electric service, harmonic components, energy losses and other necessary technical aspects. Regarding the operation of the wholesale electricity market, operating procedures must be foreseen to maintain the security of the electricity dispatch, reliability, quality, continuity and efficiency of the wholesale market.

CRE will provide regulation related to quality, reliability, continuity, security, and sustainability of the electric service, and the procedures to maintain the security of dispatch, reliability, quality and efficiency of the wholesale power market

2. Quality of the Electricity Service: Smart grid deployment will take on actions necessary to improve the quality of the service to the end user.

3. Energy Efficiency: The third motivator for the National Smart Grid program is to include economically viable energy efficiency measures, while maintaining or improving the quality of the electricity service.

4. Energy Losses: The National electric system, especially in the distribution network, presents energy losses above average worldwide levels. The smart grid program establishes a key component to include efficient parameters within the national electricity system to reduce the energy losses. 
5. Efficient Operation of the National Electric System: To increase the operating efficiency, especially in all activities related to transmission and distribution of electricity, it is needed to ensure all system elements are operating in a manner that is adequate, and that the infrastructure is periodically modernized following cost benefit analysis to incorporate new technologies and to eliminate obsolete equipment.

6. Clean Energies: Smart grids must aid in meeting the clean energy and greenhouse gas reduction targets set in the law. The smart grid program during the planning, modernization and expansion of the electricity network, must take into consideration the open access to transmission and distribution networks and include analysis of high clean energy potential zones. The network expansion and technologies chosen must include conditions of economic sustainability according to best practices and to strengthen the reliability of the network.

7. Increased Participation of Electricity Users: The program will consider the gradual impact in tariffs to include attributes in the electricity system that permit increased interaction with the final consumers. In the determination and structuring of tariffs, elements of demand response and energy efficiency will be introduced to eventually administer a dynamic tariff system.

8. Additional Services: To maximize the investment in Smart Grids, it will be necessary to increase private sector participation in the planning of the national electricity system through their various chambers and associations.

\section{Conclusion}

The new planning criteria for the National Electric System and the incorporation of Smart Grid technologies shall contribute to improve the operation of the National Electrical System, by increasing its efficiency, resilience, flexibility, Quality, Reliability, Continuity, safety and sustainability. Smart grid technologies shall promote the integration of large and distributed renewable energies and storage devices in the network. New technologies shall allow dynamic optimization of the operation of the system, support management of the wholesale electricity market and allow an increasing interface with the consumer.

\section{Table of Smart Grid Projects}

The Smart Grid National Group, which is composed by SENER, CRE, CENACE, CFE, the National Institute of Electricity and Clean Energies (INEEL) and the National commission for the efficient use of energy, have identified in the following table, twenty-four Smart Grid initial projects that followed the eight drivers. The first three projects in the table are considered key projects for the system that everyone must apply, but that the system operator, CENACE, is responsible for. The other projects in the table are specific to CENACE, the transmission operator and the distribution operator. 


\begin{tabular}{|c|c|c|}
\hline ENTITY $\nabla$ & NAME OF PROJECT & DESCRIPTION \\
\hline $\begin{array}{l}\text { KEY PROJECTS - } \\
\text { CENACE AS } \\
\text { COORDINATOR }\end{array}$ & $\begin{array}{l}\text { Enterprise architecture for the } \\
\text { Smart Grid }\end{array}$ & $\begin{array}{l}\text { The new productive enterprises of the State should seek to maximize business capabilities, where the mix of } \\
\text { current assets and new investments do not generate duplicated functionalities and that the new acquisitions } \\
\text { align with the unified vision of Smart Grids and its own business objectives. }\end{array}$ \\
\hline $\begin{array}{l}\text { KEY PROJECTS - } \\
\text { CENACE AS } \\
\text { COORDINATOR }\end{array}$ & $\begin{array}{l}\text { Telecommunications business } \\
\text { strategy }\end{array}$ & $\begin{array}{l}\text { The telecommunications infrastructure must be planned, designed, implemented and managed along with the } \\
\text { electrical infrastructure. The new responsibilities require a shareable safe, reliable and without interruptions } \\
\text { telecommunications business strategy for the safe, operation of the National Electric System. }\end{array}$ \\
\hline $\begin{array}{l}\text { KEY PROJECTS - } \\
\text { CENACE AS } \\
\text { COORDINATOR }\end{array}$ & Cybersecurity strategy & $\begin{array}{l}\text { The neutralization and remediation of potential hazard agents and the vulnerabilities of the National Electric } \\
\text { System must be identified and foreseen. }\end{array}$ \\
\hline CENACE & $\begin{array}{l}\text { Optimal dispatch of reactive } \\
\text { power }\end{array}$ & Evaluate software tools for programming and dispatching reactive power resources. \\
\hline CENACE & $\begin{array}{l}\text { Demonstration and } \\
\text { implementation of smart tools } \\
\text { to guide the restoration } \\
\text { process }\end{array}$ & $\begin{array}{l}\text { Evaluate tools and implement to support operators' decisions by improving situational awareness during } \\
\text { emergency conditions and restoring the National Electric System. }\end{array}$ \\
\hline CENACE & $\begin{array}{l}\text { Demonstration of energy } \\
\text { storage and its integration } \\
\text { into the operation }\end{array}$ & $\begin{array}{l}\text { Demonstrate with pilot projects the value of energy storage, as a resource to be able for integration of } \\
\text { renewable resources, production at peak hours, applications for primary frequency regulation, other ancillary } \\
\text { services }\end{array}$ \\
\hline CENACE & $\begin{array}{l}\text { Forecast of wind and solar } \\
\text { generation for the operation }\end{array}$ & Implement tools and forecasting methods for renewable energies' dispatch \\
\hline CENACE & $\begin{array}{l}\text { New generation phasor } \\
\text { measurement network }\end{array}$ & $\begin{array}{l}\text { Define and implement a Wide Area SynchroPhasor Measurement Network to provide the necessary analysis of } \\
\text { the current situation of the system and thus maintain the reliability and stability of the National Transmission } \\
\text { Network as a greater percentage of renewable generation is interconnected. }\end{array}$ \\
\hline CENACE & $\begin{array}{l}\text { Demand response to assist } \\
\text { the operation of the network }\end{array}$ & $\begin{array}{l}\text { 1. Understand the behavior of different types of load. } \\
\text { 2. Identify the useful demand response functions to maintain the reliability and increase the efficiency of the } \\
\text { National Electric System. } \\
\text { 3. Evaluate and incorporate the best technologies for the Wholesale Electricity Market and the contribution to } \\
\text { the load / generation balance }\end{array}$ \\
\hline CENACE & $\begin{array}{l}\begin{array}{l}\text { Research on the use of } \\
\text { dynamic limits in transmission } \\
\text { lines }\end{array} \\
\end{array}$ & $\begin{array}{l}\text { Demonstrate the use and potential benefits of dynamic transmission limit determination technology in the } \\
\text { National Electricity System. }\end{array}$ \\
\hline $\begin{array}{l}\text { TRANSMISSION } \\
\text { OPERATOR }\end{array}$ & $\begin{array}{l}\text { Study and implementation of } \\
\text { intelligent tools that guide the } \\
\text { physical operation process of } \\
\text { the National Transmission } \\
\text { Network (RNT)) }\end{array}$ & $\begin{array}{l}\text { Integrate cutting-edge technology to achieve availability, reliability and operation safety through the Energy } \\
\text { Management System (EMS), acquisition of Supervision and Data Control (SCADA) in the operation of power } \\
\text { substations and transmission infrastructure. }\end{array}$ \\
\hline \begin{tabular}{c|} 
TRANSMISSION \\
OPERATOR
\end{tabular} & Automatic fault locator & $\begin{array}{l}\text { Evaluate the benefits of implementing a Fault Location and Prevention System through the principle of Traveling } \\
\text { Wave, to automate the process to allow locating the point of failure in a transmission line in a shorter time. }\end{array}$ \\
\hline $\begin{array}{l}\text { TRANSMISSION } \\
\text { OPERATOR }\end{array}$ & $\begin{array}{l}\text { Development of a diagnostic } \\
\text { system for power switches } \\
\text { and encapsulated substations } \\
\text { (GIS) in sulfur hexafluoride gas } \\
\text { (SF6) }\end{array}$ & $\begin{array}{l}\text { Have an on-line diagnosis system to positively impact the evaluation of the performance and status of the power } \\
\text { switches and GIS (Gas Insulated Switchgear), as well as timely detection of abnormalities caused by SF6 to } \\
\text { increase the reliability of the National Transmission Network. }\end{array}$ \\
\hline
\end{tabular}




\begin{tabular}{|c|c|c|}
\hline ENTITY $\nabla$ & NAME OF PROJECT & DESCRIPTION \\
\hline $\begin{array}{c}\text { TRANSMISSION } \\
\text { OPERATOR }\end{array}$ & $\begin{array}{l}\text { Study, demonstration and } \\
\text { implementation of protocols, } \\
\text { hardware and applications for } \\
\text { the integration of Control } \\
\text { Centers. }\end{array}$ & $\begin{array}{l}\text { The modernization of the automation of substations to integrate the functions of protection, control, } \\
\text { measurement, communication and SCADA data security of a substation through standard communication } \\
\text { protocols that allow its interoperability, reliably guaranteeing the operation, maintenance and supply of electric } \\
\text { power. }\end{array}$ \\
\hline $\begin{array}{c}\text { TRANSMISSION } \\
\text { OPERATOR }\end{array}$ & $\begin{array}{l}\text { Research on the use of asset } \\
\text { condition information to } \\
\text { improve the operational } \\
\text { reliability of the system }\end{array}$ & $\begin{array}{l}\text { Have a tool for monitoring the critical devices of the power substations, with a scope to the Transmission Lines, } \\
\text { Transformers, Switches and Banks of Batteries, to achieve the implementation and diagnosis of Critical Assets. }\end{array}$ \\
\hline $\begin{array}{c}\text { TRANSMISSION } \\
\text { OPERATOR }\end{array}$ & $\begin{array}{l}\text { Geographic Information } \\
\text { System of the RNT }\end{array}$ & $\begin{array}{l}\text { For the expansion of the Electric Network, the maintenance and asset management and to better mobilize the } \\
\text { workforce, unify the information in a georeferencing platform connected to the MySAP and SCADA systems. }\end{array}$ \\
\hline $\begin{array}{c}\text { DISTRIBUTION } \\
\text { OPERATOR }\end{array}$ & $\begin{array}{l}\text { Remote operation and } \\
\text { automation in distribution } \\
\text { networks }\end{array}$ & $\begin{array}{l}\text { Provide the user with a quality electric power supply, where a service is committed is to the timely restoration of } \\
\text { the supply. }\end{array}$ \\
\hline $\begin{array}{c}\text { DISTRIBUTION } \\
\text { OPERATOR }\end{array}$ & $\begin{array}{l}\text { Geographic information } \\
\text { system of the RGD }\end{array}$ & $\begin{array}{l}\text { Implement an institutional system of geographic information supported by current information technologies } \\
\text { through a database that allows the management of infrastructure for planning, operation, connection of new } \\
\text { Load Centers and the interconnection of Power Plants, with geospatial capacity. }\end{array}$ \\
\hline $\begin{array}{c}\text { DISTRIBUTION } \\
\text { OPERATOR }\end{array}$ & $\begin{array}{l}\text { Advanced measurement } \\
\text { infrastructure }\end{array}$ & $\begin{array}{l}\text { Reduction of non-technical energy losses, encouraging the efficient use of energy, optimizing operating costs, } \\
\text { guaranteeing the supply of electric power with improved attention to the consumer needs. }\end{array}$ \\
\hline $\begin{array}{l}\text { DISTRIBUTION } \\
\text { OPERATOR }\end{array}$ & $\begin{array}{l}\text { Management of the energy } \\
\text { balance of the RGD for the } \\
\text { MEM }\end{array}$ & $\begin{array}{l}\text { Implement the measurement and communication systems necessary for hourly transactions in the wholesale } \\
\text { electricity market. In compliance with applicable regulations, ensuring that the use of the General Distribution } \\
\text { Networks is carried out correctly, and transparently. }\end{array}$ \\
\hline $\begin{array}{l}\text { DISTRIBUTION } \\
\text { OPERATOR }\end{array}$ & $\begin{array}{l}\text { Advanced Distribution } \\
\text { Management System }\end{array}$ & $\begin{array}{l}\text { Through a pilot project, develop a small-scale version of an ADMS to determine the impacts on operational } \\
\text { efficiency, system efficiency, reliability, safety, as well as other areas of importance. The behavior of the AMDS in } \\
\text { the pilot project, determine if the development of a complete system for the entire National Electric System is } \\
\text { justified. }\end{array}$ \\
\hline
\end{tabular}

